\title{
A NEW SEQUENTIAL APPROXIMATION METHOD
}

\author{
BY \\ DOUGLAS FARIES \\ Bachelor of Science \\ Western Illinois University \\ Macomb, Illinois \\ 1984 \\ Master of Science \\ Western Illinois University \\ Macomb, Illinois \\ 1986
Submitted to the Faculty of the Graduate college of the oklahoma State University in partial fulfillment of the requirements for the Degree of DOCTOR OF PHILOSOPHY MAY, 1990


A NEW SEQUENTIAL APPROXIMATION METHOD

'Thesis Approved:

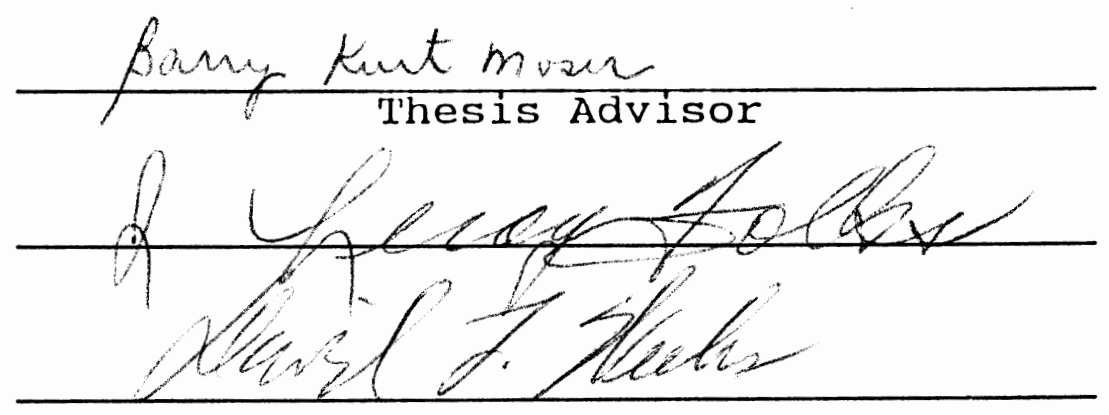

Esumeth Elose

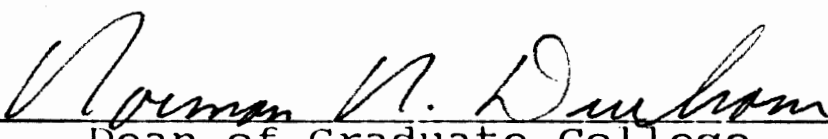

Dean of Graduate College

ii 


\section{ACKNOWLEDGMENTS}

I would like to thank all those who have provided the support that I needed during my years at oklahoma state. First of all, I would like to thank my advisor, Dr. Barry Moser, for giving me the opportunity to join him in researching sequential approximation methods. I truly appreciate the many hours of time he spent discussing the research with me. I feel fortunate to have an advisor who was enthusiastic about the research we were doing. His guidance, timely suggestions, and insights were priceless.

I would also like to thank my advisory committee. To Dr. Leroy Folks, the committee chairman, a special thanks for his questions that made me look at a problem from more than one direction. Also, his support in obtaining scholarships, summer internships, and assistantships was invaluable. Thank you to Dr. David Weeks, for his thought provoking questions and the confidence he gave me. To Dr. Ken Case, thanks for taking time out of his busy schedule. His Quality Control classes were both challenging and fun. Also, thanks to Dr. Ron McNew, who accepted a position at Arkansas before I completed my work. His comments on the paper that Dr. Moser and I submitted for publication were extremely helpful. All of the faculty and graduate students 
I encountered were more than willing to share their knowledge and help in any way possible. They made oklahoma state an enjoyable place to study.

Finally, I would like to thank my parents for their financial support in starting college and for instilling in me an appreciation of academics. I always knew that they were behind me. Also, to my wife Karen, for putting up with some long hours of work. Her love and prayers were exactly what I needed to keep me going. 
TABLE OF CONTENTS

Chapter

Page

I. INTRODUCTION AND LITERATURE REVIEW • • • • • • • 1

II. A NEW SEQUENTIAL APPROXIMATION METHOD (SAM) • • . 9

The Procedure . . . . . . . . . . . . 9

Selecting $p_{1}, \ldots, p_{K}$. . . . . . . . . . 13

Bounded and Alternate Versions . . . . . 14

III. SAM FOR BINARY DATA • . . . . . . . . . . . . . I7

Introduction . . . . . . . . . . . 17

Consistency • • • • • • • • • • • • • • •

An Example: The Two Parameter Logit Model . 22

Equivalence of the Logit Version of SAM

and a Two Dimensional RM Procedure . . . 26

Selecting $\mathrm{p}_{1}, \mathrm{p}_{2}$ Using the Two Parameter

Logit Model (Symmetric Case) . . . . . 33

selecting $\mathrm{p}_{1}, \mathrm{p}_{2}$ Using the Two Parameter

Logit Model (General Case) . . . . . . 38

Asymptotic Variance and Bias . . . . . . 42

IV. SIMULATION STUDY • • • • • • • • • • • . . 48

The setup . . • . . . . . . . . . . . 48

Initial Procedure 1 . . . . . . . . . . 52

Results of Initial Procedure 1 . . . . . 54

Initial Procedure 2 . . . . . . . . . 56

Results of Initial procedure 2... . . . 66

Analysis of the MSEs . . . . . . . . 68

V. CONCLUSION . . . . . . . . . . . . 83

BIBLIOGRAPY . . . . . . . . . . . . . 85

APPENDIXES . . . . . . . . . . . . . . . 88

APPENDIX A - PROOF OF THEOREM 1 . . . . . . . 88

APPENDIX B - PROOF OF THEOREM 2 . . . . . . . 90

APPENDIX C - PROOF OF THEOREM 4 . . • . • . . . 94 
APPENDIX D - SAS-CODE FOR THE SIMULATION STUDY • 96 APPENDIX E - USER PROGRAMS . . . . . . . . 109 
1. An Example . . . . . . . . . . . . . 25

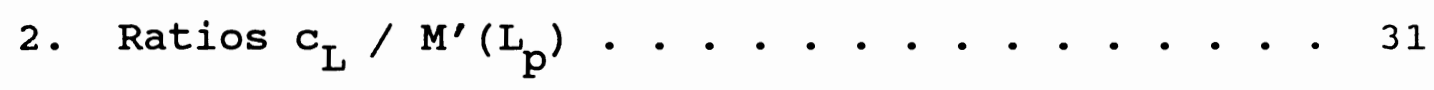

3. Minimax and Average Minimum p . . . . . . . 35

4. Monte Carlo MSE for $\operatorname{SAM}\left(p_{1}, p_{2}\right)$. . . . . . 42

5. Bias of $\hat{\mathrm{L}}_{\mathrm{p} *}$. . . . . . . . . . . . . . 45

6. Robbins-Monro, SAM Asymptotic MSEs . . . . . . 47

7. Optimal $\mathrm{n} \cdot \mathrm{A}_{\mathrm{n}} \cdot$. . . . . . . • • . . . 52

8. Monte Carlo MSE for Estimating $\mathrm{L}_{\mathrm{p}}$ * (Logit, Initial set 1) . . . . . . . . 57

9. Monte Carlo MSE for Estimating $L_{p *}$ (Logit, Initial set 2) . . . . . . . . . 58

10. Monte Carlo MSE for Estimating $\mathrm{L}_{\mathrm{p}}$ * (Probit, Initial set 1) . . . . . . . . 59

11. Monte Carlo MSE for Estimating $I_{p}$ * (Probit, Initial set 2) . . . . . . . 60

12. Monte Carlo MSE for Estimating $\mathrm{L}_{\mathrm{p}}$ * (Skewed Logit, Initial Set 1) . . . . . . 61

13. Monte Carlo MSE for Estimating $\mathrm{L}_{\mathrm{p}}$ * (Skewed Logit, Initial set 2) . . . . . . 62

14. Monte Carlo MSE for Estimating $\mathrm{L}_{\mathrm{p}}$ * (Loglog, Initial set 1) . . . . . . . . 63

15. Monte Carlo MSE for Estimating $\mathrm{L}_{\mathrm{p}}$ * (Loglog, Initial Set 2) . . . . . . . . 64 
16. Monte Carlo MSE for Estimating $\mathrm{L}_{\mathrm{p}}$ * $(\operatorname{Logit}-(.5, .813, .95))$. . . . . . . 69

17. Monte Carlo MSE for Estimating $\mathrm{L}_{\mathrm{p}}$ * $(\operatorname{Logit}-(.1, .4, .7))$. . . . . . . . . 70

18. Monte Carlo MSE for Estimating $L_{p *}$ $($ Logit- $(.3, .35, .4))$. . . . . . . . 71

19. Monte Carlo MSE for Estimating $L_{p}$ *

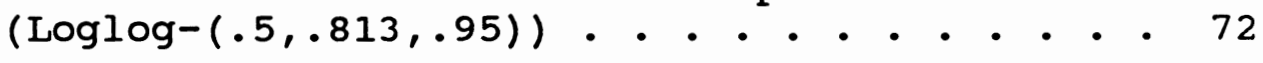

20. Monte Carlo MSE for Estimating $\mathrm{L}_{\mathrm{p} \text { * }}$ $(\log \log -(.1, .4, .7)) \quad$. . . . . . . . . 73

21. Monte Carlo MSE for Estimating $\mathrm{L}_{\mathrm{p} \text { * }}$

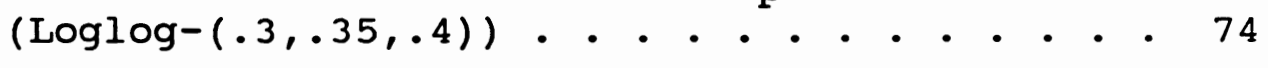

22. Monte Carlo MSE for Estimating $\mathrm{L} .25$ (Starting Levels $(.5, .813, .95) . . . . . .75$

23. Monte Carlo MSE for Estimating $L_{.25}$ (Starting Levels $(.1, .4, .7)$. . . . . . 76

24. Monte Carlo MSE for Estimating $\mathrm{L} .25$ (Starting Levels $(.3, .35, .4) . . . . . . .77$

25. Asymptotic MSE $\left(n^{*}=365\right)$. . . . . . 79

26. Asymptotic MSE $\left(n^{*}=500\right)$......... 79

27. Simulation Standard Errors . . . . . . . 80

28. Least Significant Differences . . . . . . 81

29. Number of Significant Differences . . . . . 82 


\section{LIST OF FIGURES}

Figure Page

1. Sequential Approximation Methods . . . . . . . 2

2. SAM . . . . . . . . . . . . . . . . 12

3. SAM: An Example . . . . . . . . . . . . 24

4. Logit Approximation . . . . . . . . . . 28

5. Minimax and Average Minimum $p$. . . . . . 36

6. Samsumm Output . . . . . . . . . . . . 134 
CHAPTER I

\section{INTRODUCTION AND LITERATURE REVIEW}

Let $\mathrm{Y}(\mathrm{x})$ be a random variable with distribution

function $\mathrm{P}(\mathrm{Y}(\mathrm{x}) \leq \mathrm{Y})=\mathrm{F}(\mathrm{y}, \theta \mid \mathrm{x})$ and expectation of $\mathrm{Y}(\mathrm{x})$ given by

$$
M(x)=\int_{-\infty}^{\infty} Y \partial F(y \mid x)
$$

Assume that neither the distribution function nor the expectation of the random variable is known. Consider the problem of sequentially selecting the values of $x$, the design levels, in order to efficiently estimate the entire function $\mathrm{M}(\mathrm{x})$. From the estimate of $\mathrm{M}(\mathrm{x})$, any root, $\mathrm{L}_{\mathrm{p}}$, of the equation $M(x)=p$ can then be estimated. Figure 1 on page 2 depicts the situation graphically.

Sequential approximation methods have beeen applied in several areas of research. One area in which sequential approximation methods are frequently applied is sensitivity analysis. In sensitivity tests, each specimen is assumed to have a critical threshold. The specimen will respond only if a stress greater than its critical threshold is applied. Dixon and Mood (1948) and Neyer (1989) present examples of sequential approximation methods for use in explosives research. 


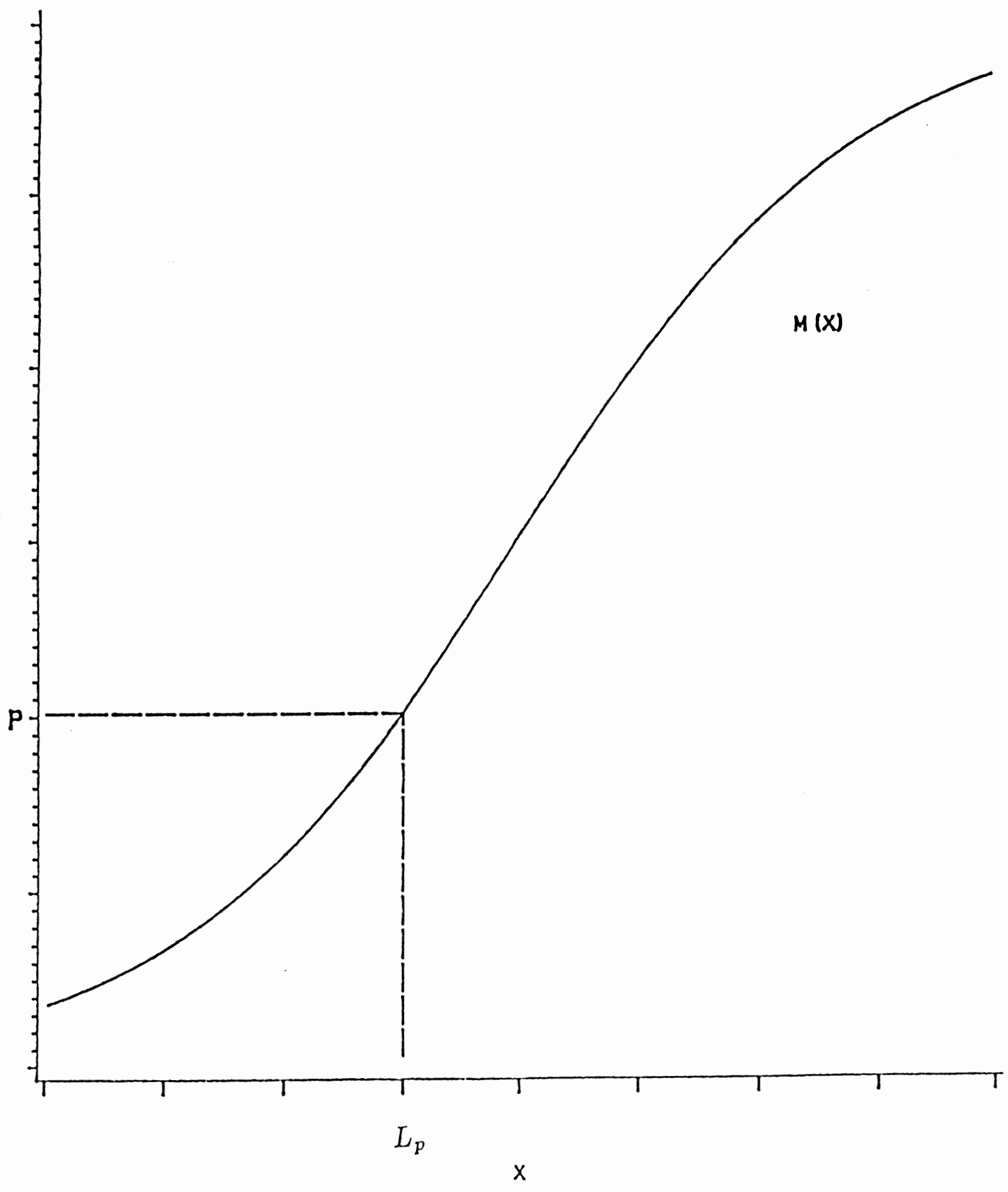

Figure 1. Sequential Approximation 
Cochran and Davis (1964) and Davis (1971) study sequential approximation methods for estimating the LD50 in bioassays. These authors demonstrated the superiority of sequential methods to traditional nonsequential designs. In their simulation study with a fixed sample size, the sequential methods produced lower mean square errors than the nonsequential designs. When estimating the LD50 with a specified standard error, they noted an important advantage of the sequential methods. Fewer animals would be required for an experiment using the sequential methods than with the nonsequential designs. Other areas of application include entomology, reliability and educational testing.

other authors have considered the problem of estimating a single root of the function $M(x)$. As previously mentioned, Dixon and Mood (1948) developed the Up and Down method for use in sensitivity analysis. For example, the sensitivity of explosive material can be defined as the impact needed to detonate the material. Weights are dropped from various heights onto samples of the explosive material and the response, explosion or no explosion, is recorded. The Up and Down method requires a starting height, $x_{1}$, and a step size, $\Delta$. Based on the previous responses, the procedure successively generates the height to drop the weight for the next experiment. Successive observations ( $Y_{n}$ $=0$ represents "no explosion" and $\mathrm{Y}_{\mathrm{n}}=1$ represents an "explosion") are taken at heights $x_{n}$, determined by the rule

$$
X_{n+1}=X_{n}+\Delta \text { if } Y_{n}=0 \text { and }
$$




$$
X_{n+1}=X_{n}-\Delta \text { if } Y_{n}=1 \text {, }
$$

where $\Delta$ is the predetermined positive step size.

Label the heights used in the experiment, from lowest to highest, by $\mathrm{h}=0,1,2$, etc.. Let $\mathrm{B}$ denote the lowest height used in the experiment (the height corresponding to $h=0)$. Let $n_{h}$ be the number of explosions at height level $h$, and let $\mathrm{N}$ be the total number of explosions. The estimate of $\mathrm{L}_{.5}$, the height at which 50 percent of the samples will detonate, is given by

$$
\hat{\mathrm{L}}_{.5}=\mathrm{B}+\Delta \cdot\left[(1 / \mathrm{N}) \sum \mathrm{h} \mathrm{h}_{\mathrm{h}}-(1 / 2)\right] \cdot
$$

Wetherill (1963) noted the effectiveness of the procedure for small or medium sample sizes is highly dependent upon the choice of starting value $\mathrm{x}_{1}$ and step size $\Delta$. Robbins and Monro (1951) suggested estimating the single root $L_{p}$ with the updating rule

$$
X_{n+1}=X_{n}-A_{n}\left(Y_{n}-p\right),
$$

where $y_{n}$ is the response associated with $X_{n}, p$ is a single predetermined constant, and $A_{n}$ is a fixed sequence of positive constants. Thus, the step size from $x_{n}$ to $x_{n+1}$ is not a single fixed constant, as it is in the Up and Down method. The term $x_{n+1}$ serves as the estimator of $L_{p}$ after $n$ updates. Under the following conditions on $M(x)$ and $\left\{A_{n}\right\}$, Robbins and Monro demonstrated that $x_{n}$ converges to $L_{p}$ in $\mathrm{L}^{2}$.
a) $M(x)$ is a nondecreasing function; $M\left(L_{p}\right)=p ; M^{\prime}\left(L_{p}\right)>0$.
b) $\exists$ a positive constant $C$ such that $P[|\mathrm{Y}(\mathrm{X})| \leq \mathrm{C}]=$ 


$$
\int_{-c}^{c} \partial H(y \mid x)=1 \text { for all } x
$$

C) $A_{n}$ is a sequence of type $1 / n$ (There exists positive constants, $d_{1}$ and $d_{2}$, such that $\left.\left[d_{1} / n\right] \leq A_{n} \leq\left[d_{2} / n\right]\right)$.

Blum (1954) and Goodsell and Hanson (1976) provided conditions for which $x_{n}$ converges to $L_{p}$ almost surely. Using $\left\{A_{n}\right\}=A / n$, for some positive constant $A$, chung (1954) and Sacks (1958) defined criteria under which $\sqrt{n}\left(X_{n}-\right.$ $I_{p}$ ) is asymptotically normal with mean $L_{p}$ and variance,

$$
\operatorname{var}\left\{\sqrt{n}\left(X_{n}-L_{p}\right)\right\}=A^{2} \cdot \sigma^{2} /\left(2 \cdot A \cdot M^{\prime}\left(L_{p}\right)-1\right),
$$

where $\sigma^{2}=\operatorname{var}\left(\mathrm{Y} \mid \mathrm{X}=\mathrm{L}_{\mathrm{p}}\right)$ and $\mathrm{M}^{\prime}\left(\mathrm{L}_{\mathrm{p}}\right)=\left.(\partial \mathrm{M}(\mathrm{X}) / \partial \mathrm{X})\right|_{\mathrm{X}=\mathrm{L}_{\mathrm{p}}} \cdot$ Chung (1954) also showed that the asymptotic variance of $x_{n}$ is minimized when $A_{n}=\left(n \cdot M^{\prime}\left(L_{p}\right)\right)^{-1}$. Thus, a RM procedure with $A_{n}=\left(n \cdot M^{\prime}\left(L_{p}\right)\right)^{-1}$ represents an optimal $R M$ process. Note that $M^{\prime}\left(L_{p}\right)$ is the slope of the tangent line of the expectation curve at the root $I_{p}$.

In practice $M^{\prime}\left(L_{p}\right)$ is usually unknown. Thus, an educated guess of $M^{\prime}\left(L_{p}\right)$ must be made prior to the experiment. Wetherill (1963) demonstrated that a poor guess of $M^{\prime}\left(L_{p}\right)$ and the starting value $x_{1}$ will make the $R M$ procedure (4) inefficient for small and medium sample sizes.

Venter (1967) and Anbar (1977) showed that the desirable properties of the RM procedure are maintained if $M^{\prime}\left(L_{p}\right)$ is replaced by a strongly consistent estimator. Venter's procedure involves taking two observations, $Y$ and $Y^{\prime}$, at $X_{n}-W_{n}$ and $X_{n}+W_{n}$, where $\left\{W_{n}\right\}$ is a sequence of constants converging to zero. Anbar (1977) suggested 
estimating $M^{\prime}\left(L_{p}\right)$ by

$$
b_{n}=\sum_{m}^{n-1} y_{i}\left(x_{1}-\bar{x}_{n-1}\right) / \sum_{m}^{n-1}\left(x_{1}-\bar{x}_{n-1}\right)^{2}
$$

the slope of the least squares line through

$$
\left(x_{m(n)}, y\left(x_{m(n)}\right)\right), \ldots,\left(x_{n-1}, y\left(x_{n-1}\right)\right) \text { for some } m(n)<n \text {. }
$$

The design levels are generated by the rule

$$
X_{n+1}=X_{n}-\left(n \cdot b_{n}\right)^{-1}\left(Y_{n}-p\right)
$$

Anbar then proved $b_{n}--\underline{a}-\underline{s}-->M^{\prime}\left(L_{p}\right), X_{n}--\underline{a}-\underline{s}-->L_{p}$, and that $\sqrt{n}\left(X_{n}-L_{p}\right)$ has the same asymptotic distribution as the optimal RM process.

Wu (1985) suggested estimating the root $L_{p}$ from an estimate of the entire function $M(x)$. He noted that a smooth nonparametric estimate of $M(x)$ was not feasible without a large number of observations. Therefore, to produce his estimators, he used a parametric form, $H(x \mid \theta), \theta$ $=\left(\theta_{1}, \ldots, \theta_{k}\right)$, for the expectation of $Y$. Wu proposed the following updating rule:

1) Find an efficient estimate $\hat{\theta}^{(n)}$ for $\theta$ based on the $n$ observations $\left[\left(y_{i}, x_{1}\right)_{1}^{n}\right]$.

2) Define the estimated expectation function $\hat{H}_{n}(x)=$ $H\left(x \mid \hat{\theta}^{(n)}\right)$ and choose $x_{n+1}$ such that $\hat{H}_{n}\left(x_{n+1}\right)=p$. After $n$ updates, $x_{n+1}$ provides an estimate of $L_{p}$.

He suggested using the maximum likelihood estimator, $\hat{\theta}^{(n)}$, as the efficient estimator of $\theta$ at each update. Using a one parameter logit expectation, for a binary random variable Y, Wu demonstrated that his procedure is equivalent to a Robbins-Monro process. Thus, $x_{n}$ from (8) converges to $L_{p}$ 
almost surely, regardless of the true distribution of $Y$. Using a two parameter logit expectation, Wu was unable to prove consistency. However, assuming consistency, he showed that a first order approximation to his procedure is asymptotically equivalent to the optimal RM procedure.

These procedures are sequential since they generate the $\mathrm{n}^{\text {th }}$ design level based on the previous $\mathrm{n}-1$ design levels and responses. One approach, however, is to select a fixed total number of observations for the experiment. If a sequential stopping rule is desired, then one can be constructed based on the asymptotic variance of the estimator. Freedman (1970) introduced stopping rules for the Up and Down method based on Bayesian decision theory. The case of a fixed total number of observations is considered in this paper.

Note that procedures (4), (7), and (8) were developed to estimate a single root of the expectation $M(x)$. With the exception of Wu's procedure, no attempt was made to estimate the entire function $M(x)$. Even though $M(x)$ was estimated at each stage in Wu's procedure, the purpose was to provide an estimate of a single $L_{p}$, not the entire curve $M(x)$.

In Chapter II of this thesis, a new sequential

approximation method called SAM is proposed. The objective of the new procedure is to provide estimates of any number of roots, $I_{p}$, of $M(x)=p$. In chapter III, SAM is studied in detail for binary data applications. Conditions under which SAM's estimates are consistent are provided. Using 
the two parameter logit expectation, SAM is shown to be asymptotically equivalent (in first order) to a two dimensional RM process . The results of a simulation study are presented in Chapter IV. 


\section{CHAPTER II}

\section{A NEW SEQUENTIAL APPROXIMATION METHOD (SAM)}

\section{The Procedure}

As in Wu's procedure (8), to produce root estimators, a parametric model, $G(x \mid \theta)=\int y g(y \mid x, \theta) \partial y$, is used for the expectation function of $Y$. Select $k$ unique constants $\mathrm{p}_{1}, \ldots, \mathrm{p}_{\mathrm{k}}$, where $\mathrm{k}$ is the dimension of the vector of parameters, $\theta=\left(\theta_{1}, \ldots, \theta_{k}\right)^{\prime}$. The updating rule for SAM is:

1) Calculate the MLE of $\theta$ using $g(y \mid x, \theta)$ as the density function of $Y ; \hat{\theta}^{(n)}=\hat{\theta}\left[\left(Y_{1 j}, x_{1 j}\right)\right]_{(1,1)}^{(n, k)}$ where $(i, j)=$ $(1,1)$ to $(n, k)$ refers to the $k$ observations that that are taken at each of the $n$ updates of the process.

2) Define the estimated expectation after the $n^{\text {th }}$ update of the process as

$$
\hat{G}_{n}(x)=G\left(x \mid \hat{\theta}^{(n)}\right),
$$

and choose the next $k$ dimensional design point $\left(x_{n+1,1}\right.$, $\left.\ldots, x_{n+1, k}\right)$ such that $\hat{G}\left(x_{n+1, j}\right)=p_{j}$ for $j=1, \ldots, k$.

After $n$ updates, $x_{n+1, j}$ provides an estimate of $L_{p_{j}}$, for $j=1, \ldots, k$. In general, estimates of any root, $L_{p^{*}}$, 
of the equation $M(x)=p^{*}$, are provided by $\hat{L}_{p^{*}}^{(n)}$, where $\hat{\mathrm{G}}_{\mathrm{n}}\left(\hat{\mathrm{L}}_{\mathrm{p}^{*}}^{(\mathrm{n})}\right)=\mathrm{p}^{*}$.

Note that both the design levels, $x_{1, j}$, and the responses, $y_{1, j}$, are random variables. However, the joint probability density function, $g\left(x_{1,1}, y_{1,1}, \ldots, x_{n, k}, y_{n, k}\right)$, is simply the product of the conditional probability densities of $Y_{i, j}$, given $x_{i, j}$. That is,

$$
g\left(x_{1,1}, y_{1,1}, \ldots, x_{n, k}, y_{n, k}\right)=\prod_{i=1}^{n} \prod_{j=1}^{k} g\left(y_{1, j} \mid x_{i, j}\right) \cdot
$$

To see this, note

$$
\begin{gathered}
g\left(x_{1,1}, y_{1,1}, \ldots, x_{n, k}, y_{n, k}\right)= \\
g\left(y_{n, 1}, \ldots, y_{n, k} \mid x_{1,1}, y_{1,1}, \ldots, y_{n-1, k}, x_{n, 1}, \ldots, x_{n, k}\right) \\
P\left(x_{n, 1}, \ldots, x_{n, k} \mid x_{1,1}, y_{1,1}, \ldots, x_{n-1, k}, y_{n-1, k}\right) \cdot \ldots \\
g\left(y_{1,1}, \ldots, y_{1, k} \mid x_{1,1}, \ldots, x_{1, k}\right) \cdot P\left(x_{1,1}, \ldots, x_{1, k}\right)
\end{gathered}
$$

The random variables $\mathrm{x}_{\mathrm{n}, 1}, \ldots, \mathrm{Y}_{\mathrm{n}, \mathrm{k}}$, given the design levels $x_{n, 1}, \ldots, x_{n, k}$, are assumed to be independent random variables. Also, $g\left(y_{i, j} \mid x_{1,1}, y_{1,1}, \ldots, x_{1-1, k}, y_{i-1, k}\right.$ $\left.x_{i, 1}, \ldots, x_{i, k}\right)=g\left(y_{i, j} \mid x_{i, j}\right)$. Since $P\left(x_{i, 1}, \ldots, x_{i, k} \mid x_{1,1}, y_{1,1}, \ldots, x_{i-1, k}, y_{1-1, k}\right)=1$ and $x_{1,1}, \ldots, x_{1, k}$ are fixed values, (11) simplifies to the result in (10). Therefore, in the maximum likelihood calculations, the likelihood function is $\prod_{i} \prod_{j} g\left(y_{i, j} \mid x_{i, j}, \theta\right)$, considered as a function of $\theta$.

SAM uses MLEs to calculate the next design levels. However, when only a few observations have been taken, MLEs may not exist. Therefore, some other procedure is needed to 
produce the initial design levels until the MLEs exist. Two methods for producing the initial design levels are given in the simulation study of chapter IV. In the first, an initial set of five design levels is chosen. A total of ten responses are observed at these levels. The second method starts with a Robbins-Monro procedure and switches to SAM's updating rules when the MLEs first exist. Two other possibilities for producing the initial design levels are the modified binary search presented by Neyer (1989) and the two dimensional Robbins-Monro process proposed by Moser and Fei (1989a).

For $k=1$, SAM (9) is equivalent to the MLE version of Wu's procedure (8), provided $H(x \mid \theta)=G(x \mid \theta)$. However, for $k>1$, the two procedures differ. At the $n^{\text {th }}$ update, SAM generates $k$ new design levels, $x_{n+1,1}, \ldots, x_{n+1, k}$, while Wu's procedure generates a single level, $x_{n+1}$.

Figure 2 on the following page is a graphical display of SAM's updating rule. A sketch of the estimated expectation curve after $n$ updates, $\hat{G}_{n}(x)$, is given. The dotted lines highlight the next $\mathrm{k}$ design levels $\left(x_{n+1,1}, \ldots, x_{n+1, k}\right)$, the solutions to $\hat{G}_{n}(x)=p_{j}, j=$ $1, \ldots, \mathrm{k}$.

The difference between SAM and Wu's procedure is also apparent in Figure 2. The design levels in Wu's procedure will be grouped around a single point, $L_{p}$. Using SAM, the design levels will be in $\mathrm{k}$ separate groups, around $\mathrm{L}_{\mathrm{p}_{1}}, \mathrm{~L}_{\mathrm{p}_{2}}$, $\ldots$, and $L_{p_{k}}$. 


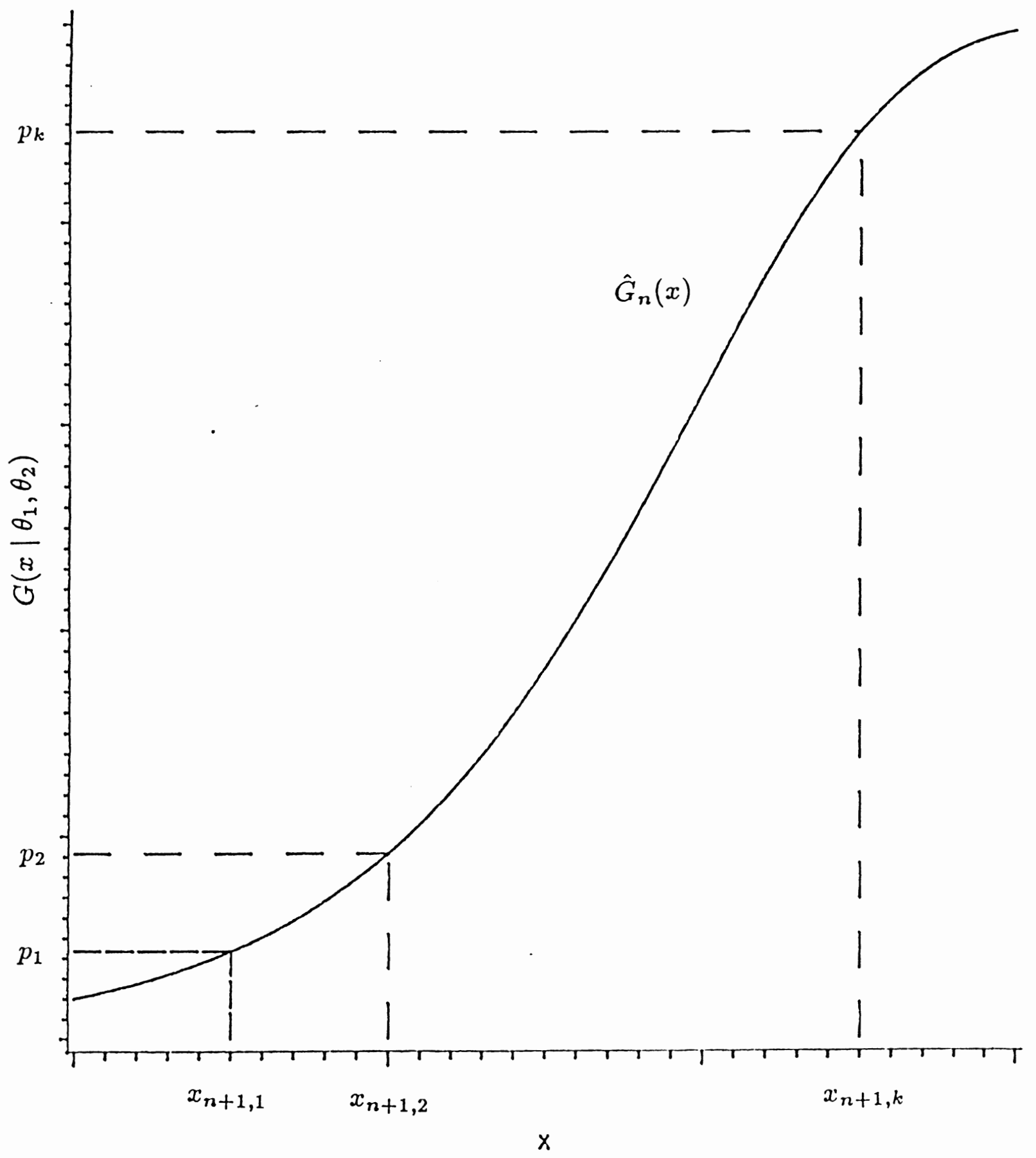

Figure 2. SAM 
Selecting $\mathrm{p}_{1}, \ldots, \mathrm{p}_{\mathrm{k}}$

SAM's updating rule requires the choice of $\mathrm{k}$ unique constants $p_{1}, p_{2}, \ldots, p_{k}$. one approach is to base the selection of $p_{1}, p_{2}, \ldots, p_{k}$ on $\operatorname{Var}\left(\hat{L}_{p^{*}}^{(n)}\right)$. This variance is a function of $M(x)$. Since $M(x)$ is unknown, a different criteria must be used to select $p_{1}, p_{2}, \ldots, p_{k}$.

For a given set of values $p_{1}, p_{2}, \ldots, p_{k}$, and for any $\mathrm{p}^{*} \in \Omega$, where $\Omega$ is the range space of $G(x \mid \theta)$, let

$$
\sigma_{n}^{* 2}=\lim _{n \longrightarrow \infty} E\left[\hat{L}_{p^{*}}^{(n)}-L_{p^{*}}\right]^{2} \text {, }
$$

where the expectation is calculated with respect to the density function $g(y \mid x, \theta)$. The value $\sigma_{n}^{* 2}$ is a function of $p^{*}, p_{1}, \ldots, p_{k}$, denoted by $\sigma_{n}^{* 2}\left(p^{*}, p_{1}, \ldots, p_{k}\right)$. The selection of $p_{1}, p_{2}, \ldots, p_{k}$ will be based on the function $\sigma_{n}^{* 2}\left(p^{*}, p_{1}, \ldots, p_{k}\right)$. If $\hat{L}_{p^{*}}^{(n)}$ is a consistent estimator of $L_{p^{*}}$ and $g(y \mid x, \theta)$ is the true density function of $Y$, then $\sigma_{n}^{* 2}$ represents the asymptotic variance of $\hat{\mathrm{L}}_{\mathrm{p}^{*}}$.

Two different criteria for selecting $p_{1}, p_{2}, \ldots, p_{k}$ are now presented. The first approach is to choose the $\mathrm{p}_{1}, \mathrm{p}_{2}, \ldots, \mathrm{p}_{\mathrm{k}}$ that minimize

$$
\int_{\Omega^{*}} \sigma_{n}^{* 2}\left(u, p_{1}, \ldots, p_{k}\right) \cdot \phi(u) \cdot \partial u
$$

where $\phi(\cdot)$ is a measure on $\mathrm{p}^{*} \in \Omega^{*} \subseteq \Omega$. The space $\Omega^{*}$ can be interpreted as the range of interest for $\mathrm{p}^{*}$, with $\phi(\cdot)$ indicating the level of interest in any $L_{p^{*}}$. If all roots, $L_{p^{*}} p^{*} \in \Omega^{*}$, are of equal interest, then $\phi(\cdot)$ is a 
Uniform $\left(\Omega^{*}\right)$ density function. The $p_{1}, p_{2}, \ldots, p_{k}$ that minimize (13) will be referred to as the average minimum $\mathrm{p}_{1}, \mathrm{p}_{2}, \ldots, \mathrm{p}_{\mathrm{k}}$ with respect to $\phi(\cdot)$.

A second approach is to choose the set $p_{1}, \ldots, p_{k}$ that minimizes the maximum $\sigma_{n}^{* 2}\left(p^{*}, p_{1}, \ldots, p_{k}\right)$ for $p^{*} \in \Omega^{*}$. That is, select the $p_{1}, p_{2}, \ldots, p_{k}$ that minimize

$$
\sup _{\in} \Omega^{*} \sigma^{* 2}\left(p^{*}, p_{1}, \ldots, p_{k}\right) .
$$

The $p_{1}, \ldots, p_{k}$ that minimize (14) will be referred to as the minimax $p_{1}, \ldots, p_{k}$. In chapter III, the average minimum and minimax values of $p_{1}, p_{2}$ are derived when $G(x \mid \theta)$ is the two parameter logit model.

\section{Bounded and Alternate Versions of SAM}

For small sample sizes, estimates of $\theta$ from SAM (9) or WU (8), and estimates of $M^{\prime}\left(I_{p}\right)$ from Anbar (6) are extremely variable. Thus, the changes in the design levels from the $\mathrm{n}^{\text {th }}$ to the $(\mathrm{n}+1)^{\text {st }}$ update can be extremely large. Wu (1985) has shown that bounded versions of these procedures, which limit the step size from $x_{n}$ to $x_{n+1}$, improve their performance for small to medium sample sizes. The following is a bounded version of SAM. Let $d_{n, j}, j=1, \ldots, k$, be the solution to $x_{n+1, j}=x_{n, j}-\left(d_{n, j} / n\right) \cdot\left(Y_{n, j}-p_{j}\right)$, where $x_{n+1}$ is the solution of $\hat{G}_{n}(x)=p_{j}$. The $(n+1, j)^{\text {th }}$ design point is then defined by 


$$
x_{n+1, j}=x_{n, j}-\left(d_{n, j}^{*} / n\right) \cdot\left(Y_{n, j}-p_{j}\right)
$$

where $d_{n, j}^{*}=\max \left[\delta_{1}, \min \left(d_{n, j}, \delta_{2}\right)\right]$ and $\delta_{1}<\delta_{2}$.

Instead of using the solutions of $\hat{G}_{n}(x)=p_{j}$ as the next design levels, the bounded version first checks the step sizes from $x_{n, j}$ to $x_{n+1, j}$. If the step sizes are not within the bounds determined by $\delta_{1}, \delta_{2}$ and $n$, then the step size bound is used to calculate $x_{n+1, j}$. Note that using $\delta_{1}$ $=-\infty$ and $\delta_{2}=\infty$ is equivalent to the unbounded version of $\operatorname{SAM}(8)$.

Using the bounded version of SAM (15), the step size, $\left|x_{n+1, j}-x_{n, j}\right|$, is bounded above by $\left|\left(\delta_{2} / n\right) \cdot\left(y_{n j}-p_{j}\right)\right| \cdot$ Note that as $\mathrm{n}$ increases, the maximum allowable step size decreases. If $\mathrm{Y}$ is a binary random variable with $\mathrm{p}=.2, \mathrm{k}$ $=2$ and $\delta_{2}=50$, at the $10^{\text {th }}$ update the maximum step size is $\left|5 \cdot\left(Y_{10, j}-.2\right)\right|$. This becomes 1 if $Y_{10, j}=0$, and 4 if $Y_{10, j}=1$. At the $30^{\text {th }}$ update, the step size is bounded by $\left|1.6 \cdot\left(Y_{30, j}-.2\right)\right|$. This bound is .32 is $Y_{30, j}=0$ and 1.28 if $\mathrm{Y}_{30, \mathrm{j}}=1$.

Instead of observing $k$ responses at each update, the following adaptation to SAM may be used. At the $(i+1)^{\text {st }}$ update, choose $x_{1+1,1}$ to be the solution of $G\left(x \mid \hat{\theta}^{(1,1)}\right)=$ $p_{1}$, where $\hat{\theta}^{(1,1)}$ is the MLE of $\theta$ based upon the previous $i$ updates $\left(\hat{\theta}^{(1)}\right.$ in the previous notation). After observing the response $Y_{i+1,1}$ at level $X_{i+1,1}$, recalculate $\hat{\theta}$ using $\left(y_{1,1}, x_{1,1}\right), \ldots,\left(y_{i, k}, x_{1, k}\right)$ and $\left(y_{i+1,1}, x_{i+1,1}\right)$. Denote this estimator by $\hat{\theta}^{(i, 2)}$. Choose $x_{i+1,2}$ to be the solution to $G\left(x \mid \hat{\theta}^{(1,2)}\right)=p_{2}$. Continue this process to produce all $\mathrm{k}$ 
design levels of the $(i+1)^{\text {st }}$ update.

The difference between this version of SAM and (9) is that updated parameter estimates are calculated after each observation, instead of after every $\mathrm{k}$ observations. This version has the advantage of using all information to calculate each new design level. However, it is often easier to run an experiment with fewer updates, observing several responses at a time. Thus, for the remainder of this paper, the original version of SAM (9) will be used. The asymptotic results in Chapter III follow for either version of SAM. 
CHAPTER III

SAM FOR BINARY DATA

\section{Introduction}

In Chapter II, a new sequential approximation method, SAM, was proposed. In this Chapter, SAM will be studied when $\mathrm{Y}$ is a binary random variable. If $\mathrm{Y}$ is a binary random variable, then $M(X)=P(Y=I \mid x)$ and $L_{p}$ is the $p^{\text {th }}$ percentile of $M(x)$. To use SAM's updating rule, a parametric model, $G(x \mid \theta)$, must be selected. Wu (1985) suggested using the logit model for binary data when $M(x)$ is unknown. Thus, without prior knowledge of $M(x), G(x \mid \theta)$ is chosen to be the two parameter logit model. When $G(x \mid \theta)$ is the two parameter logit model, SAM (9) is referred to as the logit version of SAM.

The consistency of SAM's estimates is discussed in the first section of this chapter. Three theorems are presented giving conditions for the consistency of SAM's estimators. An example of SAM's updating rule, using the two parameter logit model, is presented next. The logit version of SAM is then shown to be asymptotically equivalent (in first order) to a two dimensional RM procedure. Two approaches for selecting the constants $p_{1}$ and $p_{2}$ used in the logit version 
of SAM are also presented. The chapter concludes with a discussion of the asymptotic variances and biases of estimators from the RM procedure and the logit version of SAM .

\section{Consistency}

Using a one parameter logit expectation for $H(x \mid \theta)$, Wu (1985) demonstrated that $\hat{L}_{p}$ from his procedure (8) is a consistent estimator of $\mathrm{L}_{\mathrm{p}} \cdot \mathrm{SAM}$ and $\mathrm{Wu}$ 's procedure are the same when using one parameter expectations, provided $H(x \mid \theta)$ $=G(x \mid \theta)$. Thus $\hat{I}_{p}$ from SAM, using the one parameter logit expectation, is also a consistent estimator of $\mathrm{L}_{\mathrm{p}}$. This result holds regardless of the true expectation, $M(x)$. Using a model other than the one parameter logit for $H(x \mid \theta)$, Wu was unable to prove consistency.

It is known that under the standard regularity conditions with independent observations, MLEs are both consistent and asymptotically normal. Due to the dependence of the random variables, $Y_{1 j}, Y_{2 j}, \ldots, Y_{n j}$ it is difficult to demonstrate the consistency of SAM's or Wu's estimators using a general $\mathrm{k}$ parameter expectation. As previously mentioned, when $H(x \mid \theta)$ is the two parameter logit model, Wu was not able to provide a rigorous proof of the consistency of his estimators. However, using the results of Dubins and Freedman (1965), Wu demonstrated that if $\hat{\theta}^{(n)}$ from (8) 
converges almost surely to a constant $\theta^{*}$, then $\hat{L}_{p}$ from (8) converges to $I_{p}$ almost surely. Theorem 1 applies the work of Dubins and Freedman (1965) to SAM's estimators.

Theorem 1. Let $x_{1,1}, y_{1,1}, \ldots, x_{n, 2}, y_{n, 2}$ be a sequence of design levels of binary responses from $\operatorname{SAM}(9)$, where $G(x \mid \theta)$ is the two parameter logit expectation. Assume that the MLES, $\left(\hat{\theta}_{1}^{(n)}, \hat{\theta}_{2}^{(n)}\right)$, converge almost surely to a constant $\left(\theta_{1}^{*}, \theta_{2}^{*}\right), \theta_{2}^{*} \neq 0$. Also assume that $M(x)$ is a strictly increasing function of $x$. Then $\hat{L}_{p_{1}}^{(n)}$ and $\hat{L}_{p_{2}}^{(n)}$ from SAM converge almost surely to $L_{p_{1}}$ and $L_{p_{2}}$, respectively.

The proof is given in Appendix A. Note that Theorem 1 does not claim that $\hat{\mathrm{L}}_{\mathrm{p}^{*}}, \mathrm{p}^{*} \neq \mathrm{p}_{1}, \mathrm{p}_{2^{\prime}}$ is a consistent estimator of $L_{p^{*}}$. The estimator of any $L_{p^{* \prime}} p^{*} \neq p_{1}, p_{2}$, is a function of $G\left(x \mid \theta_{1}, \theta_{2}\right)$ (see the paragraph following (9)). If $G(x \mid \theta) \neq M(x)$, then $\hat{L}_{p_{1}}$ and $\hat{L}_{p_{2}}$ are still consistent estimators of $L_{p_{1}}$ and $L_{p_{2}}$ respectively, although $\hat{L}_{p^{*}}$ in general $\left(p^{*} \neq p_{1}, p_{2}\right)$ may not be a consistent estimator of $L_{p^{*}} \cdot$

As mentioned at the beginning of this section, $\hat{L}_{p}$ from SAM, when $G(x \mid \theta)$ is the one parameter logit expectation, is a consistent estimator of $L_{p}$. The following theorem extends this consistency result to one parameter binary expectations other than the logit model. It does not require the assumption that the MLEs converge almost surely to a constant. However, it requires the strong assumption that 
the parametric model used in SAM is the true expectation of Y. That is, $G(x \mid \theta)=M(x)$.

Theorem 2. Let $\mathrm{Y}$ be a binary random variable depending upon the level of another variable $x$. Let $G(x \mid \theta)=M(x \mid \theta)=$ $\mathrm{E}(\mathrm{Y} \mid \mathrm{x}, \theta)$, where $\theta$ is a single unknown parameter. Consider the following conditions:

1) $M(x \mid \theta)$ is continuous in $\theta$,

2) $\exists \delta_{1}, \delta_{2} \in R$ such that $\delta_{1}<\partial M / \partial \theta<\delta_{2}$.

If conditions 1) and 2), along with the standard regularity conditions on the distribution of $Y$ (given in Appendix $B$ ), are satisfied, then the estimator $\hat{L}_{p}$ produced by SAM (9) converges in probability to $\mathrm{L}_{\mathrm{p}}$.

The one parameter logit and probit models are examples of expectations which satisfy these conditions. The proof is based in the results of Crowder (1975), and is given in Appendix B.

By placing certain restrictions on the bounded version of SAM (15), it will now be shown that $\hat{L}_{p_{1}}, \hat{L}_{p_{2}}, \ldots, \hat{L}_{p_{k}}$ converge almost surely to $\mathrm{L}_{\mathrm{p}_{1}}, \mathrm{~L}_{\mathrm{p}_{2}}, \ldots, \mathrm{L}_{\mathrm{p}_{\mathrm{k}}}$. In (15), replace $d_{n, j}^{*}$ with $d_{n-1, j}^{*}$ to produce the updating rule

$$
x_{n+1, j}=x_{n, j}-\left(d_{n-1, j}^{*} / n\right) \cdot\left(Y_{n, j}-p_{j}\right) \text {, }
$$

where $d_{n-1, j}^{*}=\max \left\{\delta_{1}, \min \left(d_{n-1, j}, \delta_{2}\right)\right\}, d_{n-1, j}$ is the solution to $x_{n, j}=x_{n-1, j}-\left[d_{n-1, j} /(n-1)\right] \cdot\left(Y_{n-1, j}-p_{j}\right)$ and $x_{n, j}$ is the solution to $\hat{G}_{n-1}(x)=p_{j}$. The difference between (15) and (16) is that the step size factor in (16), $d_{n-1, j}^{*}$ is based only upon $x_{1,1}, y_{1,1}, \ldots, x_{n, k^{\prime}}$ instead of 
$x_{1,1}, Y_{1,1}, \ldots, x_{n, k}, Y_{n, k}$

Theorem 3. Let $\mathrm{Y}$ be a binary random variable with a strictly increasing expectation function, $M(x)$. Let $x_{1,1}, Y_{1,1}, \ldots x_{n, k}, Y_{n, k}$ be a sequence of design levels and responses from (16), with $0<\delta_{1}<\delta_{2}$. Then $x_{n+1, j}=\hat{L}_{p}^{(n)}$ converges to $L_{p_{j}}, j=1,2, \ldots, k$, almost surely.

The proof follows from application 2 of Robbins and siegmund (1971). Two points regarding Theorem 3 should be noted. By using $d_{n-1, j}^{*}$ in place of $d_{n, j^{\prime}}^{*}$ (16) fails to use the latest information in calculating the step sizes. Thus, it is not recommended above the updating rule in (15). The use of $d_{n-1, j}^{*}$ was simply to satisfy the conditions of Robbins and siegmund (1971). To apply their results, $d_{n-1, j}^{*}$ in (16) must be a function of $x_{1,1}, y_{1,1}, \ldots, x_{n, j}$ only (not including $\left.y_{n, j}\right)$. This does not say that Theorem 3 does not hold using $d_{n, j}^{*}$. An extension of their work, however, would be needed for that result.

Secondly, Theorem 3 states that $\hat{L}_{p_{j}}$ converges to $L_{p_{j}}$, for $\mathrm{j}=1, \ldots, \mathrm{k}$. Thus we have consistent estimators for $\mathrm{k}$ roots, $\mathrm{L}_{\mathrm{P}_{1}}, \ldots, \mathrm{L}_{\mathrm{P}_{\mathbf{k}}}$. As in Theorem 1 , this does not prove the consistency of $\hat{L}_{p^{*}}$ for $p^{*} \notin\left\{p_{1}, \ldots, p_{k}\right\}$. The estimate of any $\mathrm{L}_{\mathrm{p}^{*}}$ is the solution to $\hat{G}_{n}(x)=\mathrm{p}^{*}$, which depends upon the selected model, $G(x \mid \theta)$. For $\hat{L}_{P^{*}}$ to converge to $L_{p^{*}}$ for any $p^{*}$, the model used by $\operatorname{SAM}, G(x \mid \theta)$, must be the true expectation of $\mathrm{Y}, \mathrm{M}(\mathrm{X})$. 
In this section, three theorems have been presented. Each provides restrictions under which SAM's estimators are consistent. At this time, a rigorous proof, using less restrictive conditions, of the consistency of SAM's estimates has not been developed. However, these three theorems provide significant progress toward this goal.

An Example: The Two Parameter Logit Model

Let $Y$ be a binary random variable with expectation $M(x)$. Consider using SAM's updating rule (9), with $G(x \mid \theta)$ given by the two parameter logit model. That is, let

$$
G\left(x \mid \theta_{1}, \theta_{2}\right)=\left(1+\exp \left\{-\theta_{2}\left(x-\theta_{1}\right)\right\}\right)^{-1}
$$

Since the logit model is symmetric, let $p_{1}=p$ and $p_{2}=1-p$ for some $0<p<1 / 2$. At the $n^{\text {th }}$ update, SAM (9) consists of observing $y_{n, 1}$ and $y_{n, 2}$ at the two design levels, $x_{n, 1}$ and $x_{n, 2}$. The next two design levels, $x_{n+1,1}$ and $x_{n+1,2^{\prime}}$ are then generated by

$$
\begin{aligned}
& x_{n+1,1}=\hat{\theta}_{1}^{(n)}-\left[\ln \{(1-p) / p\} / \hat{\theta}_{2}^{(n)}\right] \text { and } \\
& x_{n+1,2}=\hat{\theta}_{1}^{(n)}+\left[\ln \{(1-p) / p\} / \hat{\theta}_{2}^{(n)}\right],
\end{aligned}
$$

where the maximum likelihood estimates $\hat{\theta}_{1}^{(n)}$ and $\hat{\theta}_{2}^{(n)}$ are determined by the normal equations

$$
\sum_{i=1}^{n} \sum_{j=1}^{2} Y_{i j}=\sum_{i=1}^{n} \sum_{j=1}^{2}\left(1+\exp \left\{-\theta_{2}\left(x_{i j}-\theta_{1}\right)\right\}\right)^{-1}
$$




$$
\sum_{i=1}^{n} \sum_{j=1}^{2} x_{i j} y_{1 j}=\sum_{i=1}^{n} \sum_{j=1}^{2} x_{i j}\left(1+\exp \left\{-\theta_{2}\left(x_{i j}-\theta_{1}\right)\right\}\right)^{-1} .
$$

For example, consider the following set of ten observations.

\section{Design Level Response}

2.0

2.0

3.0

3.0

4.0

\section{0}

0

0

1

0
Design Level Response

$\begin{array}{ll}4.0 & 0 \\ 4.5 & 1 \\ 4.75 & 0 \\ 5.0 & 1 \\ 5.0 & 1\end{array}$

Using the Newton Raphson method to solve the normal equations (19), the MLEs of $\theta_{1}$ and $\theta_{2}$ are $\hat{\theta}_{1}^{(5)}=4.250$ and $\hat{\theta}_{2}^{(5)}=1.144$. By $(18)$, using $p=.2$, the next design levels are

$$
\begin{aligned}
x_{6,1} & =\hat{\theta}_{1}^{(5)}-\left[\ln ((1-.2) / .2\} / \hat{\theta}_{2}^{(5)}\right] \\
& =4.250-[1.386 / 1.144]=3.038,
\end{aligned}
$$

and

$$
\begin{aligned}
x_{6,2} & =\hat{\theta}_{1}^{(5)}+\left[\ln \{(1-.2) / .2\} / \hat{\theta}_{2}^{(5)}\right] \\
& =4.250+[1.386 / 1.144]=5.462 .
\end{aligned}
$$

Figure 3 on the following page depicts the estimated expectation curve, $\hat{G}_{5}(x)$, after the initial ten observations. The design levels for the next experiment, 3.038 and 5.462, are emphasized with the dotted Iines.

The responses, $y_{6,1}$ and $Y_{6,2^{\prime}}$ are then observed when the experiment is run at levels 3.038 and 5.462 , respectively. If $Y_{6,1}=1$ and $Y_{6,2}=1$, then $\hat{\theta}_{1}^{(6)}=3.836$ and $\hat{\theta}_{2}^{(6)}=.936$. The design levels of the $7^{\text {th }}$ update are 


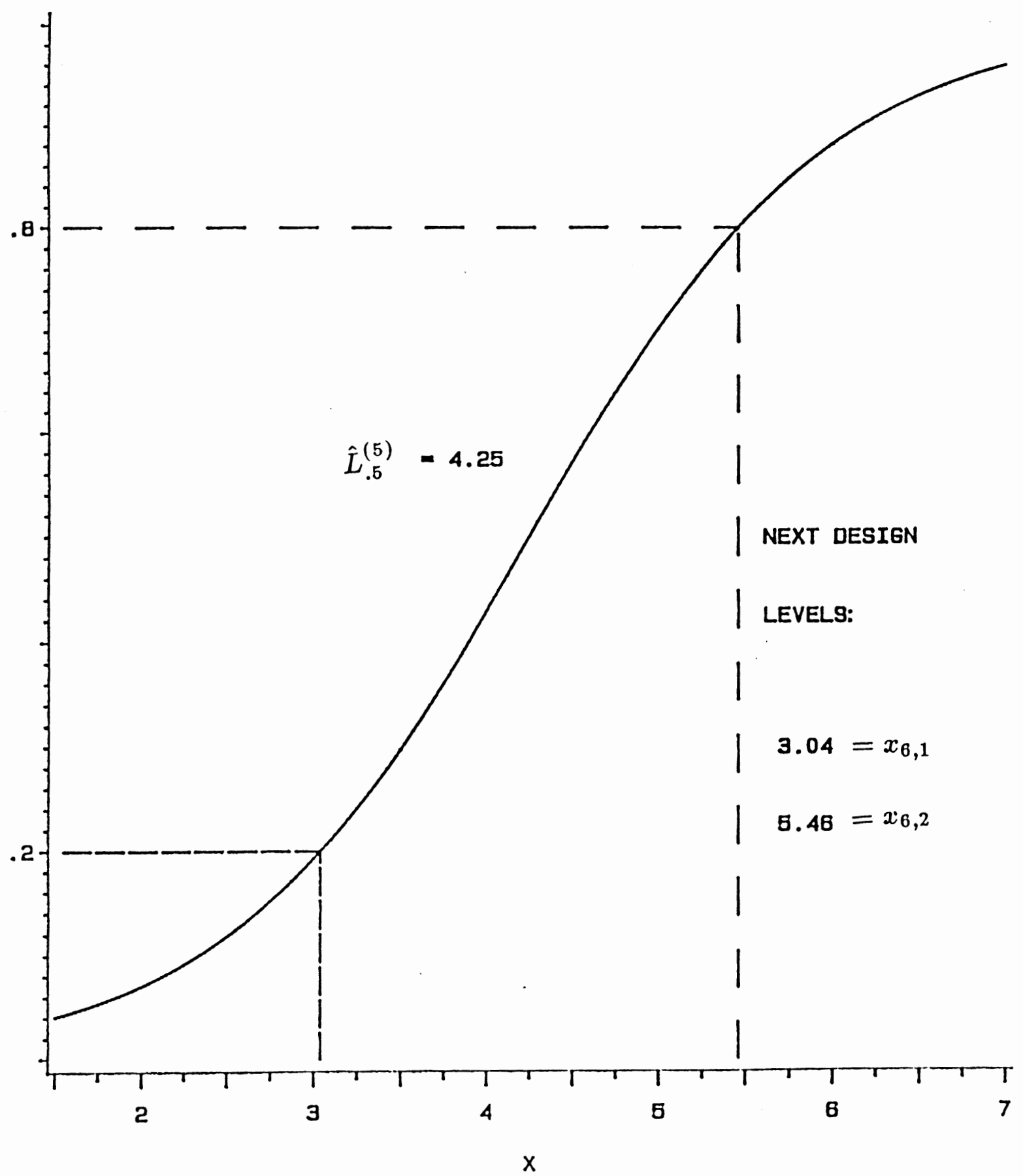

Figure 3. SAM An Example 
$x_{7,1}=2.354$ and $x_{7,2}=5.318$. Table 1 presents the designs levels and responses through the $12^{\text {th }}$ update.

\section{TABLE 1}

AN EXAMPLE

\begin{tabular}{cccccc} 
Update & Level 1 & Response 1 & Level 2 & Response 2 \\
\cline { 2 - 3 } 1 & 2.0 & 0 & 0 & 4.0 & 0 \\
2 & 2.0 & 0 & 4.5 & 1 \\
3 & 3.0 & 1 & 4.75 & 0 \\
4 & 3.0 & 0 & 5.0 & 1 \\
5 & 4.0 & 1 & 5.0 & 1 \\
6 & 3.04 & 0 & 5.46 & 1 \\
7 & 2.35 & 0 & 5.32 & 1 \\
8 & 2.62 & 0 & 5.06 & 1 \\
9 & 2.79 & 0 & 4.91 & 0 \\
10 & 2.92 & 1 & 5.33 & 1 \\
11 & 3.04 & 0 & 5.20 & 0 \\
12 & 2.60 & $\hat{\theta}_{1}^{(12)}=4.138, \hat{\theta}_{2}^{(12)}$ & $=1.003$ & 1 \\
\hline & & 0 & 5.70 & 1
\end{tabular}

Using the final estimated expectation function, $\hat{G}_{12}(x)$ $=G\left(x \mid \hat{\theta}_{1}^{(12)}, \hat{\theta}_{2}^{(12)}\right)$, estimates of the $\left(p^{*}\right)^{\text {th }}$ percentile can be constructed for any $\mathrm{p}^{*} \in(0,1)$. From (17), the solution, $\hat{\mathrm{L}}_{\mathrm{p}^{*}}^{(12)}$, of $\hat{\mathrm{G}}_{12}(\mathrm{x})=\mathrm{p}^{*}$ is $\hat{\mathrm{L}}_{\mathrm{p}^{*}}^{(12)}=\hat{\theta}_{1}^{(12)}-\ln \left[\left(1-\mathrm{p}^{*}\right) / \mathrm{p}^{*}\right] \cdot\left(\hat{\theta}_{2}^{(12)}\right)^{-1}$.

Thus, the final estimate of the $75^{\text {th }}$ percentile, $L_{.75^{\prime}}$ is 


$$
\hat{\mathrm{L}}_{.75}=4.138-\ln [1 / 3] \cdot(1.003)^{-1}=5.233
$$

In Appendix E, the codes and descriptions of programs designed to assist a researcher in using SAM's updating rule, with the two parameter logit model, are given.

Equivalence of the Logit Version of SAM and a Two Dimensional RM Procedure

Consider using the two parameter logit model (17) for $G(x \mid \theta)$ in SAM (9) and for $H(x \mid \theta)$ in Wu (8). Wu (1985), assuming the consistency of (8), proved that a first order approximation to his procedure is asymptotically equivalent to the optimal RM procedure. Using linear approximations to the two parameter logit model around $\mathrm{L}_{\mathrm{p}_{1}}$ and $\mathrm{L}_{\mathrm{p}_{2}}{ }^{\prime}$ a similar result for SAM is now presented.

Since the logit model is symmetric, let $p_{1}=p$ and $p_{2}=$ $1-\mathrm{p}$ for some $0<\mathrm{p}<1 / 2$. Consider the following approximation to $G(x \mid \theta)$ :

$$
\begin{aligned}
& \operatorname{near} L_{p} \quad(j=1) \\
& \quad\left(1+\exp \left\{-\theta_{2}\left(x-\theta_{1}\right)\right\}\right)^{-1} \cong p+\left(x-L_{p}\right) \cdot \lambda_{p} \\
& \operatorname{near} L_{1-p}(j=2) \\
& \quad\left(1+\exp \left\{-\theta_{2}\left(x-\theta_{1}\right)\right\}\right)^{-1} \cong(1-p)+\left(x-L_{1-p}\right) \cdot \lambda_{1-p}
\end{aligned}
$$

where $\lambda_{\mathrm{p}}=\lambda_{1-\mathrm{p}}=\theta_{2} \mathrm{p}(1-\mathrm{p})$ are the tangent slopes of $\mathrm{G}\left(\mathrm{x} \mid \theta_{1}\right.$, $\left.\theta_{2}\right)$ at $L_{p}$ and $L_{1-p}$, respectively. Since $\lambda_{p}=\lambda_{1-p}$, drop the subscripts and denote both by $\lambda$. From Figure 4 on the 
following page, the approximation is valid for $x_{1,1}$ near $L_{p}$ and $x_{1,2}$ near $L_{1-p}$.

Substitute $L_{1-p}=L_{p}+\{2 p(1-p) \cdot \ln [(1-p) / p]\} / \lambda$ into

(21) to obtain

near $\mathrm{L}_{1-\mathrm{p}}$

$$
\begin{aligned}
& \left(1+\exp \left(-\theta_{2}\left(x-\theta_{1}\right)\right)\right)^{-1} \cong \\
& \quad(1-p)+\left(x-L_{p}\right) \cdot \lambda-2 p(1-p) \cdot \ln [(1-p) / p]
\end{aligned}
$$

Applying (20) and (22) to the likelihood equations (19) yields

$$
\begin{aligned}
& \sum_{1}^{n}\left\{\lambda \cdot\left(x_{11}-L_{p}\right)+\lambda \cdot\left(x_{12}-L_{p}\right)+\right. \\
& 1-2 p(1-p) \cdot \ln [(1-p) / p]\}=\sum_{1}^{n}\left\{y_{11}+y_{12}\right\}
\end{aligned}
$$

and

$$
\begin{aligned}
& \sum_{1}^{n}\left\{\lambda \cdot\left(x_{11}^{2}+x_{12}^{2}\right)-\lambda \cdot L_{p}\left(x_{11}+x_{12}\right)+p x_{11}+\right. \\
& \left.\quad(1-p)(1-2 p \cdot \ln [(1-p) / p]) \cdot x_{12}\right\}=\sum_{1}^{n}\left\{x_{11} y_{11}+x_{12} y_{12}\right\}
\end{aligned}
$$

Estimators of $\lambda$ and $L_{p}$ are then obtained by solving (23),

$$
\begin{aligned}
& \hat{\lambda}_{n}=\left(\sum_{i=1}^{n} \sum_{j=1}^{2}\left(x_{i j}-\bar{x}_{n}\right)^{2}\right)^{-1} \cdot\left(\sum_{i=1}^{n} \sum_{j=1}^{2} y_{1 j}\left(x_{i j}-\bar{x}_{n}\right)-\right. \\
&\left.\{(1 / 2)-p-(1-p) \cdot \ln [(1-p) / p]\} \sum_{1}^{n}\left(x_{12}-x_{11}\right)\right) \\
& \hat{L}_{p}^{(n)}=-\left(2 n \cdot \hat{\lambda}_{n}\right)^{-1} \cdot \\
&\left(\sum_{i=1}^{n} \sum_{j=1}^{2}\left\{y_{1 j}-x_{i j} \cdot \hat{\lambda}_{n}\right\}-n\{1-2 p(1-p) \cdot \ln [(1-p) / p])\right.
\end{aligned}
$$

where $\bar{x}_{n}=\sum_{i=1}^{n} \sum_{j=1}^{2} x_{i j} / 2 n$, and the superscript on $\hat{L}_{p}^{(n)}$ and subscript on $\hat{\lambda}_{n}$ denote the $n^{\text {th }}$ update. Substituting (24) 


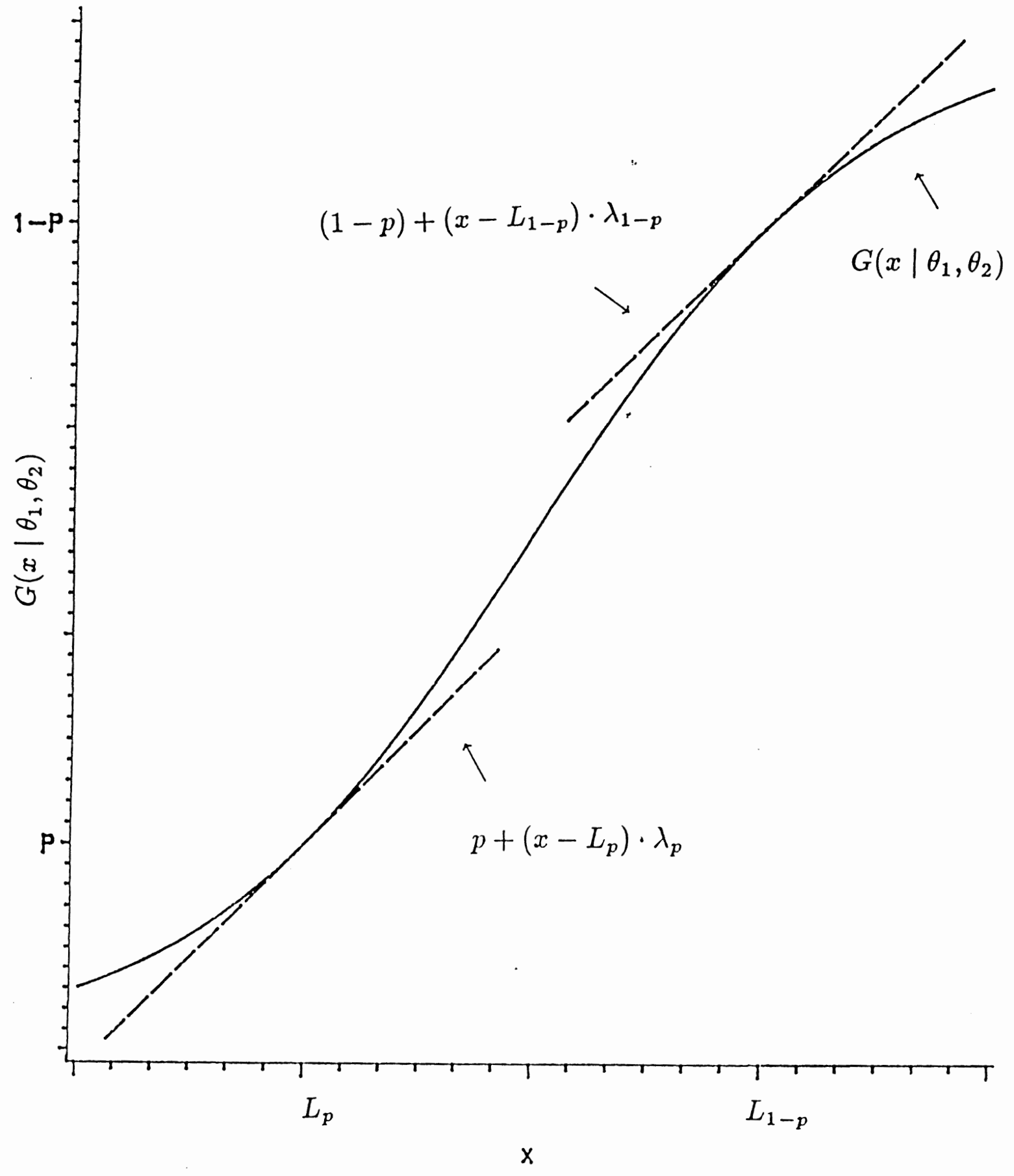

Figure 4. Logit Approximation 
into (25) produces

$$
\begin{aligned}
\hat{L}_{p}^{(n)}= & \hat{L}_{p}^{(n-1)}-\left(2 n \hat{\lambda}_{n}\right)^{-1}\left(\left(y_{n 1}-p\right) \cdot K_{1}+\right. \\
& \left.\left(y_{n 2}-(1-p)\right) \cdot K_{2}-\left(\hat{\lambda}_{n}\right)^{-1} \cdot K_{3}\right),
\end{aligned}
$$

where

$$
\begin{aligned}
\mathrm{K}_{1}= & \sum_{1=1}^{n} \sum_{j=1}^{2}\left(\mathrm{x}_{1 j}-\mathrm{x}_{\mathrm{n} 1}\right)^{2} / \sum_{i=1}^{n} \sum_{j=1}^{2}\left(\mathrm{x}_{1 j}-\bar{x}_{\mathrm{n}}\right)^{2}, \\
\mathrm{~K}_{2}= & \left(\sum_{1=1} \sum_{j=1}\left\{\mathrm{x}_{1 j}-(1 / 2)\left(\mathrm{x}_{\mathrm{n} 1}+\mathrm{x}_{\mathrm{n} 2}\right)\right\}^{2}-((n-1) / 2)\left(\mathrm{x}_{\mathrm{n} 2}-\mathrm{x}_{\mathrm{n} 1}\right)^{2}\right) \\
& / \sum_{1=1} \sum_{j=1}\left(\mathrm{x}_{1 j}-\bar{x}_{\mathrm{n}}\right)^{2}
\end{aligned}
$$

and

$$
\mathrm{K}_{3}=(1 / 2)(1-2 p-2 p \cdot \ln [(1-p) / p])\left[1+\frac{\left(x_{n 1}-\bar{x}_{n}\right) \cdot \sum\left(x_{12}-x_{i 1}\right)}{\sum_{i} \sum_{j}\left(x_{i j}-\bar{x}_{n}\right)^{2}}\right] .
$$

Assuming the consistency of SAM (9), as $n----->\infty, x_{n 1}----->$ $L_{p}$ and $x_{n 2}---->L_{1-p}$ Therefore, as $n-\cdots->\infty, K_{1}--->2$, $\mathrm{K}_{2}--->0$, and $\mathrm{K}_{3}--->0$, and from (26),

$$
x_{n+1,1}=\hat{L}_{p}^{(n)}=\hat{L}_{p}^{(n-1)}-\left(n \cdot \hat{\lambda}_{n}\right)^{-1}\left(y_{n 1}-p\right)
$$

By similar arguments,

$$
x_{n+1,2}=\hat{L}_{1-p}^{(n)}=\hat{L}_{1-p}^{(n-1)}-\left(n \cdot \hat{\lambda}_{n}\right)^{-1}\left(y_{n 2}-(1-p)\right)
$$

By Theorem 4 in Appendix $c, \hat{\lambda}_{n}$ converges almost surely to $c_{L}=\left\{2 p(1-p) \ln [(1-p) / p] /\left(L_{1-p}-L_{p}\right)\right.$. Therefore, $(27)$ and (28) are (first order) asymptotically equivalent to two independent $R M$ procedures, both with $A_{n}=\left(n \cdot c_{L}\right)^{-1}$. From Sacks (1958), with $\sigma^{2}=\lim _{x \rightarrow L_{p}} \operatorname{Var}(Y \mid x)=\lim _{x \rightarrow L_{1-p}}$ $\operatorname{Var}(\mathrm{Y} \mid \mathrm{X})$, 


$$
\left(\begin{array}{l}
\hat{L}_{p}^{(n)} \\
\hat{L}_{p}^{(n)}
\end{array}\right) \sim \operatorname{ASN}\left(\left(\begin{array}{c}
L_{p} \\
L_{p}
\end{array}\right),\left[\begin{array}{cc}
c_{L}^{-2} \sigma^{2} / n\left(2 c_{L}^{-1} M^{\prime}\left(L_{p}\right)-1\right) & 0 \\
0 & c_{L}^{-2} \sigma^{2} / n\left(2 c_{L}^{-1} M^{\prime}\left(L_{1-p}\right)-1\right)
\end{array}\right]\right) \text {. }
$$

If $M^{\prime}\left(L_{p}\right)=M^{\prime}\left(L_{1-p}\right)=c_{L^{\prime}}$, then (27) and (28) are asymptotically optimal RM procedures. If the true expectation is given by the two parameter logit model, then $M^{\prime}\left(L_{p}\right)=M^{\prime}\left(L_{1-p}\right)=\theta_{2} p(1-p)=c_{L}$, and (29) becomes

$$
\left(\begin{array}{l}
\hat{L}_{p}^{(n)} \\
\hat{L}_{1-p}^{(n)}
\end{array}\right) \sim \operatorname{ASN}\left(\left(\begin{array}{c}
L_{p} \\
L_{1-p}
\end{array}\right),\left[n \cdot \theta_{2}^{2} \cdot p \cdot(1-p)\right]^{-1} \cdot I_{2}\right)
$$

If $M(x)$ is not the two parameter logit model, then $\left(n c_{L}\right)^{-1}$ may not be optimal. The difference between the logit version of SAM and the optimal RM procedures at $p$ and 1-p can be characterized by the ratios $c_{L} / M^{\prime}\left(L_{p}\right)$ and $c_{L} /$ $M^{\prime}\left(L_{1-p}\right)$, respectively. Ratio values of 1 indicate that the logit version of SAM is asymptotically equivalent to two optimal RM processes. The ratio value is a function of the true expectation, $M(x)$, and the value of $p$. In Table 2 , ratios are provided for four models of $M(x)$ (the logit, probit, skewed logit, and loglog) with values of $(p, 1-p)$ equal to $(.2, .8)$. These four models are presented in equation (57) of chapter IV. A complete discussion of the models is given by Moser and Fei (1989b). 
TABLE 2

RATIOS $c_{L} / M^{\prime}\left(L_{p}\right)$ AND $c_{L} / M^{\prime}\left(L_{1-p}\right)$

\begin{tabular}{ccccc}
$M(x)$ & Logit & Probit & $\begin{array}{l}\text { Skewed } \\
\text { Logit }\end{array}$ & Loglog \\
\hline$p=.2$ & 1.0 & .94 & .85 & .92 \\
$1-p=.8$ & 1.0 & .94 & 1.12 & .51
\end{tabular}

From Table 2, the logit version of SAM is optimal if the true expectation, $M(x)$, is logit and nearly optimal when $M(x)$ is probit. SAM's logit version is also nearly optimal at $\mathrm{p}=.2$ when $\mathrm{M}(\mathrm{x})$ is $\log \log$.

The first order asymptotic equivalence of the logit version of SAM and the two RM processes does not depend on the assumption $p_{2}=1-p_{1}$. The results of this section hold for any $0<\mathrm{p}_{1}<\mathrm{p}_{2}<1$. A sketch of the proof is given below.

Let $\mathrm{p}_{1}, \mathrm{p}_{2}, 0<\mathrm{p}_{1}<\mathrm{p}_{2}<1$, be the two constants used in SAM (9). Consider the following approximation to $G\left(x \mid \theta_{1}, \theta_{2}\right):$

$$
\begin{aligned}
& \operatorname{near} L_{p_{1}}(j=1) \\
& \quad\left(1+\exp \left\{-\theta_{2}\left(x-\theta_{1}\right)\right\}\right)^{-1} \cong p_{1}+\left(x-L_{p_{1}}\right) \cdot \lambda_{p_{1}}, \\
& \operatorname{near} L_{p_{2}}(j=2) \\
& \quad\left(1+\exp \left\{-\theta_{2}\left(x-\theta_{1}\right)\right\}\right)^{-1} \cong p_{2}+\left(x-L_{p_{2}}\right) \cdot \lambda_{p_{2}},
\end{aligned}
$$

where $\lambda_{p_{1}}=\theta_{2} p_{1}\left(1-p_{1}\right)$ and $\lambda_{p_{2}}=\theta_{2} p_{2}\left(1-p_{2}\right)$. Note that for the two parameter logit model (16), 


$$
\begin{gathered}
\lambda_{p_{2}}=\frac{p_{2}\left(1-p_{2}\right)}{p_{1}\left(1-p_{1}\right)} \cdot \lambda_{p_{1}} \text { and } \\
L_{p_{2}}=L_{p_{1}}+\left(\lambda_{p_{1}}\right)^{-1} \cdot p_{1}\left(1-p_{1}\right) \cdot \ln \left(\frac{p_{2}\left(1-p_{1}\right)}{p_{1}\left(1-p_{2}\right)}\right) .
\end{gathered}
$$

Substitute (33) and (34) into (32) to obtain

$$
\begin{aligned}
& \operatorname{near} L_{p_{2}} \\
& \qquad \begin{aligned}
\left(1+\exp \left(-\theta_{2}\left(x-\theta_{1}\right)\right)\right)^{-1} \cong & p_{2}+\left(x-L_{p_{1}}\right) \cdot c^{\prime} \lambda_{p_{1}}- \\
& p_{1}\left(1-p_{1}\right) \cdot c^{\prime} \cdot \ln \left(\frac{p_{2}\left(1-p_{1}\right)}{p_{1}\left(1-p_{2}\right)}\right),
\end{aligned}
\end{aligned}
$$

where $c^{\prime}=p_{2}\left(1-p_{2}\right) / p_{1}\left(1-p_{1}\right)$. Solving the likelihood equations (19) with the linear substitutions (31) and (35) yields

$$
\left(\begin{array}{c}
\hat{L}_{p_{1}}^{(n)} \\
\hat{L}_{p_{2}}^{(n)}
\end{array}\right) \sim \operatorname{ASN}\left(\left(\begin{array}{c}
L_{p_{1}} \\
L_{p_{2}}
\end{array}\right),\left[\begin{array}{cc}
c_{L_{1}}^{-2} \sigma_{1}^{2} / n\left(2 c_{L 1}^{-1} M^{\prime}\left(L_{p_{1}}\right)-1\right) & 0 \\
0 & c_{L 2}^{-2} \sigma_{2}^{2} / n\left(2 C_{L 2}^{-1} M^{\prime}\left(L_{p_{2}}\right)-1\right)
\end{array}\right]\right)
$$

where $\sigma_{i}^{2}=\lim _{\mathrm{x} \longrightarrow \mathrm{L}_{\mathrm{p}_{1}}} \operatorname{Var}(\mathrm{Y} \mid \mathrm{x})$ for $i=1,2$,

$c_{L 1}=p_{1}\left(1-p_{1}\right)\left\{\ln \left[\left(1-p_{1}\right) / p_{1}\right]-\ln \left[\left(1-p_{2}\right) / p_{2}\right]\right\} /\left(L_{p_{2}}-L_{p_{1}}\right)$

and $c_{L 2}=p_{2}\left(1-p_{2}\right)\left\{\ln \left[\left(1-p_{1}\right) / p_{1}\right]-\ln \left[\left(1-p_{2}\right) p_{2}\right]\right\} /\left(L_{p_{2}}-\right.$

$\left.L_{p_{1}}\right)$. As before, these are optimal $R M$ procedures if $M^{\prime}\left(L_{p_{1}}\right)$ $=c_{L 1}$ and $M^{\prime}\left(L_{p_{2}}\right)=c_{L 2}$. If $M(x)$ is the two parameter logit model, then (36) simplifies to

$$
\left(\begin{array}{c}
\hat{L}_{p_{1}}^{(n)} \\
\hat{L}_{p_{2}}^{(n)}
\end{array}\right) \sim \operatorname{ASN}\left(\left(\begin{array}{c}
L_{p_{1}} \\
L_{p_{2}}
\end{array}\right),\left[\begin{array}{cc}
\left\{n \theta_{2}^{2} p_{1}\left(1-p_{1}\right)\right\}^{-1} & 0 \\
0 & \left\{n \theta_{2}^{2} p_{2}\left(1-p_{2}\right)\right\}^{-1}
\end{array}\right]\right)
$$


Selecting $\mathrm{p}_{1}, \mathrm{p}_{2}$ Using the Two Parameter Logit Model (Symmetric Case)

In Chapter II, average minimum and minimax criteria for selecting $p_{1}, \ldots, p_{k}$ in $S A M$ were presented. These two approaches are now used to derive $p_{1}, p_{2}$ using the two parameter logit model (17).

Let $\left[a^{*}, 1-a^{*}\right], 0<a^{*}<1 / 2$, define the range of interest for $\mathrm{p}^{*}$. That is, the range of interest of the roots $L_{\mathrm{p}^{*}}$ is the interval $\left[\mathrm{L}_{\mathrm{a}^{*}}, \mathrm{~L}_{1-\mathrm{a}^{*}}\right]$. Since the logit model is symmetric over the range of interest, let $p_{1}=p$ and $\mathrm{p}_{2}=1-\mathrm{p}$. The problem reduces to selecting a single value p by the two different approaches.

Let $\mathrm{p}^{*}$ be a particular value in the range of interest, $\left[a^{*}, 1-a^{*}\right]$. From (9) and (17), the estimator $\hat{\mathrm{L}}_{\mathrm{p}^{*}}^{(n)}$ is the solution to $\mathrm{p}^{*}=\left(1+\exp \left\{-\hat{\theta}_{2}^{(n)}\left(x-\hat{\theta}_{1}^{(n)}\right)\right\}\right)^{-1}$. Since $G\left(x \mid \theta_{1}, \theta_{2}\right)$ from (17) is completely determined by $L_{p}$ and $L_{1-p}$, the estimator, $\hat{L}_{p^{*}}^{(n)}$, can be obtained by

$$
\hat{L}_{p^{*}}^{(n)}=r \cdot \hat{L}_{p}^{(n)}+(1-r) \cdot \hat{L}_{1-p}^{(n)}
$$

where $r=(1 / 2)+\ln \left\{\left(1-\mathrm{p}^{*}\right) / \mathrm{p}^{*}\right\} / 2 \cdot \ln \{(1-\mathrm{p}) / \mathrm{p}\} \cdot \operatorname{From}(30)$ and (38), when the true expectation is the two parameter logit model, the asymptotic variance of $\hat{\mathrm{L}}_{\mathrm{p}^{*}}^{(\mathrm{n})}$ is

$$
\sigma_{n}^{* 2}\left(p^{*}, p\right)=\left(2 n \theta_{2}^{2} p(1-p)\right)^{-1}\left(1+\frac{\left(\ln \left\{p^{*} /\left(1-p^{*}\right)\right\}\right)^{2}}{(\ln \{p /(1-p)\})^{2}}\right)
$$

The minimax solution is the value of $p$ that minimizes 
the maximum $\sigma_{n}^{* 2}\left(p^{*}, p\right)$ for $p^{*} \in\left[a^{*}, 1-a^{*}\right]$. Note that for any given value of $p$,

$$
\max _{p^{*} \in\left[a^{*}, 1-a^{*}\right]}\left(p^{*}, p\right)=\sigma_{n}^{* 2}\left(a^{*}, p\right)
$$

That is, the maximum value of $\sigma_{n}^{* 2}\left(p^{*}, p\right)$ occurs at the boundaries of the interval $\left[a^{*}, 1-a^{*}\right]$. Thus, the problem reduces to finding the $\mathrm{p}$ that minimizes

$$
(p(1-p))^{-1}\left(1+\frac{\left(\ln \left\{a^{*} /\left(1-a^{*}\right)\right\}\right)^{2}}{(\ln \{p /(1-p)\})^{2}}\right)
$$

Column 2 of Table 3 gives optimal minimax values of $p$ for various $a^{*}$.

Consider the average minimum approach of Chapter II. Let $\phi(\cdot)$ be the Uniform $\left[a^{*}, 1-a^{*}\right]$ density function. This is equivalent to assigning equal interest to each root, $L_{p^{*}} p^{*}$ $\epsilon\left[\mathrm{a}^{*}, 1-\mathrm{a}^{*}\right]$. By (13) and (39), the average minimum solution is the value of $p$ that minimizes

$$
\int_{a}^{1-a^{*}}(2 p(1-p))^{-1}\left(1+\frac{(\ln \{u /(1-u)\})^{2}}{(\ln \{p /(1-p)\})^{2}}\right) \partial u
$$

Column 3 of Table 3, labelled Avg-min, gives the average minimum values of $p$ for various choices of $a^{*}$. 
TABLE 3

\section{MINIMAX AND AVERAGE MINIMUM P}

$\begin{array}{lcc}\mathrm{a}^{*} & \text { Minimax } \mathrm{p} & \text { Avg-min } \mathrm{p} \\ .05 & .13 & .19 \\ .10 & .15 & .20 \\ .15 & .17 & .22 \\ .20 & .19 & .24 \\ .25 & .21 & .26 \\ .30 & .23 & .28 \\ .40 & .30 & .34\end{array}$

Figure 5 on the next page graphically demonstrates the difference between the average minimum and minimax approaches. Each value of $p$ produces a different $\sigma_{n}^{* 2}\left(p^{*}, p\right)$ curve. In Figure 5 , the function $\sigma_{n}^{* 2}\left(p^{*}, p\right)$ is graphed for both $\mathrm{p}=.15$ and $\mathrm{p}=.2$. The curve $\sigma_{\mathrm{n}}^{* 2}\left(\mathrm{p}^{*}, .15\right)$ has $\mathrm{a}$ smaller maximum for $\mathrm{p}^{*} \in[.1, .9]$ than the curve $\sigma_{\mathrm{n}}^{* 2}\left(\mathrm{p}^{*}, .2\right)$. However, the area under the $\sigma_{n}^{* 2}\left(p^{*}, .2\right)$ curve is smaller. Thus, between these two possibilities, $p=.15$ is the minimax solution and $\mathrm{p}=.2$ is the average minimum solution. As presented in Table 3, these are the minimax and average minimum solutions (when $a^{*}=.1$ ) over all values of $p, 0<p$ $<1 / 2$

To obtain the results in Table 3 , the two parameter logit model was used for $G(x \mid \theta)$. Thus, $\sigma_{n}^{* 2}\left(p^{*}, p\right)$ was calculated using $G(x \mid \theta)=\left(1+\exp \left\{-\theta_{2}\left(x-\theta_{1}\right)\right\}\right)^{-1}$. If a different model is chosen for $G(x \mid \theta)$, then the minimax and average minimum values of $\mathrm{p}$ would change. Moser and Fei (1989b), consider the selection of $p_{1}$ and $p_{2}$ using four 


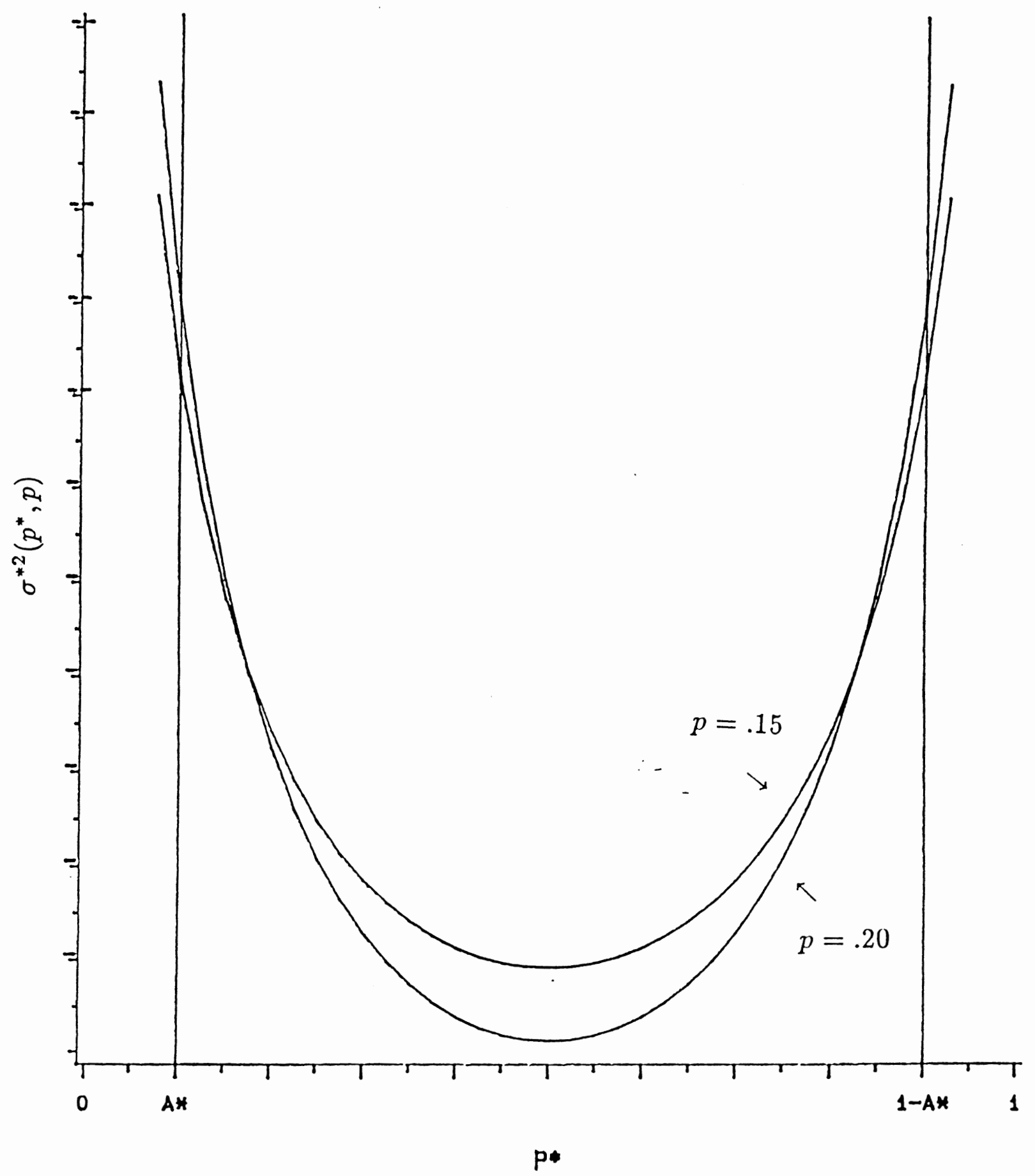

Figure 5. Minimax and Average Minimum $\mathrm{p}$ 
different models (logit, probit, loglog, skewed logit) for $G(x \mid \theta)$. Their discussion is based on a different method (a two dimensional Robbins Monro process). However, it is applicable to SAM because of the asymptotic equivalence of SAM and two independent RM processes.

The average minimum and minimax rules for $\mathrm{p}_{1}, \ldots, \mathrm{p}_{\mathrm{k}}$ are not only applicable to SAM, but are also valid for selecting $\mathrm{p}_{1}, \ldots, \mathrm{p}_{\mathrm{k}}$ for $\mathrm{k}$ independent $\mathrm{RM}$ procedures. For instance, Wetherill (1963) considered running two independent optimal RM procedures,

$$
\begin{gathered}
x_{n+1}^{(1)}=x_{n}^{(1)}-\left(n \cdot M^{\prime}\left(L_{p}\right)\right)^{-1} \cdot\left(y_{n}^{(1)}-p\right) \\
x_{n+1}^{(2)}=x_{n}^{(2)}-\left(n \cdot M^{\prime}\left(L_{1-p}\right)\right)^{-1} \cdot\left(y_{n}^{(2)}-(1-p)\right),
\end{gathered}
$$

to obtain estimates of $\mathrm{L}_{\mathrm{p}}$ and $\mathrm{L}_{1-p}$ for the logit model (17). Using these two estimates, an estimate of any root could be obtained from (38). He then demonstrated that the choice of $\mathrm{p}=.2$ minimizes the product $\operatorname{Var}\left(\hat{\gamma}_{1}\right) \cdot \operatorname{Var}\left(\hat{\gamma}_{2}\right)$, where $\hat{\gamma}_{1}=\hat{\mathrm{L}}_{.5}=$ $(.5) \cdot\left(x_{n}^{(1)}+x_{n}^{(2)}\right)$ and $\hat{\gamma}_{2}=\left[x_{n}^{(1)}+x_{n}^{(2)}\right] /[2 \cdot \ln (p /(1-p)]$. From Table 3, a value of $p=.2$ is approximately the average minimum and minimax solution when the range of interest is $(.1, .9)$ and $(.2, .8)$, respectively.

Wetherill also demonstrated that the nonsequential design that minimizes the product of the asymptotic variances of the parameter estimates is to divide the design levels equally into two groups at $\mathrm{L}_{.176}$ and $\mathrm{L}_{.824} \cdot$ Since $\mathrm{L}_{.176}$ and $\mathrm{L}_{.824}$ are unknown before the experiment, using a sequential procedure to obtain design levels approaching these values is intuitively appealing. 
Selecting $p_{1}, p_{2}$ Using the Two Parameter Logit Model (General Case)

In the previous section, the average minimum and minimax criteria were used to derive $p_{1}$ and $p_{2}$ using the logit model. The range of interest for $\mathrm{p}^{*}$ was $\left[\mathrm{a}^{*}, 1-\mathrm{a}^{*}\right], 0$ $<\mathrm{a}^{*}<1 / 2$. In many applications, however, the range of interest of $\mathrm{p}^{*}$ is not symmetric about .5. For instance, a researcher may be interested in estimating $\mathrm{L}_{.95}$ and $\mathrm{L}_{.99}$ ' the $95^{\text {th }}$ and $99^{\text {th }}$ percentiles of $\mathrm{M}(\mathrm{x})$, respectively. Let $\left[a_{1}, a_{2}\right], 0<a_{1}<a_{2}<1$, be the range of interest (where $a_{2}$ is not necessarily $1-a_{1}$ ). In this section, the minimum avarage and minimax criteria will be used to select $p_{1}$ and $\mathrm{p}_{2}$, where $\mathrm{p}_{2}$ is not necessarily $1-\mathrm{p}_{1}$. The two parameter logit model is again used for $G(x \mid \theta)$.

As a generaliation of equation (38), the estimate of any $L_{p}^{*}$ can be obtained from $\hat{L}_{p_{1}}$ and $\hat{L}_{p_{2}}$ by

$$
\hat{\mathrm{L}}_{\mathrm{p}^{*}}=\mathrm{r}^{\prime} \cdot \hat{\mathrm{L}}_{\mathrm{p}_{1}}+\left(1-r^{\prime}\right) \cdot \hat{\mathrm{L}}_{\mathrm{p}_{2}} \text {, }
$$

where

$$
r^{\prime}=\frac{\ln \left\{\left(1-p_{2}\right) / p_{2}\right\}-\ln \left\{\left(1-p^{*}\right) / p^{*}\right)}{\ln \left\{\left(1-p_{2}\right) / p_{2}\right\}-\ln \left\{\left(1-p_{1}\right) / p_{1}\right\}} .
$$

The average minimum approach will be considered first.

Assume that the roots from $\mathrm{L}_{a_{1}}$ to $\mathrm{L}_{\mathrm{a}_{2}}$ are of equal interest. Therefore, let $\phi(\cdot)$ be the Uniform $\left[a_{1}, a_{2}\right]$ density function. Using (13), (37), and (44), assuming that $M(x)$ is the two parameter logit model, the average minimum solution is the 
pair $\left(p_{1}, p_{2}\right)$ that minimizes

$$
\int_{a_{1}}^{a_{2}}\left[\frac{r^{\prime 2}}{p_{1} \cdot\left(1-p_{1}\right)}+\frac{\left(1-r^{\prime}\right)^{2}}{p_{2} \cdot\left(1-p_{2}\right)}\right] \partial p^{*}
$$

For a range of interest on $p^{*}$ of $[.95, .99]$ (that is $\left.\left[a_{1}, a_{2}\right]=[.95, .99]\right)$, the expression (45) was calculated for a grid of $\left(p_{1}, p_{2}\right)$ values $\left(p_{1}=.025\right.$ to .925 by $.025, p_{2}=$ $\mathrm{p}_{1}+.05$ to .975 by .025). The pair that produced the smallest value of $(45)$ was $\left(p_{1}, p_{2}\right)=(.15, .85)$. This results is somewhat surprising. Since the range of interest is in the upper tail, the minimum average $p_{1}$ and $p_{2}$ may be expected to be shifted toward the upper tail. Intuitively, using $\left(p_{1}, p_{2}\right)=(.15, .95)$ is a more appropriate choice than $\left(p_{1}, p_{2}\right)=(.05, .85)$.

To understand why $(.15, .85)$ is the average minimum $\left(p_{1}, p_{2}\right)$, recall that by $(44), \hat{L}_{p^{*}}$ is a linear function of $\hat{L}_{p_{1}}$ and $\hat{L}_{p_{2}}\left(r^{\prime} \hat{L}_{p_{1}}+\left(1-r^{\prime}\right) \hat{L}_{p_{2}}\right)$. Also, the asymptotic variance of $\hat{L}_{p}$ decreases as $p$ approaches .5 . When $\left(p_{1}, p_{2}\right)=$ $(.05, .85)$ is used to estimate $I_{p^{*}} \in\left(L_{.95}, L_{.99}\right)$, the value of $r^{\prime}$ from (44) satisfies $\left(1-r^{\prime}\right)>r^{\prime}$. Thus, more weight is placed on $\hat{L}_{.85^{\prime}}$, which has a smaller variance than $\hat{L}_{.05}$. When $\left(p_{1}, p_{2}\right)=(.15, .95)$, more weight is placed on $\hat{L}_{.95}$ ' which has a larger asymptotic variance than $\hat{L}_{.15}$ (and $\hat{L}_{.85}$ ). Asymptotically, therefore, using $\left(p_{1}, p_{2}\right)=(.05, .85)$ is superior to using $\left(p_{1}, p_{2}\right)=(.15, .95)$. It is important to note that pairs $\left(p_{1}, p_{2}\right)$, such as $(.2, .8)$ and $(.15, .95)$, produced only slightly larger values for (45) than the 
average minimum solution of $(.05, .85)$.

The minimax solution in this general case is the pair $\left(\mathrm{p}_{1}, \mathrm{p}_{2}\right)$ that minimizes the maximum $\sigma_{\mathrm{n}}^{* 2}\left(\mathrm{p}^{*}, \mathrm{p}_{1}, \mathrm{p}_{2}\right)$ for $\mathrm{p}^{*} \in$ $\left[a_{1}, a_{2}\right]$. That is, the pair $\left(p_{1}, p_{2}\right)$ that minimizes

$$
\mathrm{p}^{*} \in\left[\mathrm{a}_{1}, \mathrm{a}_{2}\right] \quad\left[\frac{\mathrm{r}^{\prime 2}}{\mathrm{p}_{1} \cdot\left(1-\mathrm{p}_{1}\right)}+\frac{\left(1-\mathrm{r}^{\prime}\right)^{2}}{\mathrm{p}_{2} \cdot\left(1-\mathrm{p}_{2}\right)}\right]
$$

When $\left[a_{1}, a_{2}\right]=[.95, .99]$, the minimax pair, using the program described above, was found to be $\left(p_{1}, p_{2}\right)=$ $(.075, .875)$. This is similar to the average minimum pair, $\left(\mathrm{p}_{1}, \mathrm{p}_{2}\right)=(.05, .85)$.

Estimating roots in the tails of a binary distribution with a small number of samples is a difficult task. As shown by Silvapulle (1981) and discussed in the first section of Chapter IV, MLEs do not exist when the responses are all 0's or all 1's, or when there is no overlapping in the responses. No overlapping in the responses occurs when the smallest design level with a response of $1(0)$ is greater than the largest design level with a response of 0 (1). If all of the design levels fall in the upper tail of the distribution, then it is fairly likely that all of the responses will be 1's. Even if both 1's and 0's are observed, it is very possible that no overlap in the responses has occurred. If the design levels are in both tails, but not spread throughout the distribution, then it is again likely that no overlapping of the responses has occurred. In both of these situations, MLEs do not exist. 
The average minimum pair $\left(p_{1}, p_{2}\right)$ for estimating $L_{p^{*}}, p^{*}$ $\in[.95, .99]$ was found to be $(.05, .85)$. Based on the discussion of the previous paragraph, $(.05, .85)$ may not be a good choice of $\left(p_{1}, p_{2}\right)$ for small or medium sample sizes. The simulation study below was designed to determine which pairs, $\left(\mathrm{p}_{1}, \mathrm{p}_{2}\right)$, perform well in estimating $\mathrm{L}_{\mathrm{p}^{*}}, \mathrm{p}^{*} \epsilon$ $[.95, .99]$ for small and medium sized samples.

The performance of SAM was studied using the following four pairs of $\left(\mathrm{p}_{1}, \mathrm{p}_{2}\right):(.2, .8),(.05, .85),(.15, .95)$, and $(.4, .9)$. Each SAM procedure was given the same initial set of ten observations (as in Initial Procedure 1 of Chapter IV). A two parameter logit model $\left(\theta_{1}=0, \theta_{2}=1\right)$ was used to generate the binary responses. The $\sqrt{\text { MSEs }}$ of $\hat{\mathrm{L}}_{.5}^{(n)}, \hat{\mathrm{L}}_{.9}^{(n)}$, $\hat{\mathrm{L}}_{.95}^{(\mathrm{n})}$, and $\hat{\mathrm{L}}_{.99}^{(\mathrm{n})}$ are reported in Table 4 on the following page.

The average minimum solution for a range of interest on $p^{*}$ of $[.95, .99]$ was found to be $\left(p_{1}, p_{2}\right)=(.05, .85)$. In this simulation study, $\left(\mathrm{p}_{1}, \mathrm{p}_{2}\right)=(.05, .85)$ generated the smallest MSEs for estimating $\mathrm{L}_{.99^{\circ}}$. For estimating $\mathrm{L}_{.95^{\prime}}$ the pairs $(.05, .85)$ and $(.2, .8)$ produced the lowest MSEs. However, for estimating $\mathrm{L}_{.5}$ and $\mathrm{L}_{.9^{\prime}}(.05, .85) \mathrm{did}$ not perform as well as using $\left(p_{1}, p_{2}\right)=(.2, .8)$. Using $(.2, .8)$ compared reasonably well to the other choices in every situation. 
MONTE CARLO VMSE FOR ESTIMATING $\mathrm{L}_{\mathrm{p}^{*}}$ USING SAM

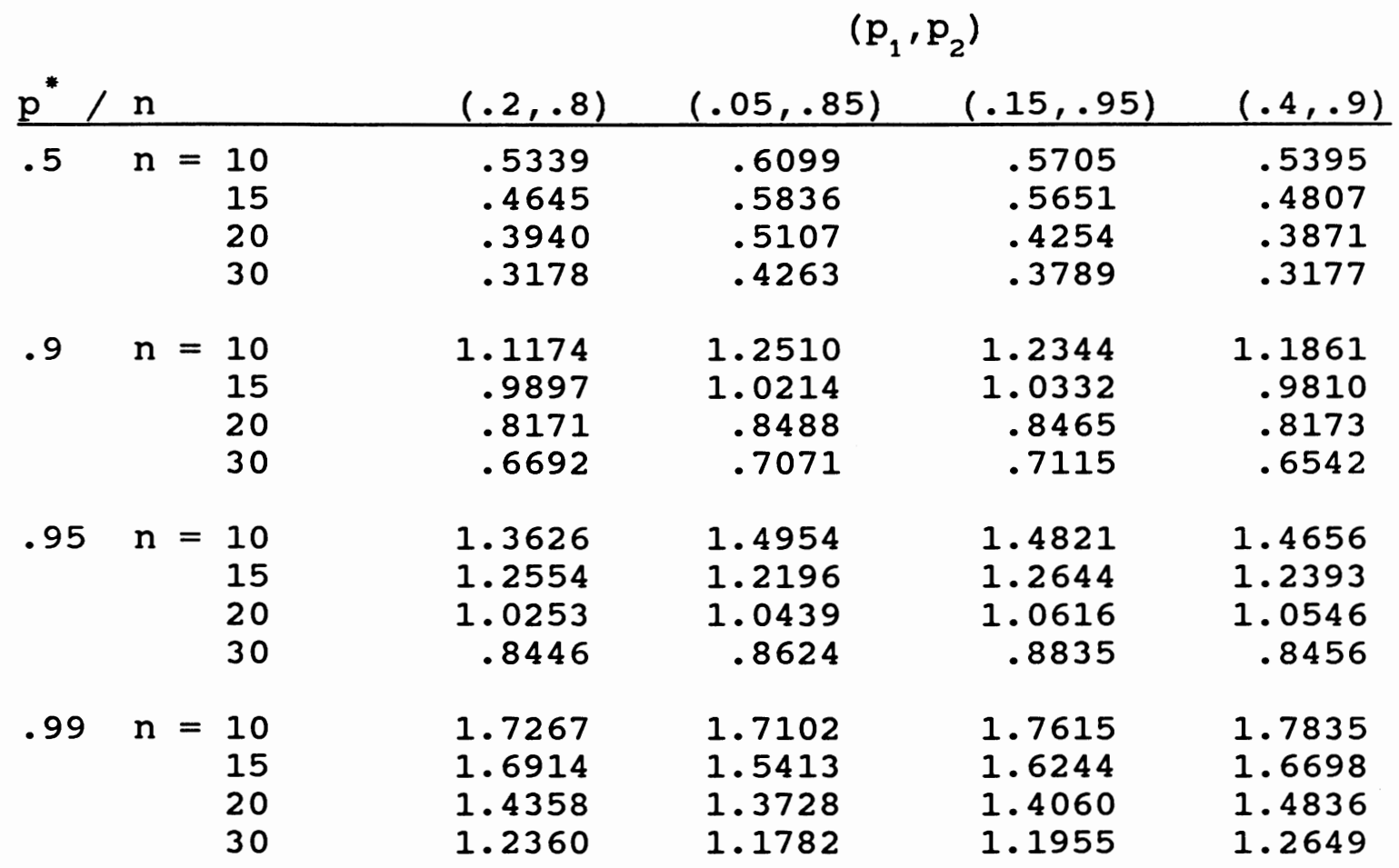

Asymptotic Variance and Bias

In this section, the asymptotic variances of estimators from the logit version of SAM are presented. To study the robustness of SAM, the asymptotic variances and biases are also derived when the true expectation of $\mathrm{Y}, \mathrm{M}(\mathrm{x})$, is not the two parameter logit model. The derivation depends upon the first order equivalence of the logit version of SAM and a two dimensional RM procedure. Thus, the discussion begins by introducing the two dimensional RM process. Consider estimating $\mathrm{I}_{\mathrm{p}^{*}}$ using two independent $\mathrm{RM}$ procedures (with $\mathrm{n}$ 
observations each), one to estimate $L_{p}$ and the other to estimate $L_{1-p^{\prime}}$ both using the optimal $n \cdot A_{n}=M^{\prime}\left(L_{p}\right)^{-1}=$ $M^{\prime}\left(L_{1-p}\right)^{-1}$. Using the two parameter logit model, an estimate of any root $L_{p^{*}}$ can be constructed as in (38). First, consider the case where the expectation of $Y$, $M(x)$, is the two parameter logit model. By (5) and (38), the asymptotic variance of $\hat{\mathrm{L}}_{\mathrm{p}^{*}}$ obtained from the two independent RM procedures is

$$
\left\{2 n \theta_{2}^{2} p(1-p)\right\}^{-1}\left[1+\frac{\ln \left\{p^{*} /\left(1-p^{*}\right)\right\}^{2}}{\ln \{p /(1-p)\}^{2}}\right] \text {. }
$$

Earlier in this chapter, a first order approximation to SAM was shown to be asymptotically equivalent to two independent RM procedures. Therefore, the expression in (47) is also the asymptotic variance of $\hat{L}_{p^{*}}$ from the logit version of SAM. For the sample sizes and values of $\mathrm{p}^{*}$ used in the simulation study of chapter IV, (47) is evaluated and presented in the last row of Tables 8 and 9 .

When the true expectation of $Y, M(x)$, is not the two parameter logit model, then estimators from either procedure may be biased. Recall that the consistency of $x_{n}$ from the RM procedure (4) is not dependent upon the true expectation of $Y$. Thus, the consistency of $\hat{L}_{p}$ and $\hat{L}_{1-p}$ from both the two independent RM procedures and SAM (by the first order asymptotic equivalence) holds regardless of $M(x)$. However, the estimate of any root $L_{p^{*}}$ for $p^{*} \neq p, 1-p$, using (38), is based on the two parameter logit model. If $M(x)$ is not the two parameter logit model, then the constant, $r^{\prime}$, used in 
(38) will be incorrect, and a biased estimate will be produced. Thus, even though $\hat{I}_{p}$ and $\hat{I}_{1-p}$ are consistent estimators of $L_{p}$ and $L_{1-p}$, the estimator of any other $L_{p^{*}}$ may not be consistent.

To generalize the above discussion, consider running two independent $\mathrm{RM}$ procedures to estimate $\mathrm{L}_{\mathrm{p} *}$, as before. However, use $p=p_{1}$ for one procedure and $p=p_{2}$ ' $\mathrm{p}_{2}>\mathrm{p}_{1}$ for the other, with $\mathrm{p}_{2}$ not necessarily $1-\mathrm{p}_{1}$. Estimate $\mathrm{L}_{\mathrm{p} *}$ with

$$
\hat{L}_{p^{*}}=k_{a} \cdot \hat{L}_{p_{1}}+\left(1-k_{a}\right) \cdot \hat{L}_{p_{2}}
$$

where $\mathrm{k}_{\mathrm{a}}$ is a constant determined by a selected model, $\mathrm{G}^{*}(\mathrm{x} \mid \theta)$. For instance, if $\mathrm{G}^{*}(\mathrm{x} \mid \theta)$ is the two parameter logit model, then from (44)

$$
\mathrm{k}_{\mathrm{a}}=\frac{\ln \left\{\left(1-\mathrm{p}_{2}\right) / \mathrm{p}_{2}\right\}-\ln \left\{\left(1-\mathrm{p}^{*}\right) / \mathrm{p}^{*}\right)}{\ln \left\{\left(1-\mathrm{p}_{2}\right) / \mathrm{p}_{2}\right\}-\ln \left\{\left(1-\mathrm{p}_{1}\right) / \mathrm{p}_{1}\right\}}
$$

Let $k_{t}$ be the corresponding constant for the true expectation of $Y$. Since $\hat{L}_{p_{1}}-\cdots->L_{p_{1}}$ and $\hat{L}_{p_{2}}$ $\hat{\mathrm{L}}_{\mathrm{p}^{*}}$ converges to $\mathrm{k}_{\mathrm{a}} \cdot \mathrm{L}_{\mathrm{p}_{1}}+\left(1-\mathrm{k}_{\mathrm{a}}\right) \cdot \mathrm{L}_{\mathrm{p}_{2}}$. The bias of $\mathrm{L}_{\mathrm{p}^{*}}$ is then $\left(k_{t}-k_{a}\right)\left(L_{p_{2}}-L_{p_{1}}\right)$. Consider using the two independent $\mathrm{RM}$ procedures with $\mathrm{p}_{1}=.2, \mathrm{p}_{2}=.8$ and the two parameter logit model for $G^{*}(x \mid \theta)$. Table 5 presents the biases of $\hat{\mathrm{L}}_{\mathrm{p}^{*}}, \mathrm{p}^{*}=.25, .5, .75$, when $\mathrm{M}(\mathrm{x})$, the true expectation of $Y$, follows one of three different models. The probit, skewed logit and loglog models used in Table 5 are described in equation (57) of Chapter IV. 
TABLE 5

BIAS OF $\hat{\mathrm{L}}_{\mathrm{P}^{*}}$

\begin{tabular}{lccc} 
Model & .25 & .5 & .75 \\
\hline Probit $\left(\theta_{1}=-.25, \theta_{2}=2\right)$ & .0202 & 0 & -.0202 \\
Skewed Logit $\left(\theta_{1}=-1, \theta_{2}=.7\right)$ & .0289 & .1158 & .0376 \\
Loglog $\left(\theta_{1}=0, \theta_{2}=.5\right)$ & -.0976 & -.2912 & -.1118
\end{tabular}

By (36), these biases are also appropriate for $\hat{\mathrm{L}}_{\mathrm{p}^{*}}$ from the logit version of SAM.

Fei (1989) and Moser and Fei (1989b) both present detailed discussions of the asymptotic variance and biases of $\mathrm{L}_{\mathrm{p}^{*}}$ from using two independent $\mathrm{RM}$ procedures. Formulas and calculations are presented for the logit, probit, skewed logit and loglog models. The following development of the mean square error (MSE) of $\hat{\mathrm{L}}_{\mathrm{p}^{*}}$ follows their approach.

The optimal values for $n \cdot A_{n}$ for the two independent $R M$ procedures are $M^{\prime}\left(L_{p_{1}}\right)^{-1}$ and $M^{\prime}\left(L_{p_{2}}\right)^{-1}$. Let $A_{1}^{(a)}$ and $A_{2}^{(a)}$ be the corresponding values using $G^{*}(x \mid \theta)$. If $A_{1}^{(a)} \neq$ $M^{\prime}\left(L_{p_{1}}\right)^{-1}$ or $A_{2}^{(a)} \neq M^{\prime}\left(L_{p_{2}}\right)^{-1}$, then the $R M$ procedures will not be optimal. Using (5) and (48), the asymptotic variance of $\hat{\mathrm{L}}_{\mathrm{p}^{*}}$ using the two independent $\mathrm{RM}$ procedures is

$$
\begin{aligned}
(1 / n) \cdot\left(k_{a}^{2} p_{1}\left(1-p_{1}\right) A_{1}^{(a)^{2}}\left(2 A_{1}^{(a)} \cdot M^{\prime}\left(L_{p_{1}}\right)-1\right)^{-1}+\right. \\
\left.\left(1-k_{a}\right)^{2} p_{2}\left(1-p_{2}\right) A_{2}^{(a)^{2}}\left(2 A_{2}^{(a)} \cdot M^{\prime}\left(L_{p}\right)-1\right)^{-1}\right)
\end{aligned}
$$


If $A_{1}^{(a)}=M^{\prime}\left(L_{p_{1}}\right)^{-1}, A_{2}^{(a)}=M^{\prime}\left(L_{p_{2}}\right)^{-1}, p_{1}=p, p_{2}=1-p$, and $M(x)$ is the two parameter logit model, then equation (50) simplifies to the expression presented in (47).

Let $L_{p}^{(a)}$ be the $p^{\text {th }}$ percentile of the selected model, $G^{*}(x \mid \theta)$. Recall that $\hat{L}_{p_{1}}, \hat{L}_{p_{2}}$ from the two RM procedures converge to $\mathrm{L}_{\mathrm{p}_{1}}, \mathrm{~L}_{\mathrm{p}_{2}}$ respectively, regardless of the selected model $G^{*}(x \mid \theta)$. Since the convergence of $\hat{L}_{p_{1}}, \hat{L}_{p_{2}}$ is independent of the true expectation of $Y, \hat{L}_{p_{1}}, \hat{L}_{p_{2}}$ also converge to $L_{p_{1}}^{(a)}, L_{p_{2}}^{(a)}$. Thus, in this notation, $\left(L_{p_{1}}^{(a)}\right.$, $\left.L_{p_{2}}^{(a)}\right)=\left(L_{p_{1}}, L_{p_{2}}\right)$. Consider the MSE of $\hat{L}_{p^{*}}$

$$
\begin{aligned}
& \operatorname{MSE}\left(\hat{L}_{p^{*}}\right)=E\left\{\hat{L}_{p^{*}}-L_{p^{*}}\right\}^{2}=E\left\{\hat{L}_{p^{*}}-L_{p^{*}}^{(a)}\right\}^{2} \\
&+\left(L_{p^{*}}^{(a)}-L_{p^{*}}\right)^{2}+2 \cdot\left\{L_{p^{*}}^{(a)}-L_{p^{*}}\right\} \cdot E\left\{\hat{L}_{p^{*}}-L_{p^{*}}^{(a)}\right\} .
\end{aligned}
$$

Now, $\hat{\mathrm{L}}_{\mathrm{p}^{*}}$ converges to $\mathrm{k}_{\mathrm{a}} \cdot \mathrm{L}_{\mathrm{p}_{1}}+\left(1-\mathrm{k}_{\mathrm{a}}\right) \cdot \mathrm{L}_{\mathrm{p}_{2}}=\mathrm{L}_{\mathrm{p}^{*}}^{(\mathrm{a})}$. Therefore, the MSE of $\hat{\mathrm{L}}_{\mathrm{p}^{*}}$ converges to

$$
\begin{aligned}
& \operatorname{MSE}\left(\hat{\mathrm{L}}_{p^{*}}\right)=\operatorname{Var}\left(\hat{\mathrm{L}}_{\mathrm{p}^{*}}\right)+\left(\mathrm{L}_{\mathrm{p}^{*}}^{(a)}-\mathrm{L}_{\mathrm{p}^{*}}\right)^{2} \\
& \quad=\operatorname{Var}\left(\mathrm{k}_{\mathrm{a}} \hat{\mathrm{L}}_{\mathrm{p}_{1}}+\left(1-\mathrm{k}_{\mathrm{a}}\right) \hat{\mathrm{L}}_{\mathrm{p}_{2}}\right)+\left(\mathrm{k}_{\mathrm{a}}-\mathrm{k}_{t}\right)^{2}\left(\mathrm{~L}_{\mathrm{p}_{1}}-\mathrm{L}_{p_{2}}\right)^{2} .
\end{aligned}
$$

Note that the MSE of $\hat{\mathrm{L}}_{\mathrm{p}^{*}}$ includes both a variance term and a bias term. Note that the bias term of (52) is the square of the biases listed in Table 5. Using $\mathrm{p}_{1}=.2$ and $\mathrm{p}_{2}=.8$, Table 6 presents the MSEs of $\hat{\mathrm{L}}_{p^{*}}$ under the four models used for $M(x)$ in the simulation study of chapter IV. In each case, the two parameter logit model was used to construct 
the estimators.

TABLE 6

ROBBINS-MONRO, SAM ASYMPTOTIC MSES

True Model:

Logit Loglog Skewed Logit Probit

MSE :

$\hat{\mathrm{L}}_{.25} \frac{5.085}{\mathrm{n}} \frac{17.222}{\mathrm{n}}+.0095 \frac{5.609}{\mathrm{n}}+.0007 \frac{6.664}{\mathrm{n}}+.0004$

$\hat{\mathrm{L}}_{.5} \frac{3.125}{\mathrm{n}} \quad \frac{7.039}{\mathrm{n}}+.0851 \quad \frac{4.606}{\mathrm{n}}+.0134 \quad \frac{4.095}{\mathrm{n}}$

$\hat{\mathrm{L}}_{.75} \frac{5.088}{\mathrm{n}} \frac{5.686}{\mathrm{n}}+.0133 \frac{9.381}{\mathrm{n}}+.0014 \frac{6.664}{\mathrm{n}}+.0004$

These values are calculated and presented in the last row of the appropriate simulation tables of Chapter IV (Tables 8 - 15). Consult Moser and Fei (1989b) for a more detailed discussion of the MSE values. 


\section{CHAPTER IV}

\section{SIMULATION STUDY}

\section{The Setup}

In the first three chapters, asymptotic properties of the various procedures have been presented. Under certain conditions, Robbins-Monro, Anbar, SAM, and Wu's procedures are asymptotically equivalent. In this chapter, a simulation study is performed to compare the procedures for small and medium binary data samples. The procedures will be evaluated on their ability to estimate a single root, $L_{p}$ ' and multiple roots.

Recall that Robbins-Monro's (4), Anbar's (7), and Wu's (8) procedures were designed to estimate a single root, $\mathrm{L}_{\mathrm{p}}$ ' of $M(x)=p$. Two methods of extending these procedures to estimate any number of roots are considered. First, two independent versions of the same procedure (either two independent Robbins-Monro, two independent Anbar, or two independent Wu procedures) can be run to obtain estimates of $\mathrm{L}_{\mathrm{p}_{1}}$ and $\mathrm{L}_{\mathrm{p}_{2}}$. Then, using the two parameter logit model, an estimate of any $L_{p^{*}}$ can be obtained from (44). Based on the results in chapter III, $\mathrm{p}_{1}=.2$ and $\mathrm{p}_{2}=.8$ are used in this 
simulation study.

As a second extension, Anbar's and Wu's procedures can be run as designed (estimating $\mathrm{L}_{.5}$ ) and the slope estimator in combination with $\hat{\mathrm{L}}_{.5}$ can be used to estimate any $\mathrm{L}_{\mathrm{p}}$ ** For Anbar's procedure, again using the two parameter logit model,

$$
\hat{\mathrm{L}}_{\mathrm{p}^{*}}^{(\mathrm{n})}=\hat{\mathrm{L}}_{\cdot 5}^{(\mathrm{n})}+\left(1 / 4 \cdot \mathrm{b}_{\mathrm{n}}\right) \cdot \ln \left\{\mathrm{p}^{*} /\left(1-\mathrm{p}^{*}\right)\right\}
$$

where $b_{n}$ is given in (6) with $m(n)=1$. For Wu's procedure,

$$
\hat{L}_{p}^{(n)}=\hat{L}_{.5}^{(n)}+\left(\hat{\theta}_{2}^{(n)}\right)^{-1} \cdot \ln \left\{p^{*} /\left(1-p^{*}\right)\right\}
$$

The RM procedure is not extended by the second method since a slope estimator is never calculated from the data during the process.

As mentioned in Chapter II, bounded versions of sequential approximation procedures have been found to improve their performance for small to medium sample sizes. The following truncated versions of the procedures, in which the step size from $x_{n}$ to $x_{n+1}$ is bounded, are used in this study. For Anbar's procedure the updating rule is

$$
X_{n+1}=X_{n}-\left(h_{n} / n\right)\left(Y_{n}-p\right)
$$

where $\mathrm{h}_{\mathrm{n}}=\max \left\{\delta_{1}, \min \left(\delta_{2}, \mathrm{~b}_{\mathrm{n}}^{-1}\right)\right\}, 0 \leq \delta_{1}<\delta_{2}$. Wu defined the following truncated version of (8). Let $d_{n}$ be the solution of $X_{n+1}=X_{n}-\left(d_{n} / n\right) \cdot\left(Y_{n}-p\right)$, where $X_{n+1}=\hat{\theta}_{1}^{(n)}-(1 /$ $\left.\hat{\theta}_{2}^{(n)}\right) \cdot \ln \{(1-p) / p\}$. The $(n+1)^{\text {st }}$ design point is chosen by the rule 


$$
x_{n+1}=x_{n}-\left(d_{n}^{*} / n\right) \cdot\left(Y_{n}-p\right)
$$

where $d_{n}^{*}=\max \left[\delta_{1}, \min \left(d_{n}, \delta_{2}\right)\right]$, for $0 \leq \delta_{1}<\delta_{2}$. The truncated version of SAM is given in chapter II by (15).

The following six basic procedures, all with a total of $2 \cdot \mathrm{n}$ design points, are considered:

1) $\mathrm{SAM}-\delta_{2}$-- procedure (15) with upper bound $\delta_{2}$, where $\mathrm{L}_{\mathrm{p}^{*}}$ is estimated by (38);

2) RM-W -- two independent versions of procedure (4), with $\mathrm{n}$ updates each, one with $\mathrm{p}=.2$ and the other with $p=.8$, both with $A_{n}=w / n$, where $\mathrm{L}_{\mathrm{p}^{*}}$ is estimated by (38):

3) AN1- $\delta_{2}$-- procedure (55) with $p=.5$, where $L_{p^{*}}$ is estimated by (53);

4) AN2- $\delta_{2}$-- two independent versions of procedure (55) using $\mathrm{p}=.2$ and $\mathrm{p}=.8$, with $\mathrm{n}$ updates each, where $L_{p^{*}}$ is estimated by (38);

5) $\mathrm{WU1}-\delta_{2}--$ procedure (56) with $\mathrm{p}=.5$, where $\mathrm{L}_{\mathrm{p}^{*}}$ is estimated by (54);

6) WU2 $\left(\delta_{2}\right)$-- two independent versions of procedure (56) using $\mathrm{p}=.2$ and $\mathrm{p}=.8$, with $\mathrm{n}$ updates each, where $I_{p^{*}}$ is estimated by (38). Since SAM, WU1, and WU2 require the existence of MLEs at each update, a starting procedure is needed to generate the design levels until MLEs exist. Two different initial 
procedures are considered. The first has five fixed initial design levels (a total of 10 intitial observations), and samples for which MLEs do not exist are discarded. The second uses a Robbins-Monro procedure to generate initial design levels until MLEs exist.

Silvapulle (1981) provided existence conditions for MLEs from binary distributions. Let $\mathrm{x}_{\max (\min )}^{+}=$ $\max (\min )\left\{x_{1 j}: y_{1 j}=1\right\}$ and $x_{\max (\min )}^{-}=\max (\min )\left\{x_{1 j}: y_{1 j}=0\right\}$. For the two parameter logit model, if
1) $\left(x_{\min }^{+}, x_{\max }^{+}\right) \cap\left(x_{\min }^{-}, x_{\max }^{-}\right) \neq \varnothing$,
2) $x_{\min }^{+}<x_{\min }^{-}=x_{\max }^{-}<x_{\max }^{+}$, or
3) $x_{\min }^{-}<x_{\min }^{+}=x_{\max }^{+}<x_{\max }^{-}$,

then the MLEs of $\theta_{1}$ and $\theta_{2}$ exist and are unique. Thus, for existence and uniqueness of MLEs, there must be some overlapping of the responses. If MLEs exist at the $n^{\text {th }}$ update, then they exist at each subsequent update. Therefore, once the existence conditions have been satisfied, design levels can be calculated by SAM's and Wu's updating rules for every future update.

In order to evaluate the robustness of the procedures, four different parametric models for the expectation $M(x)$ are used to generate the binary responses.

$$
\begin{array}{ll}
\text { logit: } & 1 /\left(1+\exp \left(-\theta_{2}\left(x-\theta_{1}\right)\right)\right. \\
& \text { with } \theta_{1}=0, \theta_{2}=1 \\
\text { probit: } \quad & \Phi\left(\left(x-\theta_{1}\right) / \theta_{2}\right\} \\
& \text { with } \theta_{1}=-.25, \theta_{2}=2
\end{array}
$$




$$
\begin{array}{ll}
\text { log-log: } & 1-\exp \left[-\exp \left\{\theta_{2}\left(x-\theta_{1}\right)\right\}\right] \\
& \text { with } \theta_{1}=0, \theta_{2}=.5 \\
\text { skewed logit: } & {\left[1+\exp \left\{-\theta_{2}\left(x-\theta_{1}\right)\right\}\right]^{-2}} \\
& \text { with } \theta_{1}=-1, \theta_{2}=.7
\end{array}
$$

Regardless of the true model, the MLEs in SAM, WU1, and WU2 were calculated using the two parameter logit model. In the simulation program, all procedures use the same set of random numbers for each set of trials.

Recall that the optimal $A_{n}$ for the RM procedure (4) is $A_{n}=\left(n \cdot M^{\prime}\left(L_{p}\right)\right)^{-1}$. For the models in this simulation study (57), Table 7 presents the optimal values of $n \cdot A_{n}$ when $p=$ $.2, .5$, and .8 .

\begin{tabular}{|c|c|c|c|c|}
\hline $\mathrm{p}$ & Logit & Probit & Loglog & Skewed Logit \\
\hline .2 & 6.25 & 7.14 & 11.24 & 6.45 \\
\hline .5 & 4.00 & 5.03 & 5.78 & 4.88 \\
\hline .8 & 6.25 & 7.14 & 6.25 & 8.46 \\
\hline
\end{tabular}

TABLE 7

$$
\text { OPTIMAL } n \cdot A_{n}
$$

Model

Initial procedure 1

In the first initial design, ten binary observations are generated at five fixed design levels. If the MLEs 
exist, the starting values for each procedure are calculated using $\hat{\theta}_{1}^{(10)}, \hat{\theta}_{2}^{(10)}$. For example, the design levels at the $11^{\text {th }}$ update for SAM, RM, AN2, and WU2 are $x_{11,1}=\hat{\theta}_{1}^{(10)}-$ $\left(\hat{\theta}_{2}^{(10)}\right)^{-1} \cdot \ln \{(1-.2) / .2\}$ and $x_{11,2}=\hat{\theta}_{1}^{(10)}+$ $\left(\theta_{2}(10)\right)^{-1} \cdot \ln \{(1-.2) / .2\}$. For ANI and WU1, the $11^{\text {th }}$ design level is $x_{11}=\hat{\theta}_{1}^{(10)}$. once the starting levels have been obtained, the individual procedures are used to calculate design levels for the remaining updates. If the MLEs do not exist for the initial sample of ten observations, or if $\hat{\theta}_{2}^{(10)} \leq 0$, then the sample is discarded. Two sets of ten initial design levels are used:

Set 1: Levels $\mathrm{L}_{.1}, \mathrm{~L}_{.3}, \mathrm{~L}_{.5}, \mathrm{~L}_{.7}, \mathrm{~L}_{.9}$ with $1,2,4,2$, and 1 observations, respectively ;

Set 2: Levels $\mathrm{L}_{.3^{\prime}} \mathrm{L}_{.46^{\prime}} \mathrm{L}_{.56}, \mathrm{~L}_{.66^{\prime}} \mathrm{L}_{.8}$ with $1,2,4,2$, and 1 observations, respectively.

Upper bounds of $\delta_{2}=10,50$, and 100, and a lower bound of $\delta_{1}=0$ were selected. The larger values of $\delta_{2}$ allow larger steps from $x_{n}$ to $x_{n+1}$ at each update. A total of 500 samples are generated, including the discarded samples. The MSE is calculated by $\left(\sum\left(\hat{L}_{p^{*}}-L_{p^{*}}\right)^{2} / n^{\prime}\right)^{1 / 2}$, where $\hat{L}_{p^{*}}$ is the estimate from the given procedure, $L_{p^{*}}$ is the true $\left(p^{*}\right)^{\text {th }}$ percentile from the appropriate model (57), and the summation is over the $n^{\prime}$ nondiscarded samples. 
Results of Initial Procedure 1

Tables 8 - 15 present the MSEs for the four different models using each set of design levels. Each table provides the MSEs of $\hat{\mathrm{L}}_{.5}$ and $\hat{\mathrm{L}}_{.75}$.

The MSEs from SAM for estimating $L_{.75}$ are less than those from any other procedure in almost every situation. In a few situations, WU1 or WU2 produced MSEs of similar size as SAM. For estimating $\mathrm{L}_{.5}$, SAM's only competition comes from WU1. In general, wUl has smaller MSEs when $\mathrm{n}=$ 15 and $\mathrm{n}=20$. This advantage does not hold, for larger ( $\mathrm{n}$ = 30) sample sizes, where the MSEs for WU1 and SAM are similar in size. These patterns hold for all four of the models used to generate the binary responses. SAM, WU1, and WU2 use a logit model to calculate the new design levels at each update. However, they generally continued to outperform AN1, AN2, and RM, even when a skewed model (such as the loglog or skewed logit) generated the binary responses. One exception to this rule occured for the loglog model with initial set 2 . For $n=10$ and $n=15$, AN2 $\left(\delta_{2}=10\right)$ and RM-6 produced MSEs of similar size as WU1 and SAM for estimating $\mathrm{L}_{.5}$.

For estimating $\mathrm{L}_{.5}$ with the $\mathrm{RM}$ procedures, $\mathrm{RM}-6$ is superior to $\mathrm{RM}-1$ and $\mathrm{RM}-36$. For estimating $\mathrm{L}_{.75}$, both $\mathrm{RM}-6$ and RM-36 produce lower MSEs than RM-1. Several times, the MSEs from the RM-1 procedure increased when more observations were taken. From Table 7, RM-6 is closer to 
the optimal RM procedure than RM-1 or RM-36 in each situation.

Note that SAM's performance is not affected greatly by the choice of bounds. WU1 and WU2 also remain fairly stable over the various bounds. On occasion, WU1 and WU2 performed poorer when the bounds were too restrictive $\left(\delta_{2}=10\right)$. For AN1 and AN2, the the tighter bounds were often superior.

Recall that $\mathrm{AN} 1$ and WU1 are designed to estimate a single root ( $L_{.5}$ in this study). By choosing the design levels around $\mathrm{L}_{.2}$ and $\mathrm{L}_{.8}$ instead of a single value, AN2 and WU2 were constructed to provide better estimates of the roots throughout the entire curve, $M(x)$. As expected, WU1 outperformed its counterpart (WU2) in estimating $\mathrm{L}_{.5}$. However, WU2 did not always prove to be better in estimating $L_{.75^{\circ}}$ For small sample sizes, WU1 even produced better $L_{.75}$ estimates than wU2. AN2 proved to be superior to AN1 for estimating both $\mathrm{L}_{.5}$ and $\mathrm{L}_{.75^{\circ}}$

In order to compare the simulation and asymptotic results, the asymptotic variance of $\hat{\mathrm{L}}_{\mathrm{p}^{*}}^{(n)}$ from the $\mathrm{RM}$ procedure is presented in the last row of each table. The asymptotic values were derived in the last section of Chapter III. Due to the first order asymptotic equivalence of SAM and the RM process, these values will also be the asymptotic variances of $\hat{\mathrm{L}}_{\mathrm{p}^{*}}^{(\mathrm{n})}$ from SAM.

For the logit model, the MSEs from SAM's $\mathrm{L}_{.5}$ estimator were very similar to their asymptotic value for all sample sizes. For $\mathrm{L}_{.75}$, the MSEs were similar for $\mathrm{n}=20$ and $\mathrm{n}=$ 
30. Note that the MSEs from SAM proved to be fairly similar to the asymptotic value for the other three models as well. The asymptotic variances of $\hat{\mathrm{L}}_{.5}$ from wU1 and $\mathrm{AN} 1$ are less than for SAM and RM. However, the simulation results show that they approach their asymptotic values much more slowly than SAM.

The number of discarded samples was not small. It ranged from 136 to 157 of the 500 samples. By selecting the initial design levels in a different manner, the proportion of discarded samples could be reduced. The results of this section are based on those samples for which MLEs existed after ten initial observations.

\section{Initial Procedure 2}

In the second initial procedure, a RM procedure is used to generate the initial design levels. Three values of $n \cdot A_{n}$ $(1,6$, and 36) and three starting design levels (design levels for the first update) are used. From Table 7, the $n \cdot A_{n}$ values of 1 and 36 represent over and underestimates of the asymptotically optimal values, respectively. The initial step sizes using $n \cdot A_{n}=36$ will be much larger than using $n \cdot A_{n}=1$.

For SAM, AN2, and WU2, two independent RM procedures, one with $\mathrm{p}=.2$ and the other with $\mathrm{p}=.8$, are used to calculate the initial design levels. Thus, two starting 
TABLE 8

MONTE CARLO $\sqrt{ }$ MSES FOR ESTIMATING $L_{p^{*}}$

MODEL: LOGIT $\theta_{1}=0, \theta_{2}=1$

INITIAL SET 1

(143 discarded samples)

\begin{tabular}{|c|c|c|c|c|c|c|c|c|}
\hline $\mathrm{p}^{\bullet}$ & & & & & & & 75 & \\
\hline N & 10 & 15 & 20 & 30 & 10 & 15 & 20 & 30 \\
\hline $\begin{array}{l}R M-1 \\
R M-6 \\
R M-36\end{array}$ & $\begin{array}{l}.7208 \\
.6168 \\
.9419\end{array}$ & $\begin{array}{l}.7819 \\
.5996 \\
.8078\end{array}$ & $\begin{array}{l}.7318 \\
.5098 \\
.6935\end{array}$ & $\begin{array}{l}.7221 \\
.4560 \\
.6245\end{array}$ & $\begin{array}{l}1.1939 \\
1.0393 \\
1.2308\end{array}$ & $\begin{array}{r}1.2400 \\
.9813 \\
1.0378\end{array}$ & $\begin{array}{r}1.2819 \\
.9629 \\
.9297\end{array}$ & $\begin{array}{r}1.2135 \\
.7847 \\
.7787\end{array}$ \\
\hline $\begin{array}{l}\text { AN1-10 } \\
\text { AN1-50 } \\
\text { AN1-100 }\end{array}$ & $\begin{array}{l}.7878 \\
.7508 \\
.7664\end{array}$ & $\begin{array}{l}.6065 \\
.6232 \\
.6316\end{array}$ & & & $\begin{array}{l}1.3565 \\
1.0625 \\
1.0649\end{array}$ & $\begin{array}{l}1.0993 \\
1.1168 \\
1.1474\end{array}$ & $\begin{array}{r}.9967 \\
1.0025 \\
1.0061\end{array}$ & $\begin{array}{l}.7977 \\
.7217 \\
.7428\end{array}$ \\
\hline $\begin{array}{l}\text { AN2-10 } \\
\text { AN2-50 } \\
\text { AN2-100 }\end{array}$ & $\begin{array}{l}.6153 \\
.6120 \\
.6129\end{array}$ & $\begin{array}{l}.5874 \\
.5765 \\
.5774\end{array}$ & $\begin{array}{l}.4900 \\
.4875 \\
.4872\end{array}$ & $\begin{array}{l}.4444 \\
.4359 \\
.4399\end{array}$ & & $\begin{array}{l}.9124 \\
.9370 \\
.9415\end{array}$ & $\begin{array}{l}.8282 \\
.8299 \\
.8328\end{array}$ & $\begin{array}{l}.6929 \\
.7133 \\
.7266\end{array}$ \\
\hline $\begin{array}{l}\text { WU1-10 } \\
\text { WU1-50 } \\
\text { WU1-100 }\end{array}$ & $\begin{array}{l}.6124 \\
.5062 \\
.5095\end{array}$ & $\begin{array}{l}.4052 \\
.4184 \\
.4180\end{array}$ & $\begin{array}{l}.3618 \\
.3654 \\
.3648\end{array}$ & $\begin{array}{l}.3071 \\
.2972 \\
.2993\end{array}$ & $\begin{array}{l}.8972 \\
.8182 \\
.8385\end{array}$ & $\begin{array}{l}.6885 \\
.7141 \\
.7075\end{array}$ & $\begin{array}{l}.66775 \\
.6738 \\
.6733\end{array}$ & $\begin{array}{l}.6063 \\
.5969 \\
.6094\end{array}$ \\
\hline $\begin{array}{l}\text { WU2 }-10 \\
\text { WU2 }-50 \\
\text { WU2-100 }\end{array}$ & $\begin{array}{l}.6389 \\
.6259 \\
.6227\end{array}$ & $\begin{array}{l}.5643 \\
.5173 \\
.5159\end{array}$ & $\begin{array}{l}.4690 \\
.4490 \\
.4577\end{array}$ & $\begin{array}{l}.3859 \\
.3626 \\
.3735\end{array}$ & $\begin{array}{r}1.0486 \\
.8870 \\
.8785\end{array}$ & $\begin{array}{l}.8799 \\
.6512 \\
.6399\end{array}$ & $\begin{array}{l}.7639 \\
.5471 \\
.5644\end{array}$ & $\begin{array}{l}.5698 \\
.4719 \\
.4940\end{array}$ \\
\hline $\begin{array}{l}\text { SAM-10 } \\
\text { SAM-50 } \\
\text { SAM-100 }\end{array}$ & $\begin{array}{l}.5344 \\
.5263 \\
.5169\end{array}$ & $\begin{array}{l}.4749 \\
.4621 \\
.5159\end{array}$ & $\begin{array}{l}.4182 \\
.4047 \\
.3901\end{array}$ & $\begin{array}{l}.3329 \\
.3189 \\
.3158\end{array}$ & $\begin{array}{l}.7351 \\
.7271 \\
.7292\end{array}$ & $\begin{array}{l}.6505 \\
.6445 \\
.6361\end{array}$ & $\begin{array}{l}.5524 \\
.5370 \\
.5355\end{array}$ & $\begin{array}{l}.4429 \\
.4403 \\
.4393\end{array}$ \\
\hline $\begin{array}{l}\text { Asympt. } \\
\text { RM }\end{array}$ & 5590 & .4564 & .3953 & .3227 & .7133 & .5824 & .5044 & .4118 \\
\hline
\end{tabular}


TABLE 9

MONTE CARLO $\sqrt{M S E S}$ FOR ESTIMATING $L_{p *}$

MODEL: LOGIT $\theta_{1}=0, \theta_{2}=1$

INITIAL SET 2

(150 discarded samples)

\begin{tabular}{|c|c|c|c|c|c|c|c|c|}
\hline \multirow[t]{2}{*}{$p^{0}$} & \multicolumn{4}{|c|}{.5} & \multicolumn{4}{|c|}{.75} \\
\hline & 10 & 15 & 20 & 30 & 10 & 15 & 20 & 30 \\
\hline$R M-1$ & .5493 & .6101 & .5925 & .5319 & 1.1449 & 1.1865 & 1.1609 & 1.1871 \\
\hline$R M-6$ & .5730 & .6454 & .6474 & .5972 & 1.1803 & 1.2414 & 1.2431 & 1.2897 \\
\hline$R M-36$ & .5777 & .6521 & .6580 & .6098 & 1.1868 & 1.2512 & 1.2581 & 1.3081 \\
\hline AN1-10 & 1.0454 & .7121 & .7026 & .5771 & 1.3625 & 1.1251 & 1.0900 & .9636 \\
\hline AN1-50 & 1.0722 & .7564 & .7181 & .5934 & 1.3949 & 1.1979 & 1.0872 & .9459 \\
\hline AN1-100 & 1.1581 & .8254 & .7569 & .6102 & 1.4729 & 1.2677 & 1.1257 & .9856 \\
\hline AN2-10 & .5017 & .4953 & .4467 & .3926 & .9938 & .9059 & .7889 & .7299 \\
\hline AN2 - 50 & .6242 & .5801 & .5442 & .4804 & 1.1026 & .9659 & .8657 & .7650 \\
\hline AN2 $2-100$ & .6482 & .6113 & .5792 & .4976 & 1.1225 & 1.0006 & .8944 & .7823 \\
\hline WU1-10 & .5762 & .3384 & .2978 & .3629 & .8001 & .6635 & .6662 & .7299 \\
\hline WU1-50 & . 3795 & .3356 & .2963 & .3622 & .6522 & .6617 & .6669 & .7226 \\
\hline WU1-100 & .3748 & .3387 & .2933 & .3614 & .6513 & .6710 & .6641 & .7176 \\
\hline WU2-10 & .5640 & .5416 & .4819 & .4521 & 1.0134 & .8974 & .7545 & .6629 \\
\hline WU2-50 & .7562 & .5787 & .4872 & .4305 & .9328 & .7172 & .5855 & .5225 \\
\hline WU2-100 & .7682 & .5857 & .5092 & .4184 & .9587 & .7439 & .6091 & .5071 \\
\hline SAM-10 & .5372 & .4417 & . 3759 & .3181 & .7870 & .6744 & .5475 & .4477 \\
\hline SAM-50 & .4800 & .4349 & .3867 & .3038 & .7259 & .6149 & .5406 & .4405 \\
\hline SAM-100 & .4828 & .4512 & . 3861 & .3033 & .7255 & .6181 & .5421 & .4479 \\
\hline Asympt. & & & & & & & & \\
\hline & .5590 & .4564 & .3953 & .3227 & .7133 & .5824 & .5044 & .4118 \\
\hline
\end{tabular}


TABLE 10

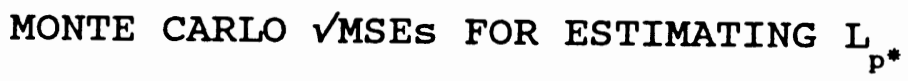
MODEL: PROBIT $\theta_{1}=-.25 \quad \theta_{2}=2$

INITIAL SET 1

(139 discarded samples)

\begin{tabular}{|c|c|c|c|c|c|c|c|c|}
\hline \multirow{2}{*}{$\begin{array}{l}\mathbf{p}^{\circ} \\
\mathbf{N}\end{array}$} & \multicolumn{4}{|c|}{.5} & \multicolumn{4}{|c|}{.75} \\
\hline & 10 & 15 & 20 & 30 & 10 & 15 & 20 & 30 \\
\hline$R M-1$ & .8111 & .8668 & .8303 & .7979 & 1.3636 & 1.4078 & 1.4344 & 1.3624 \\
\hline$R M-6$ & .8442 & .9240 & .9044 & .8893 & 1.4060 & 1.4776 & 1.5310 & 1.4827 \\
\hline$R M-36$ & .8499 & .9342 & .9179 & .9063 & 1.4135 & 1.4899 & 1.5482 & 1.5046 \\
\hline AN $1-10$ & .9651 & .7779 & .6465 & .5251 & 1.5058 & 1.2937 & 1.1453 & .9782 \\
\hline ANI-50 & .9176 & .8020 & .6447 & .5391 & 1.8273 & 1.4725 & 1.1821 & .9066 \\
\hline AN1-100 & .9569 & .8187 & .6655 & .5406 & 1.8224 & 1.5167 & 1.1971 & .9324 \\
\hline AN2-10 & .6812 & .6298 & .5513 & .4693 & 1.1290 & .9939 & .8919 & .7246 \\
\hline AN2-50 & .7148 & .6227 & .5487 & .4643 & 1.2296 & 1.0033 & .9165 & .7374 \\
\hline AN2 -100 & .7225 & .6315 & .5563 & .4694 & 1.2578 & 1.0250 & .9396 & .7592 \\
\hline WU1-10 & .7194 & .4931 & .4350 & .3762 & 1.5836 & 1.2919 & 1.2858 & 1.1997 \\
\hline WU1-50 & .6116 & .5079 & .4454 & .3692 & .9509 & .8777 & .8096 & .7248 \\
\hline WU1-100 & .6169 & .5100 & .4454 & .3693 & .9740 & .8714 & .8169 & .7290 \\
\hline WU2-10 & .7017 & $: 6136$ & .5247 & .4392 & 1.1819 & .9877 & .8445 & .6223 \\
\hline WU2-50 & .7456 & .6135 & .5255 & .4278 & .9968 & .7359 & .6390 & .5641 \\
\hline WU2-100 & .7633 & .5997 & .5221 & .4353 & 1.0355 & .7225 & .6335 & .5800 \\
\hline$S A M-10$ & .6171 & .5513 & .4812 & .3795 & .9135 & .7502 & .6290 & .5064 \\
\hline$S A M-50$ & .6238 & .5321 & .4561 & .3621 & .9095 & .7574 & .6237 & .5052 \\
\hline SAM-100 & .6202 & .5327 & .4556 & .3636 & .9174 & .7571 & .6194 & .5078 \\
\hline AsY & & & & & & & & \\
\hline$R M$ & .6399 & .5225 & .4525 & .3695 & .8163 & .6665 & .5772 & .4713 \\
\hline
\end{tabular}


TABLE 11

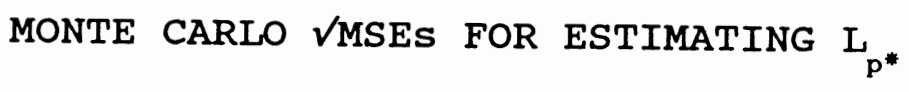

MODEL: PROBIT $\theta_{1}=-.25 \quad \theta_{2}=2$

INITIAL SET 2

(136 discarded samples)

\begin{tabular}{|c|c|c|c|c|c|c|c|c|}
\hline$p^{\circ}$ & & & 5 & & & .7 & & \\
\hline $\mathbf{N}$ & 10 & 15 & 20 & 30 & 10 & 15 & 20 & 30 \\
\hline$M-1$ & . 9779 & .9812 & .9100 & .8299 & 1.5199 & 1.5745 & 1.4460 & 1.3994 \\
\hline & & & & & 1.3196 & 1.2216 & 1.0076 & .8547 \\
\hline$M-36$ & 1.0555 & .9070 & .7819 & .6506 & 1.3166 & 1.1022 & 1.0047 & .8165 \\
\hline N1-10 & 1.1936 & .9158 & .8657 & .6756 & 1.6098 & 1.4068 & 1.3526 & 1.1863 \\
\hline AN1-50 & 1.2072 & . 9568 & .88 & .69 & 1.7557 & 1.5716 & 1.3653 & 1.1733 \\
\hline AN1-100 & 1.2724 & .9996 & .9109 & .71 & 1.8099 & 1.5834 & 1.3973 & 1.2411 \\
\hline N2 -10 & .8003 & 95 & .5605 & .4613 & 2431 & 689 & .8657 & .7037 \\
\hline $\mathrm{N} 2-50$ & .82 & & & & & & & \\
\hline 1N2-100 & 1.0418 & .8207 & .7247 & .6616 & 1.6301 & 1.2570 & 1.1371 & .9128 \\
\hline$U 1-10$ & .6612 & .4409 & .3818 & .4216 & .9212 & .8084 & .7977 & .7921 \\
\hline$\pi 1-50$ & .50 & .43 & .37 & & .77 & .7891 & .7838 & .8749 \\
\hline WU1-100 & .5058 & .4427 & .3809 & .6118 & .7798 & .8160 & .7896 & .9774 \\
\hline U2-10 & .89 & 362 & .70 & .63 & 1.38 & 1.3521 & 1.0 & \\
\hline WU2-50 & 1.02 & .90 & .732 & .67 & 1.37 & 1.2661 & .9852 & .9134 \\
\hline WU2-100 & 1.0934 & .9027 & .7539 & .6694 & 1.4526 & 1.2812 & .9990 & .9168 \\
\hline SAM-10 & .5566 & .504 & .445 & .36 & .8410 & .7697 & & \\
\hline SAM-50 & .5510 & .494 & .448 & .35 & .7907 & .8433 & .6530 & .5208 \\
\hline SAM-100 & .5664 & .4980 & .4379 & .3624 & .7807 & .7505 & .6520 & .5305 \\
\hline & & & & & & & & \\
\hline & .6399 & .5225 & .4525 & .3695 & .8163 & .6665 & .5772 & .4713 \\
\hline
\end{tabular}


TABLE 12

MONTE CARLO VMSES FOR ESTIMATING $\mathrm{L}_{\mathrm{p}}$ *

MODEL: SKEWED LOGIT $\theta_{1}=-1 \quad \theta_{2}=.7$

INITIAL SET 1

(143 discarded samples)

\begin{tabular}{|c|c|c|c|c|c|c|c|c|}
\hline$p^{\circ}$ & & & 5 & & & .75 & & \\
\hline $\mathbf{N}$ & 10 & 15 & 20 & 30 & 10 & 15 & 20 & 30 \\
\hline $2 M-1$ & .8358 & .8821 & .8435 & .8269 & 1.2323 & 1.2595 & 1.2869 & 1.2226 \\
\hline & & .6757 & & & .0577 & .9792 & .9314 & .8042 \\
\hline$R M-36$ & 1.0957 & .9116 & .8006 & .7100 & 1.4913 & 1.2428 & 1.1017 & .9585 \\
\hline N1-10 & .9061 & 971 & .6466 & .5171 & 1.3772 & 1.2685 & 1.1203 & .9350 \\
\hline AN $1-50$ & .9391 & .8077 & .65 & .52 & 1.7308 & 1.4107 & 1.1928 & .9037 \\
\hline N $1-100$ & 1.0090 & .8182 & .6580 & .5293 & 1.8041 & 1.4443 & 1.2318 & .9031 \\
\hline N2-10 & .70 & 541 & .5796 & .50 & .0363 & .9212 & & .7417 \\
\hline AN2 - 50 & .728 & .66 & .593 & .52 & 1.1726 & 1.0295 & .9659 & .8352 \\
\hline AN2 -100 & .7379 & .6716 & .5968 & .5351 & 1.2135 & 1.0373 & .9688 & .8670 \\
\hline WU1-10 & .6578 & .4998 & .4264 & .3647 & 1.0059 & .8942 & .8396 & .7542 \\
\hline WU1-50 & .611 & .51 & .45 & .38 & & .89 & & .7431 \\
\hline WU1-100 & .6083 & .5167 & .4790 & .3572 & .9576 & .8964 & .8605 & .7365 \\
\hline TU2-10 & .7382 & .6538 & .5936 & .4731 & 1.08 & .93 & & .6648 \\
\hline WU2-50 & .8198 & .6498 & .5816 & .47 & & .84 & .79 & .6700 \\
\hline WU2-100 & .8338 & .6347 & .5875 & .4755 & 1.1924 & .8341 & .7975 & .6805 \\
\hline$A M-10$ & .6321 & .582 & .4958 & .4147 & & .8673 & & .5863 \\
\hline$A M-50$ & .6483 & .579 & .4882 & .40 & & .86 & & .5978 \\
\hline SAM-100 & .6385 & .5811 & .4852 & .4135 & .8695 & .8543 & .7022 & .6045 \\
\hline & & & & & & & & \\
\hline & .6787 & .5541 & .4799 & .3918 & .9685 & .7908 & .6849 & .5592 \\
\hline
\end{tabular}


TABLE 13

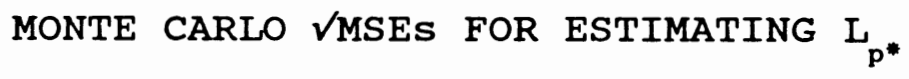
MODEL: SKEWED LOGIT $\theta_{1}=-1 \quad \theta_{2}=.7$

INITIAL SET 2

(136 discarded samples)

\begin{tabular}{|c|c|c|c|c|c|c|c|c|}
\hline \multirow{2}{*}{$\begin{array}{l}\mathrm{p}^{\bullet} \\
\mathrm{N}\end{array}$} & \multicolumn{4}{|c|}{.5} & \multicolumn{4}{|c|}{.75} \\
\hline & 10 & 15 & 20 & 30 & 10 & 15 & 20 & 30 \\
\hline $\begin{array}{l}R M-1 \\
R M-6 \\
R M-36\end{array}$ & $\begin{array}{l}1.0013 \\
1.0312 \\
1.0365\end{array}$ & $\begin{array}{l}1.0332 \\
1.0820 \\
1.0906\end{array}$ & $\begin{array}{r}.9373 \\
1.0054 \\
1.0176\end{array}$ & $\begin{array}{l}.8649 \\
.9485 \\
.9634\end{array}$ & $\begin{array}{l}1.4682 \\
1.5099 \\
1.5172\end{array}$ & $\begin{array}{l}1.5397 \\
1.6089 \\
1.6208\end{array}$ & $\begin{array}{l}1.3767 \\
1.4741 \\
1.4913\end{array}$ & $\begin{array}{l}1.3399 \\
1.4602 \\
1.4817\end{array}$ \\
\hline $\begin{array}{l}\text { AN1-10 } \\
\text { AN1-50 } \\
\text { AN1-100 }\end{array}$ & $\begin{array}{l}1.3032 \\
1.3260 \\
1.3578\end{array}$ & $\begin{array}{l}1.0093 \\
1.0304 \\
1.0608\end{array}$ & $\begin{array}{l}.9081 \\
.9339 \\
.9435\end{array}$ & $\begin{array}{l}.7075 \\
.7214 \\
.7290\end{array}$ & $\begin{array}{l}1.6796 \\
1.8162 \\
1.9127\end{array}$ & $\begin{array}{l}1.4855 \\
1.6120 \\
1.6671\end{array}$ & $\begin{array}{l}1.4012 \\
1.4432 \\
1.4272\end{array}$ & $\begin{array}{l}1.2245 \\
1.2214 \\
1.2757\end{array}$ \\
\hline $\begin{array}{l}\text { AN2-10 } \\
\text { AN2 }-50 \\
\text { AN2-100 }\end{array}$ & $\begin{array}{r}.8384 \\
.9956 \\
1.1452\end{array}$ & $\begin{array}{l}.7551 \\
.8386 \\
.9449\end{array}$ & $\begin{array}{l}.5987 \\
.7038 \\
.7842\end{array}$ & $\begin{array}{l}.4983 \\
.5799 \\
.7330\end{array}$ & $\begin{array}{l}1.2177 \\
1.5615 \\
1.7349\end{array}$ & $\begin{array}{l}1.0979 \\
1.2692 \\
1.3767\end{array}$ & $\begin{array}{r}.8664 \\
1.0709 \\
1.2120\end{array}$ & $\begin{array}{r}.7457 \\
.8861 \\
1.0283\end{array}$ \\
\hline $\begin{array}{l}\text { WU1-10 } \\
\text { WU1-50 } \\
\text { WU1-100 }\end{array}$ & $\begin{array}{l}.7567 \\
.4824 \\
.4925\end{array}$ & $\begin{array}{l}.4313 \\
.4173 \\
.5349\end{array}$ & $\begin{array}{l}.3727 \\
.3615 \\
.3663\end{array}$ & $\begin{array}{l}.3129 \\
.3071 \\
.3110\end{array}$ & $\begin{array}{r}1.0227 \\
.8263 \\
.8293\end{array}$ & $\begin{array}{l}.9412 \\
.8335 \\
.9466\end{array}$ & $\begin{array}{l}.8874 \\
.8215 \\
.8188\end{array}$ & $\begin{array}{l}.8657 \\
.8021 \\
.8020\end{array}$ \\
\hline $\begin{array}{l}\text { WU2-10 } \\
\text { WU2-50 } \\
\text { WU2-100 }\end{array}$ & $\begin{array}{l}.8675 \\
.8946 \\
.9739\end{array}$ & $\begin{array}{l}.7738 \\
.7624 \\
.7667\end{array}$ & $\begin{array}{l}.6353 \\
.6591 \\
.6861\end{array}$ & $\begin{array}{l}.5434 \\
.5617 \\
.5604\end{array}$ & $\begin{array}{l}1.2544 \\
1.2081 \\
1.3024\end{array}$ & $\begin{array}{r}1.1140 \\
1.0430 \\
.9957\end{array}$ & $\begin{array}{l}.8953 \\
.8637 \\
.8544\end{array}$ & $\begin{array}{l}.7566 \\
.7562 \\
.7018\end{array}$ \\
\hline $\begin{array}{l}\text { SAM-10 } \\
\text { SAM-50 } \\
\text { SAM-100 }\end{array}$ & $\begin{array}{l}.5799 \\
.5875 \\
.5712\end{array}$ & $\begin{array}{l}.5716 \\
.5239 \\
.5286\end{array}$ & $\begin{array}{l}.4603 \\
.4576 \\
.4589\end{array}$ & $\begin{array}{l}.3833 \\
.3852 \\
.3847\end{array}$ & $\begin{array}{l}.9857 \\
.8557 \\
.8448\end{array}$ & $\begin{array}{l}.8113 \\
.7913 \\
.7869\end{array}$ & $\begin{array}{l}.7014 \\
.6907 \\
.6930\end{array}$ & $\begin{array}{l}.6032 \\
.5887 \\
.5976\end{array}$ \\
\hline $\begin{array}{l}\text { Asympt. } \\
\text { RM }\end{array}$ & .6787 & .5541 & . 4799 & .3918 & .9685 & .7908 & .6849 & .5592 \\
\hline
\end{tabular}


TABLE 14

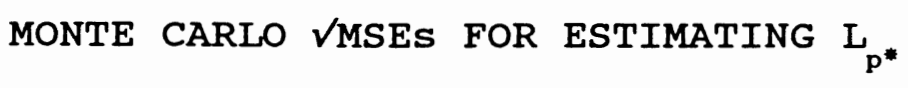

MODEL: LOGLOG $\theta_{1}=0 \quad \theta_{2}=.5$

INITIAL SET 1

(144 discarded samples)

\begin{tabular}{|c|c|c|c|c|c|c|c|c|}
\hline \multirow[t]{2}{*}{$p^{\bullet}$} & \multicolumn{4}{|c|}{.5} & \multicolumn{4}{|c|}{.75} \\
\hline & 10 & 15 & 20 & 30 & 10 & 15 & 20 & 30 \\
\hline $\begin{array}{l}R M-1 \\
R M-6\end{array}$ & $\begin{array}{l}.9190 \\
.9526\end{array}$ & $\begin{array}{r}.9885 \\
1.0464\end{array}$ & $\begin{array}{r}.9624 \\
1.0390\end{array}$ & $\begin{array}{r}.9067 \\
1.0025\end{array}$ & $\begin{array}{l}1.5460 \\
1.5916\end{array}$ & $\begin{array}{l}1.5429 \\
1.6178\end{array}$ & $\begin{array}{l}1.6181 \\
1.7216\end{array}$ & $\begin{array}{l}1.5439 \\
1.6757\end{array}$ \\
\hline$R M-36$ & .9585 & 1.0566 & 1.0528 & 1.0199 & 1.5994 & 1.6308 & 1.7397 & 1.6990 \\
\hline AN $1-10$ & 1.0087 & .8072 & .7437 & .6114 & 1.5543 & 1.3606 & 1.3097 & 1.1300 \\
\hline AN 1-50 & 1.0212 & .8629 & .7693 & .6602 & 2.2065 & 1.6957 & 1.4913 & 1.1618 \\
\hline AN1-100 & 1.0953 & .8960 & .7739 & .6672 & 2.1372 & 1.7189 & 1.4929 & 1.1573 \\
\hline AN2 -10 & .7598 & .7289 & .6348 & .5444 & 1.2426 & 1.0586 & .9326 & .7143 \\
\hline AN2-50 & .7735 & .7047 & .6286 & .5620 & 1.2594 & 1.0121 & .8547 & .6711 \\
\hline AN2-100 & .7933 & .7056 & .6298 & .5607 & 1.3197 & 1.0239 & .8655 & .6769 \\
\hline WU1-10 & .7983 & .5804 & .5226 & .4312 & 1.8197 & 1.4150 & 1.5318 & 1.4156 \\
\hline WU1-50 & .7112 & .5788 & .5313 & .4311 & 1.0785 & .8857 & .9624 & .7863 \\
\hline WU1-100 & .7150 & .5788 & .5423 & .4316 & 1.0788 & .8994 & .9858 & .7745 \\
\hline WU2-10 & .8002 & .7600 & .6433 & .6050 & 1.2664 & 1.0651 & .9243 & .7059 \\
\hline WU2-50 & .8649 & .7592 & .6732 & .6176 & .8756 & .6777 & .5783 & .5190 \\
\hline WU2-100 & .8441 & .7351 & .6879 & .6152 & .9246 & .6581 & .5829 & .5183 \\
\hline$S A M-10$ & .7191 & .6703 & .6131 & .5301 & .9303 & .6960 & .6321 & .4946 \\
\hline SAM-50 & .7315 & .6694 & .6171 & .5204 & .9173 & .7067 & .6299 & .5010 \\
\hline SAM-100 & .7326 & .6787 & .6143 & .5182 & .9172 & .7075 & .6301 & .4993 \\
\hline Asyn & & & & & & & & \\
\hline & .8390 & .6850 & .5932 & .4844 & .7540 & .6157 & .5332 & .4353 \\
\hline
\end{tabular}




\section{TABLE 15}

MONTE CARLO $\sqrt{M S E S}$ FOR ESTIMATING $\mathrm{L}_{\mathrm{p}}$

MODEL: LOGLOG $\theta_{1}=0 \quad \theta_{2}=.5$

INITIAL SET 2

(157 discarded samples)

\begin{tabular}{|c|c|c|c|c|c|c|c|c|}
\hline \multirow{2}{*}{$\begin{array}{l}\mathrm{p}^{\bullet} \\
\mathrm{N}\end{array}$} & \multicolumn{4}{|c|}{.5} & \multicolumn{4}{|c|}{.75} \\
\hline & 10 & 15 & 20 & 30 & 10 & 15 & 20 & 30 \\
\hline $\begin{array}{l}R M-1 \\
R M-6 \\
R M-36\end{array}$ & $\begin{array}{r}.7921 \\
.7052 \\
1.0948\end{array}$ & $\begin{array}{r}.7330 \\
.6152 \\
1.0186\end{array}$ & $\begin{array}{l}.7789 \\
.5842 \\
.9063\end{array}$ & $\begin{array}{l}.7074 \\
.4969 \\
.7814\end{array}$ & $\begin{array}{l}1.3210 \\
1.1567 \\
1.1586\end{array}$ & $\begin{array}{l}1.3215 \\
1.0553 \\
1.0124\end{array}$ & $\begin{array}{r}1.3121 \\
.9405 \\
.8459\end{array}$ & $\begin{array}{r}1.2341 \\
.7891 \\
.7148\end{array}$ \\
\hline $\begin{array}{l}\text { AN1-10 } \\
\text { AN1-50 } \\
\text { AN1-100 }\end{array}$ & $\begin{array}{r}.8878 \\
.9047 \\
1.0124\end{array}$ & $\begin{array}{l}.7117 \\
.7588 \\
.7917\end{array}$ & $\begin{array}{l}.6467 \\
.6794 \\
.7080\end{array}$ & $\begin{array}{l}.5485 \\
.5928 \\
.5957\end{array}$ & $\begin{array}{l}1.4560 \\
1.6918 \\
1.8664\end{array}$ & $\begin{array}{l}1.3061 \\
1.4569 \\
1.4939\end{array}$ & $\begin{array}{l}1.2510 \\
1.2483 \\
1.2726\end{array}$ & $\begin{array}{l}1.1514 \\
1.1305 \\
1.1464\end{array}$ \\
\hline $\begin{array}{l}\text { AN2 }-10 \\
\text { AN2 }-50 \\
\text { AN2 }-100\end{array}$ & $\begin{array}{r}.6975 \\
.8725 \\
1.0576\end{array}$ & $\begin{array}{l}.6086 \\
.7367 \\
.8493\end{array}$ & $\begin{array}{l}.5852 \\
.7105 \\
.7890\end{array}$ & $\begin{array}{l}.5058 \\
.6285 \\
.7031\end{array}$ & $\begin{array}{l}1.1160 \\
1.2706 \\
1.5837\end{array}$ & $\begin{array}{r}.9815 \\
1.0673 \\
1.2899\end{array}$ & $\begin{array}{r}.8429 \\
.9335 \\
1.1069\end{array}$ & $\begin{array}{l}.6811 \\
.7318 \\
.8596\end{array}$ \\
\hline $\begin{array}{l}\text { WU1-10 } \\
\text { WU1-50 } \\
\text { WU1-100 }\end{array}$ & $\begin{array}{l}.7029 \\
.6680 \\
.7765\end{array}$ & $\begin{array}{l}.5318 \\
.5985 \\
.6028\end{array}$ & $\begin{array}{l}.4431 \\
.5650 \\
.5726\end{array}$ & $\begin{array}{l}.3760 \\
.6278 \\
.5201\end{array}$ & $\begin{array}{r}.9573 \\
.9098 \\
1.0111\end{array}$ & $\begin{array}{l}.9214 \\
.8807 \\
.8875\end{array}$ & $\begin{array}{l}.7994 \\
.8957 \\
.9002\end{array}$ & $\begin{array}{l}.7555 \\
.9746 \\
.8788\end{array}$ \\
\hline $\begin{array}{l}\text { WU2-10 } \\
\text { WU2 }-50 \\
\text { WU2-100 }\end{array}$ & $\begin{array}{r}.7600 \\
1.0386 \\
1.0193\end{array}$ & $\begin{array}{l}.7136 \\
.8117 \\
.8425\end{array}$ & $\begin{array}{l}.6807 \\
.7560 \\
.7669\end{array}$ & $\begin{array}{l}.6131 \\
.6526 \\
.6524\end{array}$ & $\begin{array}{r}1.1344 \\
.9885 \\
1.1010\end{array}$ & $\begin{array}{l}.9944 \\
.7453 \\
.8634\end{array}$ & $\begin{array}{l}.8187 \\
.6047 \\
.6767\end{array}$ & $\begin{array}{l}.6335 \\
.5698 \\
.5534\end{array}$ \\
\hline $\begin{array}{l}\text { SAM-10 } \\
\text { SAM-50 } \\
\text { SAM-100 }\end{array}$ & $\begin{array}{l}.7091 \\
.7265 \\
.7633\end{array}$ & $\begin{array}{l}.6341 \\
.6387 \\
.6599\end{array}$ & $\begin{array}{l}.5344 \\
.5777 \\
.5561\end{array}$ & $\begin{array}{l}.4541 \\
.4767 \\
.5022\end{array}$ & $\begin{array}{l}.7755 \\
.8548 \\
.8257\end{array}$ & $\begin{array}{l}.7251 \\
.8019 \\
.7054\end{array}$ & $\begin{array}{l}.5897 \\
.6178 \\
.6071\end{array}$ & $\begin{array}{l}.4506 \\
.4768 \\
.4777\end{array}$ \\
\hline $\begin{array}{l}\text { Asympt. } \\
\text { RM }\end{array}$ & .8390 & .6850 & .5932 & .4844 & .7540 & .6157 & .5332 & .4353 \\
\hline
\end{tabular}


levels $\left(x_{1,1}\right.$ and $\left.x_{1,2}\right)$ are needed for these procedures. For AN1 and WU1, a single RM procedure with $\mathrm{p}=.5$ generates the initial design levels, and a single starting level $\left(x_{1}\right)$ is required. Three different sets of starting levels, $\left(\mathrm{L}_{.1}, \mathrm{~L}_{.4}, \mathrm{~L}_{.7}\right),\left(\mathrm{L}_{.5}, \mathrm{~L}_{.813^{\prime}} \mathrm{L}_{.95}\right),\left(\mathrm{L}_{.3}, \mathrm{~L}_{.35}, \mathrm{~L}_{.4}\right)$, are used in this study. The first and third values of each triple are the starting levels for SAM, AN2, and WU2. The middle value is the starting level for AN1 and WU1.

The updates at which the six procedures switch from the initial RM procedure to their own updating rules are given below.

AN1 -- the first $n \geq 10$ such that $b_{n}$ (6) is nonzero AN2 -- each of the two independent Anbar processes is started separately at the first $n \geq 5$ such that $b_{n}$ is nonzero.

WU1 -- the first $n \geq 10$ such that the MLEs exist

WU2 -- each of the two independent wu procedures is started separately at the first $n \geq 5$ such that the MLEs exist

SAM -- the first $n \geq 5$ such that the MLEs from the two combined independent $\mathrm{RM}$ initial procedures exist

An upper bound of $\delta_{2}=100$ and a lower bound of $\delta_{1}=.05$ is used for all procedures. The MSE, the average of $\left(\hat{\mathrm{L}}_{\mathrm{p}^{*}}\right.$ $\left.\mathrm{L}_{\mathrm{p}^{*}}\right)^{2}$ over the 500 samples, is again used to compare the procedures. 
Results of Initial Procedure 2

Tables 16 - 24 contain the MSEs for the logit and loglog models at each of the three starting levels. The MSEs of both $\hat{\mathrm{L}}_{.5}$ and $\hat{\mathrm{L}}_{.75}$ are given in Tables $16-21$. The MSEs of $\hat{\mathrm{L}}_{.25}$ were also obtained in each situation, and are presented seperately in Tables $22-24$. The results for $\hat{\mathrm{L}}_{.25}$ and $\hat{\mathrm{L}}_{.75}$ are fairly similar. Thus, the conclusions in the discussion below for $L_{.75}$ hold also for $L_{.25}$, except when mentioned specifically.

For estimating $\hat{\mathrm{L}}_{.75}$, SAM consistently produced the lowest MSEs of any procedure. Note that SAM was superior for both the logit and loglog models. An exception occurred with starting values $\left(\mathrm{L}_{.3}, \mathrm{~L}_{.35}, \mathrm{~L}_{.4}\right)$. With $\mathrm{n} \cdot \mathrm{A}_{\mathrm{n}}=1$, the RM-1 procedure produced the lowest MSEs of any procedure. However, for estimating $I_{.25}$ in this situation, the RM-1 produced larger MSEs than SAM, except when $n=10$.

The comparisons between the two $\mathrm{Wu}$ procedures and between the two Anbar procedures differed from initial procedure 1. Using initial procedure 2, WU2 proved to be superior to WUl for estimating $L_{.75^{\circ}}$ In initial procedure 1, the initial design levels for the procedures are evenly spread throughout the distribution. With initial procedure 2, however, procedures such as WU1 and AN1 may have their initial design levels in one section of the distribution. This would make the procedure less efficient in estimating $L_{.75}$ and $L_{.25}$ for small sample sizes. However, the MSEs 
from AN2 for estimating $L_{.75}$ were not always better than AN1.

For estimating $\mathrm{L}_{.5}$, no one procedure performed the best in all situations. In various situations, estimates from WU2, AN2, and SAM all produced the lowest MSEs of any procedure. In most cases, these three were superior to AN2 WU2 and RM. Regardless of the model, WU1 produced the lowest MSEs for $\hat{L}_{.5}$ when $n \cdot A_{n}=36$. Using the larger step size and spreading out the initial design levels appeared to help the WUI procedure. For starting values $\left(\mathrm{L}_{.5}, \mathrm{~L}_{.813}, \mathrm{~L}_{.95}\right)$, SAM generally produced the lowest MSEs when $n \cdot A_{n}=1$, while ANl produced the lowest when $n \cdot A_{n}=6$. For the other starting levels with $n \cdot A_{n} \neq 36$, no clear pattern emerged.

The RM procedure worked well only in specific situations. With starting values $\left(L_{.1} L_{.7}, L_{.4}\right)$ and $n \cdot A_{n}=$ 1 , the RM procedure performed very well. Using $n \cdot A_{n}=1$ does not allow the design levels to change very quickly. Thus, when the starting levels are close to the true values, the RM-1 procedure performs well. When the initial starting levels are not good, however; RM-1 did not perform well. Using the near optimal $\mathrm{RM}-6$ was preferable to $\mathrm{RM}-1$ in these situations. When $\mathrm{n}=10$, the RM procedures occasionally produced $\hat{L}_{.5}$ MSEs of similar size as SAM and WU1. This could be a result of the instability of parameter estimates for very small sample sizes.

For a given model, as $\mathrm{n}$ increased to 30 , SAM produced 
fairly constant MSEs. That is, the MSEs produced by SAM were very similar regardless of the starting levels and values of $n \cdot A_{n}$. For the logit model with $n=30$, SAM produced MSEs for $\hat{\mathrm{L}}_{.5}$ and $\hat{\mathrm{L}}_{.75}$ near .33 and .45 , respectively. Using initial procedure 1, the MSEs for SAM in this situation were near .32 and .44 .

The time at which the procedures switched from the initial RM procedure to their own updating rules is a random variable. For SAM, the average number of updates until MLEs existed ranged from 5.23 to 8.51 . The smaller averages occurred when the near optimal constant $n \cdot A_{n}=6$ was used in the initial RM design. The larger averages resulted when $n \cdot A_{n}=1$ and the loglog model was used to generate the binary responses.

\section{Analysis of the MSEs}

In this section, the differences between SAM's and Wu's MSEs (Tables 8 - 24) are studied. Least significant differences for the MSEs produced by SAM and WU1 are derived.

For SAM, using the first order asymptotic results of Chapter III (equation (29)),

$$
\begin{gathered}
\hat{L}_{p} \sim N\left(L_{p}, c_{L}^{-2} p(1-p) / n\left(2 c_{L}^{-1} M^{\prime}\left(L_{p}\right)-1\right)\right) \text { and } \\
\hat{L}_{1-p} \sim N\left(L_{1-p^{\prime}}, c_{L}^{-2} p(1-p) / n\left(2 c_{L}^{-1} M^{\prime}\left(L_{1-p}\right)-1\right)\right),
\end{gathered}
$$


TABLE 16

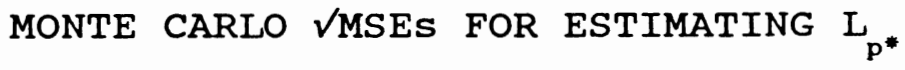

MODEL: LOGIT $\theta_{1}=0 \quad \theta_{2}=1$

STARTING LEVELS $(.5, .813, .95)$

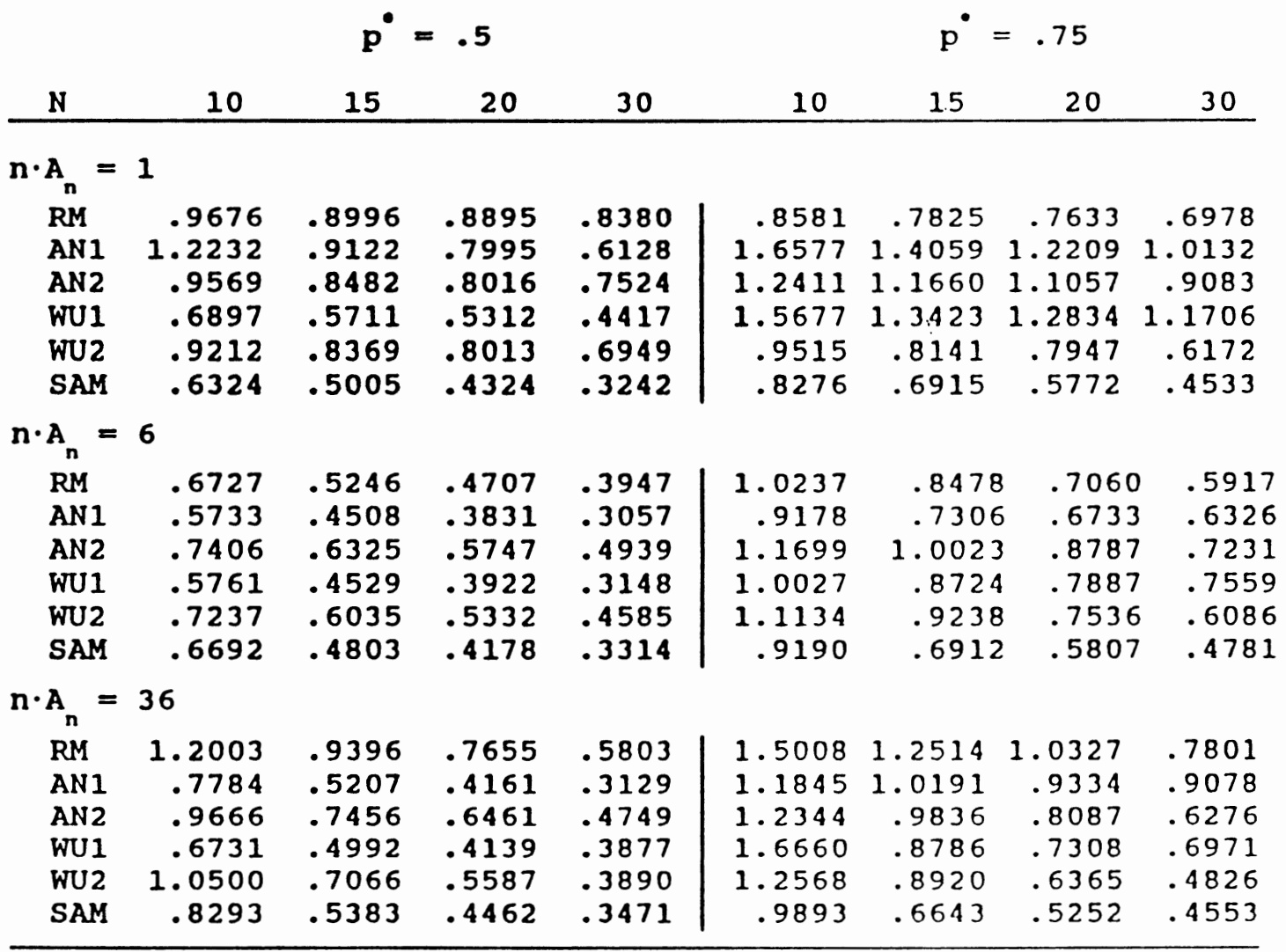


TABLE 17

MONTE CARLO $\sqrt{M S E S ~ F O R ~ E S T I M A T I N G ~} \mathrm{~L}_{\mathrm{p}^{*}}$

MODEL: LOGIT $\theta_{1}=0 \quad \theta_{2}=1$

STARTING LEVELS $(.1, .4, .7)$

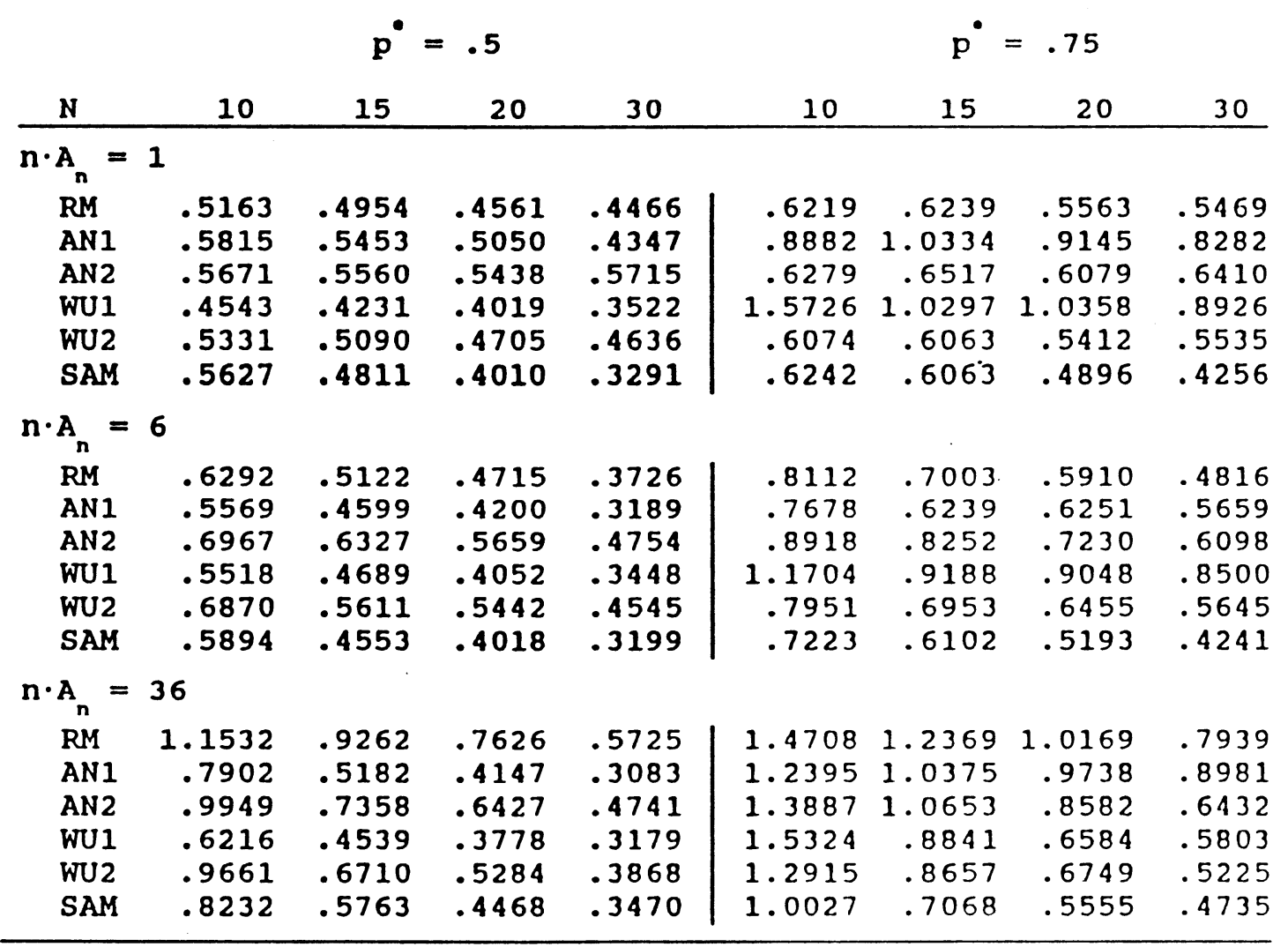


TABLE 18

MONTE CARLO $\sqrt{ }$ MSES FOR ESTIMATING $\mathrm{L}_{p^{*}}$

MODEL: LOGIT $\theta_{1}=0 \quad \theta_{2}=1$

STARTING LEVELS $(.3, .35, .4)$

\begin{tabular}{|c|c|c|c|c|c|c|c|c|}
\hline $\mathrm{N}$ & 10 & 15 & 20 & 30 & 10 & 15 & 20 & 30 \\
\hline \multicolumn{9}{|c|}{$n \cdot A_{n}=1$} \\
\hline $\begin{array}{l}\text { RM } \\
\text { AN1 } \\
\text { AN2 } \\
\text { WU1 } \\
\text { WU2 } \\
\text { SAM }\end{array}$ & $\begin{array}{l}.4299 \\
.6625 \\
.8924 \\
.5078 \\
.6354 \\
.5766\end{array}$ & $\begin{array}{l}.4006 \\
.6380 \\
.8927 \\
.4661 \\
.4667 \\
.4162\end{array}$ & $\begin{array}{l}.3810 \\
.5806 \\
.8735 \\
.3888 \\
.4730 \\
.3881\end{array}$ & $\begin{array}{l}.3279 \\
.4893 \\
.7830 \\
.3661 \\
.3900 \\
.3198\end{array}$ & $\begin{array}{r}.4114 \\
.8330 \\
.7929 \\
1.4422 \\
.6171 \\
.6918\end{array}$ & $\begin{array}{r}.3850 \\
1.3193 \\
.8123 \\
1.1002 \\
.4872 \\
.5550\end{array}$ & $\begin{array}{r}.3705 \\
.8740 \\
.8709 \\
1.0522 \\
.5413 \\
.5046\end{array}$ & $\begin{array}{l}.3502 \\
.8202 \\
.7892 \\
.9294 \\
.4888 \\
.4354\end{array}$ \\
\hline \multicolumn{9}{|c|}{$n \cdot A_{n}=6$} \\
\hline $\begin{array}{l}\text { RM } \\
\text { AN1 } \\
\text { AN2 } \\
\text { WU1 } \\
\text { WU2 } \\
\text { SAM }\end{array}$ & $\begin{array}{l}.6457 \\
.5724 \\
.7600 \\
.5786 \\
.7774 \\
.6318\end{array}$ & $\begin{array}{l}.5022 \\
.4712 \\
.6037 \\
.4857 \\
.5921 \\
.4869\end{array}$ & $\begin{array}{l}.4714 \\
.4148 \\
.5906 \\
.4098 \\
.5455 \\
.4262\end{array}$ & $\begin{array}{l}.3877 \\
.3305 \\
.4871 \\
.3448 \\
.4539 \\
.3244\end{array}$ & $\begin{array}{r}.9415 \\
.8016 \\
1.1323 \\
1.0900 \\
1.0440 \\
.7354\end{array}$ & $\begin{array}{l}.7864 \\
.6324 \\
.9677 \\
.8797 \\
.8546 \\
.6229\end{array}$ & $\begin{array}{l}.6576 \\
.5923 \\
.9160 \\
.8431 \\
.7053 \\
.5697\end{array}$ & $\begin{array}{l}.5536 \\
.5384 \\
.7309 \\
.7576 \\
.5903 \\
.4277\end{array}$ \\
\hline \multicolumn{9}{|c|}{$n \cdot A_{n}=36$} \\
\hline $\begin{array}{l}\text { RM } \\
\text { AN1 } \\
\text { AN2 } \\
\text { WU1 } \\
\text { WU2 } \\
\text { SAM }\end{array}$ & $\begin{array}{r}1.1413 \\
.7944 \\
.8638 \\
.6081 \\
.9671 \\
.7726\end{array}$ & $\begin{array}{l}.9157 \\
.5212 \\
.6345 \\
.4581 \\
.6616 \\
.5237\end{array}$ & $\begin{array}{l}.7740 \\
.4148 \\
.5727 \\
.3740 \\
.5011 \\
.4489\end{array}$ & $\begin{array}{l}.5629 \\
.3075 \\
.4456 \\
.3130 \\
.3642 \\
.3316\end{array}$ & $\begin{array}{r}1.4851 \\
1.2405 \\
1.2799 \\
1.4300 \\
1.2215 \\
.9005\end{array}$ & $\begin{array}{r}1.2462 \\
1.0459 \\
.9612 \\
.8428 \\
.8660 \\
.6536\end{array}$ & $\begin{array}{r}1.0373 \\
.9715 \\
.7894 \\
.6436 \\
.6461 \\
.5599\end{array}$ & $\begin{array}{l}.7768 \\
.8935 \\
.6069 \\
.5921 \\
.4703 \\
.4511\end{array}$ \\
\hline
\end{tabular}


TABLE 19

MONTE CARLO $\sqrt{ }$ MSES FOR ESTIMATING $L_{p}$ *

MODEL: LOGLOG $\theta_{1}=0 \quad \theta_{2}=.5$

STARTING LEVELS $(.5, .813, .95)$

\begin{tabular}{|c|c|c|c|c|c|c|c|c|}
\hline $\mathbf{N}$ & 10 & 15 & 20 & 30 & 10 & 15 & 20 & 30 \\
\hline \multicolumn{9}{|c|}{$n \cdot A_{n}=1$} \\
\hline $\begin{array}{l}\text { RM } \\
\text { AN1 } \\
\text { AN2 } \\
\text { WU1 } \\
\text { WU2 } \\
\text { SAM }\end{array}$ & $\begin{array}{r}.9484 \\
1.4208 \\
1.0767 \\
1.0810 \\
.9614 \\
.8685\end{array}$ & $\begin{array}{r}.8739 \\
1.1946 \\
1.0077 \\
.8048 \\
.8348 \\
.6750\end{array}$ & $\begin{array}{r}.8633 \\
1.0672 \\
.9729 \\
.7602 \\
.7609 \\
.5911\end{array}$ & $\begin{array}{l}.7965 \\
.8321 \\
.9226 \\
.6245 \\
.6815 \\
.5007\end{array}$ & $\begin{array}{l}1.4461 \\
2.2488 \\
1.8137 \\
2.3629 \\
1.5535 \\
1.3554\end{array}$ & $\begin{array}{l}1.3541 \\
2.0361 \\
1.7403 \\
2.1073 \\
1.3540 \\
1.0951\end{array}$ & $\begin{array}{r}1.3346 \\
1.7992 \\
1.6522 \\
2.0123 \\
1.2354 \\
.9636\end{array}$ & $\begin{array}{r}1.2442 \\
1.4677 \\
1.4014 \\
1.8210 \\
1.1070 \\
.7929\end{array}$ \\
\hline \multicolumn{9}{|c|}{$n \cdot A_{n}=6$} \\
\hline $\begin{array}{l}\text { RM } \\
\text { AN1 } \\
\text { AN2 } \\
\text { WU1 } \\
\text { WU2 } \\
\text { SAM }\end{array}$ & $\begin{array}{r}.9016 \\
.8201 \\
1.0813 \\
.8643 \\
1.0353 \\
.9152\end{array}$ & $\begin{array}{l}.7892 \\
.6573 \\
.9433 \\
.6863 \\
.9105 \\
.7495\end{array}$ & $\begin{array}{l}.7258 \\
.5779 \\
.8901 \\
.5902 \\
.8634 \\
.6352\end{array}$ & $\begin{array}{l}.6586 \\
.4533 \\
.7731 \\
.4993 \\
.7751 \\
.5567\end{array}$ & $\begin{array}{l}1.1937 \\
1.2772 \\
1.5134 \\
1.5742 \\
1.4433 \\
1.3553\end{array}$ & $\begin{array}{l}1.0962 \\
1.1285 \\
1.3727 \\
1.3641 \\
1.2668 \\
1.1099\end{array}$ & $\begin{array}{r}.9690 \\
1.0329 \\
1.2857 \\
1.3061 \\
1.1562 \\
.9378\end{array}$ & $\begin{array}{r}.8589 \\
.9662 \\
1.0807 \\
1.2363 \\
.9929 \\
.8135\end{array}$ \\
\hline \multicolumn{9}{|c|}{$n \cdot A_{n}=36$} \\
\hline $\begin{array}{l}\text { RM } \\
\text { AN1 } \\
\text { AN2 } \\
\text { WU1 } \\
\text { WU2 } \\
\text { SAM }\end{array}$ & $\begin{array}{r}1.2669 \\
1.0013 \\
1.2060 \\
.8641 \\
1.1235 \\
1.0561\end{array}$ & $\begin{array}{r}1.1305 \\
.7514 \\
1.0429 \\
.6530 \\
.9286 \\
.8667\end{array}$ & $\begin{array}{l}.9521 \\
.5942 \\
.9738 \\
.5465 \\
.7527 \\
.6991\end{array}$ & $\begin{array}{l}.8245 \\
.4611 \\
.8021 \\
.4355 \\
.6275 \\
.5488\end{array}$ & $\begin{array}{l}1.8381 \\
1.5146 \\
1.7766 \\
1.8460 \\
1.5240 \\
1.3163\end{array}$ & $\begin{array}{l}1.5493 \\
1.3379 \\
1.5001 \\
1.3205 \\
1.1260 \\
1.0588\end{array}$ & $\begin{array}{r}1.3352 \\
1.1676 \\
1.3353 \\
1.2011 \\
.9748 \\
.8990\end{array}$ & $\begin{array}{r}1.1209 \\
1.1028 \\
1.1040 \\
1.0561 \\
.8130 \\
.7575\end{array}$ \\
\hline
\end{tabular}


TABLE 20

MONTE CARLO VMSES FOR ESTIMATING $\mathrm{L}_{\mathrm{p}}$ *

MODEL: LOGLOG $\theta_{1}=0 \quad \theta_{2}=.5$

STARTING LEVELS $(.1, .4, .7)$

$$
\mathbf{p}^{\bullet}=.5 \quad \mathbf{p}^{\bullet}=.75
$$

\begin{tabular}{lllllllll}
$N$ & 10 & 15 & 20 & 30 & 10 & 15 & 20 & 30 \\
\hline
\end{tabular}

\begin{tabular}{|c|c|c|c|c|c|c|c|c|}
\hline \multicolumn{9}{|c|}{$n \cdot A_{n}=1$} \\
\hline $\mathbf{R M}$ & 1.1269 & 1.1035 & 1.0570 & 1.0528 & 1.2906 & 1.2820 & 1.2131 & 1.1982 \\
\hline AN1 & .7483 & .6790 & .6482 & .5567 & 1.3702 & 1.4685 & 1.6135 & 1.3051 \\
\hline AN2 & 559 & 1.1328 & 1.0576 & 977 & 1.2884 & 1.2933 & 1.1920 & 1.1793 \\
\hline WU1 & .5964 & .5849 & .5265 & .5069 & 2.0399 & 1.6280 & 1.6166 & 1.4759 \\
\hline WU2 & 1.1342 & 1.1008 & 1.0493 & 1.0179 & 1.2750 & 1.2631 & 1.1848 & 1.1648 \\
\hline SAM & .9890 & .8397 & & & & 1.0287 & & .7088 \\
\hline \multicolumn{9}{|c|}{$n \cdot A_{n}=6$} \\
\hline $\mathrm{RM}$ & .8992 & .7984 & .6936 & .6435 & 1.2227 & 1.1696 & .9687 & .8828 \\
\hline AN1 & .7933 & .68 & & & 1. & 1.07 & .9930 & .9099 \\
\hline AN2 & 1.0324 & .9294 & .80 & .7582 & 1.3161 & 1.2959 & 1.1104 & 1.0582 \\
\hline WU1 & .8312 & .681 & .60 & & & 1.4 & 1.4350 & 1.2961 \\
\hline WU2 & .9464 & .8494 & .7348 & .7022 & 1.1634 & 1.1029 & .9267 & .9046 \\
\hline SAM & .8583 & .7611 & .6556 & .5456 & 1.1125 & .9875 & .8297 & .7126 \\
\hline \multicolumn{9}{|c|}{$n \cdot A_{n}=36$} \\
\hline $\mathrm{RM}$ & 1.2803 & 1.1148 & .9804 & .8161 & 1.76 & 1.5598 & 1.3536 & 1.1340 \\
\hline AN1 & .9916 & .7451 & .598 & .44 & 1.7171 & 1.4616 & 1.3160 & 1.2263 \\
\hline AN2 & 1.2637 & 1.0472 & .971 & .77 & 1.7385 & 1.4355 & 1.2739 & 1.0477 \\
\hline & .8169 & .6027 & & .42 & 1.6243 & 1.0958 & 1.0444 & .9988 \\
\hline WU2 & 1.1372 & .90 & .76 & .66 & 1.59 & 1.2062 & 1.0556 & .8668 \\
\hline SAM & 1.1669 & .8888 & .7154 & .5697 & 1.3360 & 1.0808 & .9337 & .7362 \\
\hline
\end{tabular}


TABLE 21

MONTE CARLO $\sqrt{M S E S}$ FOR ESTIMATING $\mathrm{L}_{\mathrm{p}}$ *

MODEL: LOGLOG $\theta_{1}=0 \quad \theta_{2}=.5$

STARTING LEVELS $(.3, .35, .4)$

$$
\mathrm{p}^{\bullet}=.5 \quad \mathrm{p}^{\bullet}=.75
$$

\begin{tabular}{|c|c|c|c|c|c|c|c|c|}
\hline $\mathbf{N}$ & 10 & 15 & 20 & 30 & 10 & 15 & 20 & 30 \\
\hline \multicolumn{9}{|c|}{$n \cdot A_{n}=1$} \\
\hline RM & .7066 & .6833 & .6480 & .6400 & .5604 & .5240 & .5227 & .5045 \\
\hline AN1 & .9196 & .8516 & .7718 & .6520 & 1.2484 & 2.5337 & 1.5865 & 1.2384 \\
\hline AN2 & 1.5434 & 1.3937 & 1.3246 & 1.0978 & 1.1141 & 1.1135 & 1.1726 & 1.0704 \\
\hline WU1 & .7236 & .7069 & .6443 & .5909 & 2.0421 & 1.6148 & 1.5053 & 1.3977 \\
\hline WU2 & 1.1139 & .7228 & .6440 & .5380 & .8997 & .7083 & .7192 & .6858 \\
\hline SAM & .8331 & .5928 & .5743 & .5047 & 1.0731 & .8258 & .7945 & .7257 \\
\hline \multicolumn{9}{|c|}{$n \cdot A_{n}=6$} \\
\hline RM & .9096 & .7821 & .7477 & .6737 & 1.3688 & 1.2190 & 1.0873 & .9375 \\
\hline AN1 & .8075 & .6567 & .5939 & .4658 & 1.2273 & 1.0416 & 1.0339 & .9204 \\
\hline AN2 & 1.1536 & .9696 & .9632 & .7809 & 1.5869 & 1.4481 & 1.3994 & 1.1659 \\
\hline WU1 & .8108 & .6775 & .6014 & .4835 & 1.6731 & 1.4099 & 1.4068 & 1.2497 \\
\hline WU2 & 1.0434 & .8632 & .8473 & .7221 & 1.5264 & 1.3526 & 1.2299 & 1.0333 \\
\hline SAM & .8823 & .6973 & .6077 & .5097 & 1.1967 & .9610 & .8746 & .7149 \\
\hline \multicolumn{9}{|c|}{$n \cdot A_{n}=36$} \\
\hline RM & 1.2981 & 1.1426 & .9788 & .8051 & 1.8149 & 1.5441 & 1.3558 & 1.1161 \\
\hline AN1 & .9954 & .7438 & .6008 & .4506 & 1.7321 & 1.4625 & 1.3255 & 1.2449 \\
\hline AN2 & 1.4404 & 1.1207 & 1.0144 & .7557 & 1.7413 & 1.4326 & 1.2691 & 1.0521 \\
\hline WU1 & .8217 & .6124 & .5255 & .4247 & 1.6406 & 1.0710 & 1.0124 & .9805 \\
\hline WU2 & 1.1856 & .9032 & .7613 & .6485 & 1.4704 & 1.1196 & .9642 & .8224 \\
\hline SAM & .9955 & .7727 & .6775 & .5394 & 1.1724 & 1.0337 & .8909 & .7157 \\
\hline
\end{tabular}


TABLE 22

MONTE CARLO VMSE FOR ESTIMATING L ${ }_{.25}$ STARTING LEVELS: $(.5, .813, .95)$

LOGIT $\theta_{1}=0, \theta_{2}=1 \quad$ LOGLOG $\theta_{1}=0, \theta_{2}=.5$

\begin{tabular}{|c|c|c|c|c|c|c|c|c|}
\hline $\mathbf{N}$ & 10 & 15 & 20 & 30 & 10 & 15 & 20 & 30 \\
\hline \multicolumn{9}{|c|}{$n \cdot A_{n}=1$} \\
\hline $\begin{array}{l}\text { RM } \\
\text { AN1 } \\
\text { AN2 } \\
\text { WU1 } \\
\text { WU2 } \\
\text { SAM }\end{array}$ & $\begin{array}{r}1.1268 \\
1.2547 \\
1.0963 \\
.7273 \\
1.0993 \\
.8695\end{array}$ & $\begin{array}{r}1.0689 \\
.9646 \\
1.0084 \\
.5978 \\
1.0413 \\
.7264\end{array}$ & $\begin{array}{r}1.0570 \\
.8018 \\
.9638 \\
.6061 \\
1.0008 \\
.6680\end{array}$ & $\begin{array}{r}1.0237 \\
.6215 \\
.9844 \\
.5866 \\
.9391 \\
.4952\end{array}$ & $\begin{array}{r}.8449 \\
1.4685 \\
.8012 \\
1.1015 \\
.8010 \\
1.0379\end{array}$ & $\begin{array}{r}.7869 \\
1.2786 \\
.7076 \\
.7542 \\
.7367 \\
.8329\end{array}$ & $\begin{array}{r}.7807 \\
1.0222 \\
.7144 \\
.8273 \\
.7045 \\
.7470\end{array}$ & $\begin{array}{l}.7418 \\
.7346 \\
.8103 \\
.6181 \\
.6970 \\
.5866\end{array}$ \\
\hline \multicolumn{9}{|c|}{$n \cdot A_{n}=6$} \\
\hline $\begin{array}{l}\text { RM } \\
\text { AN1 } \\
\text { AN2 } \\
\text { WU1 } \\
\text { WU2 } \\
\text { SAM }\end{array}$ & $\begin{array}{r}.8190 \\
.7373 \\
.8917 \\
.9926 \\
.7600 \\
.7026\end{array}$ & $\begin{array}{l}.6270 \\
.6401 \\
.7746 \\
.8956 \\
.6492 \\
.5911\end{array}$ & $\begin{array}{l}.6032 \\
.6411 \\
.7397 \\
.7881 \\
.6215 \\
.5300\end{array}$ & $\begin{array}{l}.4866 \\
.5593 \\
.6267 \\
.7185 \\
.5589 \\
.4337\end{array}$ & $\begin{array}{r}1.0579 \\
1.0493 \\
1.1564 \\
1.4348 \\
1.0584 \\
.8464\end{array}$ & $\begin{array}{r}.8061 \\
.8898 \\
.9169 \\
1.2682 \\
.8548 \\
.7386\end{array}$ & $\begin{array}{r}.7647 \\
.8281 \\
.8865 \\
1.1313 \\
.8439 \\
.6194\end{array}$ & $\begin{array}{r}.6974 \\
.7192 \\
.7614 \\
1.0266 \\
.7870 \\
.5352\end{array}$ \\
\hline \multicolumn{9}{|c|}{$n \cdot A_{n}=36$} \\
\hline $\begin{array}{l}\text { RM } \\
\text { AN1 } \\
\text { AN2 } \\
\text { WU1 } \\
\text { WU2 } \\
\text { SAM }\end{array}$ & $\begin{array}{l}1.5931 \\
1.1791 \\
1.4456 \\
1.6580 \\
1.4050 \\
1.0156\end{array}$ & $\begin{array}{r}1.1894 \\
.9875 \\
1.0889 \\
.8726 \\
.8764 \\
.6835\end{array}$ & $\begin{array}{r}1.0162 \\
.9074 \\
.9323 \\
.7131 \\
.7560 \\
.6021\end{array}$ & $\begin{array}{l}.7706 \\
.8523 \\
.7187 \\
.6264 \\
.5259 \\
.4513\end{array}$ & $\begin{array}{l}1.3626 \\
1.6177 \\
1.0717 \\
2.2801 \\
1.3337 \\
1.0866\end{array}$ & $\begin{array}{r}1.1545 \\
1.4814 \\
.8553 \\
1.5156 \\
1.0901 \\
.8932\end{array}$ & $\begin{array}{r}.9582 \\
1.3738 \\
.7436 \\
1.2455 \\
.8080 \\
.7207\end{array}$ & $\begin{array}{r}.7907 \\
1.2521 \\
.6282 \\
.9331 \\
.6089 \\
.5488\end{array}$ \\
\hline
\end{tabular}




\section{TABLE 23}

MONTE CARLO $\sqrt{ }$ MSE FOR ESTIMATING $L_{\text {.25 }}$ STARTING LEVELS: $(.1, .4, .7)$

\begin{tabular}{|c|c|c|c|c|c|c|c|c|}
\hline \multirow[b]{2}{*}{$\mathrm{N}$} & \multicolumn{2}{|c|}{ LOGIT } & $\theta_{1}=0$, & $\theta_{2}=1$ & LOGLOG & $\theta_{1}=$ & $0, \quad \theta_{2}=$ & \multirow{2}{*}{$\begin{array}{r}.5 \\
30 \\
\end{array}$} \\
\hline & 10 & 15 & 20 & 30 & 10 & 15 & 20 & \\
\hline$\cdot A_{n}$ & $=1$ & & & & & & & \\
\hline $\begin{array}{l}\text { RM } \\
\text { AN1 } \\
\text { AN2 } \\
\text { WU1 } \\
\text { WU2 } \\
\text { SAM }\end{array}$ & $\begin{array}{r}.4990 \\
1.1866 \\
.7104 \\
1.6893 \\
.5907 \\
.7154\end{array}$ & $\begin{array}{r}.4716 \\
1.2198 \\
.6665 \\
1.3160 \\
.5613 \\
.6334\end{array}$ & $\begin{array}{r}.4556 \\
1.0902 \\
.7305 \\
1.2499 \\
.5319 \\
.5300\end{array}$ & $\begin{array}{r}.4330 \\
1.0269 \\
.7666 \\
1.1337 \\
.5160 \\
.4343\end{array}$ & $\begin{array}{r}.6734 \\
1.6242 \\
1.0572 \\
2.6911 \\
.8121 \\
.9571\end{array}$ & $\begin{array}{r}.6451 \\
1.6501 \\
.9666 \\
2.0854 \\
.7733 \\
.7663\end{array}$ & $\begin{array}{r}.6208 \\
1.6795 \\
1.0215 \\
1.9594 \\
.6812 \\
.6217\end{array}$ & $\begin{array}{r}.6117 \\
1.4218 \\
1.0289 \\
1.7532 \\
.6554 \\
.5121\end{array}$ \\
\hline$n \cdot A_{n}$ & $=6$ & & & & & & & \\
\hline $\begin{array}{l}\text { RM } \\
\text { AN1 } \\
\text { AN2 } \\
\text { WU1 } \\
\text { WU2 } \\
\text { SAM }\end{array}$ & $\begin{array}{r}.8982 \\
.7503 \\
1.0477 \\
1.1836 \\
.9614 \\
.7817\end{array}$ & $\begin{array}{l}.7489 \\
.6545 \\
.9669 \\
.9882 \\
.7967 \\
.6553\end{array}$ & $\begin{array}{l}.7003 \\
.5759 \\
.8409 \\
.9081 \\
.7586 \\
.5855\end{array}$ & $\begin{array}{l}.5355 \\
.5139 \\
.7257 \\
.8755 \\
.5800 \\
.4632\end{array}$ & $\begin{array}{r}1.0680 \\
1.1948 \\
1.3816 \\
1.8005 \\
1.2031 \\
.9384\end{array}$ & $\begin{array}{r}.8418 \\
1.0420 \\
1.1839 \\
1.4046 \\
.9839 \\
.8277\end{array}$ & $\begin{array}{r}.7313 \\
.8513 \\
1.0031 \\
1.3015 \\
.8657 \\
.7241\end{array}$ & $\begin{array}{r}.5616 \\
.7795 \\
.8193 \\
1.1618 \\
.6567 \\
.5622\end{array}$ \\
\hline$n \cdot A_{n}$ & $=36$ & & & & & & & \\
\hline $\begin{array}{l}\text { RM } \\
\text { AN1 } \\
\text { AN2 } \\
\text { WU1 } \\
\text { WU2 } \\
\text { SAM }\end{array}$ & $\begin{array}{l}1.5564 \\
1.1645 \\
1.2994 \\
1.5460 \\
1.2495 \\
1.0016\end{array}$ & $\begin{array}{r}1.1777 \\
.9750 \\
.9565 \\
.9169 \\
.8342 \\
.7201\end{array}$ & $\begin{array}{r}1.0117 \\
.9544 \\
.8053 \\
.7175 \\
.6738 \\
.5741\end{array}$ & $\begin{array}{l}.7597 \\
.8536 \\
.6356 \\
.6231 \\
.5059 \\
.4601\end{array}$ & $\begin{array}{l}1.4183 \\
1.7061 \\
1.4965 \\
2.0142 \\
1.0924 \\
1.2227\end{array}$ & $\begin{array}{r}1.1059 \\
1.5724 \\
1.2582 \\
1.2082 \\
.8423 \\
.9092\end{array}$ & $\begin{array}{r}.9750 \\
1.4786 \\
1.0655 \\
.9724 \\
.7020 \\
.7121\end{array}$ & $\begin{array}{r}.7613 \\
1.3964 \\
.8394 \\
.8708 \\
.5747 \\
.5665\end{array}$ \\
\hline
\end{tabular}


TABLE 24

MONTE CARLO VMSE FOR ESTIMATING L .25

STARTING LEVELS: $(.3, .35, .4)$

LOGIT $\theta_{1}=0, \theta_{2}=1 \quad$ LOGLOG $\theta_{1}=0, \theta_{2}=.5$

\begin{tabular}{|c|c|c|c|c|c|c|c|c|}
\hline $\mathbf{N}$ & 10 & 15 & 20 & 30 & 10 & 15 & 20 & 30 \\
\hline \multicolumn{9}{|c|}{$n \cdot A_{n}=1$} \\
\hline $\begin{array}{l}\text { RM } \\
\text { AN1 } \\
\text { AN2 } \\
\text { WU1 } \\
\text { WU2 } \\
\text { SAM }\end{array}$ & $\begin{array}{r}.8961 \\
1.2605 \\
1.3334 \\
1.7436 \\
1.0369 \\
.9578\end{array}$ & $\begin{array}{r}.8073 \\
1.5418 \\
1.2959 \\
1.4712 \\
.7854 \\
.7452\end{array}$ & $\begin{array}{r}.7755 \\
1.1532 \\
1.2075 \\
1.3369 \\
.7339 \\
.6471\end{array}$ & $\begin{array}{r}.7419 \\
1.0771 \\
1.1166 \\
1.2133 \\
.5976 \\
.5355\end{array}$ & $\begin{array}{l}1.3309 \\
1.7769 \\
2.4649 \\
2.9345 \\
1.8223 \\
1.4227\end{array}$ & $\begin{array}{r}1.2376 \\
2.6936 \\
2.1663 \\
2.3625 \\
1.1401 \\
.9218\end{array}$ & $\begin{array}{r}1.1893 \\
1.7967 \\
1.9818 \\
2.0877 \\
.9773 \\
.8015\end{array}$ & $\begin{array}{r}1.1457 \\
1.4782 \\
1.6276 \\
1.8928 \\
.7720 \\
.6704\end{array}$ \\
\hline \multicolumn{9}{|c|}{$n \cdot A_{n}=6$} \\
\hline $\begin{array}{l}\text { RM } \\
\text { AN1 } \\
\text { AN2 } \\
\text { WU1 } \\
\text { WU2 } \\
\text { SAM }\end{array}$ & $\begin{array}{r}.8972 \\
.8028 \\
1.0591 \\
1.1488 \\
1.0273 \\
.8392\end{array}$ & $\begin{array}{l}.7434 \\
.6693 \\
.8760 \\
.9938 \\
.7917 \\
.6699\end{array}$ & $\begin{array}{l}.6818 \\
.5874 \\
.7871 \\
.8706 \\
.7390 \\
.5666\end{array}$ & $\begin{array}{l}.5138 \\
.5200 \\
.6765 \\
.8114 \\
.5709 \\
.4636\end{array}$ & $\begin{array}{r}.8972 \\
.8028 \\
1.0591 \\
1.1488 \\
1.0273 \\
.8392\end{array}$ & $\begin{array}{r}.7434 \\
.6693 \\
.8760 \\
.9938 \\
.7917 \\
.6699\end{array}$ & $\begin{array}{l}.6818 \\
.5874 \\
.7871 \\
.8706 \\
.7390 \\
.5666\end{array}$ & $\begin{array}{l}.5138 \\
.5200 \\
.6765 \\
.8114 \\
.5709 \\
.4636\end{array}$ \\
\hline \multicolumn{9}{|c|}{$n \cdot A_{n}=36$} \\
\hline $\begin{array}{l}\text { RM } \\
\text { AN1 } \\
\text { AN2 } \\
\text { WU1 } \\
\text { WU2 } \\
\text { SAM }\end{array}$ & $\begin{array}{l}1.5148 \\
1.1624 \\
1.1888 \\
1.4624 \\
1.2581 \\
1.0023\end{array}$ & $\begin{array}{r}1.1366 \\
.9773 \\
.9484 \\
.8916 \\
.8275 \\
.7082\end{array}$ & $\begin{array}{r}1.0101 \\
.9501 \\
.7961 \\
.7172 \\
.6508 \\
.6004\end{array}$ & $\begin{array}{l}.7570 \\
.8451 \\
.6276 \\
.6395 \\
.4976 \\
.4595\end{array}$ & $\begin{array}{l}1.5148 \\
1.1624 \\
1.1888 \\
1.4624 \\
1.2581 \\
1.0023\end{array}$ & $\begin{array}{r}1.1366 \\
.9773 \\
.9484 \\
.8916 \\
.8275 \\
.7082\end{array}$ & $\begin{array}{r}1.0101 \\
.9501 \\
.7961 \\
.7172 \\
.6508 \\
.6004\end{array}$ & $\begin{array}{l}.7570 \\
.8451 \\
.6276 \\
.6395 \\
.4976 \\
.4595\end{array}$ \\
\hline
\end{tabular}


where $c_{L}=2 p(1-p) \ln [(1-p) / p] /\left(L_{1-p}-L_{p}\right)$. When the true expectation, $M(x)$, is the two parameter logit model, (58) reduces to

$$
\begin{aligned}
& \hat{L}_{p} \sim N\left(L_{p^{\prime}}\left\{n \theta_{2}^{2} p(1-p)\right\}^{-1}\right) \text { and } \\
& \hat{L}_{1-p} \sim N\left(L_{1-p^{\prime}}\left\{n \theta_{2}^{2} p(1-p)\right\}^{-1}\right) .
\end{aligned}
$$

Thus, using (38) and (58), when $M(x)$ is the two parameter logit model,

$$
\hat{\mathrm{L}}_{\mathrm{p}^{*}} \sim \mathrm{N}\left(\mathrm{L}_{\mathrm{p}^{*}},\left\{\mathrm{n} \theta_{2}^{2} \mathrm{p}(1-\mathrm{p})\right\}^{-1}\left\{1-2 \mathrm{r}+2 \mathrm{r}^{2}\right\}\right)
$$

where $\mathrm{r}=(1 / 2)+\left\{\ln \left[\left(1-\mathrm{p}^{*}\right) / \mathrm{p}^{*}\right] / 2 \cdot \ln [(1-\mathrm{p}) / \mathrm{p}]\right\}$.

The square of the values in Tables $8-24$ are averages of $\mathrm{n}^{*}\left(\mathrm{n}^{*}=\mathrm{n}^{\prime}\right.$ for initial procedure 1 and $\mathrm{n}^{*}=500$ for initial procedure 2) individual mean squares, $\left(\hat{L}_{p^{*}}-L_{p^{*}}\right)^{2}$. Define the random variable $S=\left(\hat{\mathrm{L}}_{\mathrm{p}^{*}}-\mathrm{L}_{\mathrm{p}^{*}}\right)^{2}$. Using (60), asymptotically, $s^{*}=s \cdot\left\{1-2 r+2 r^{2}\right\}^{-1} \cdot\left\{n \theta_{2}^{2} p(1-p)\right\} \sim \chi_{1}^{2} \cdot$ This implies the asymptotic variance of $S$ is $2 \cdot\left(1-2 r+2 r^{2}\right)^{2} /$ $\left(n \theta_{2}^{2} p(1-p)\right)^{2}$. By the central limit theorem, an average of $\mathrm{n}^{*}$ of these random variables is approximately normal with a variance of $2 \cdot\left(1-2 r+r^{2}\right)^{2} / n^{*}\left(n \theta_{2}^{2} p(1-p)\right)^{2}$.

The same approach can be followed for $\hat{\mathrm{L}}_{.5}$ from wU1, using the asymptotic equivalence of $\mathrm{Wu}^{\prime} \mathrm{s}$ procedure and the optimal RM process. Tables 25 and 26 give the asymptotic standard errors of SAM's and WU1's MSEs for $n^{*}=365$ and $n^{*}=$ 500 , respectively, when $M(x)$ is given by the two parameter logit model. 
TABLE 25

ASYMPTOTIC (MSE) STANDARD ERRORS $\left(\mathrm{n}^{*}=365\right)$

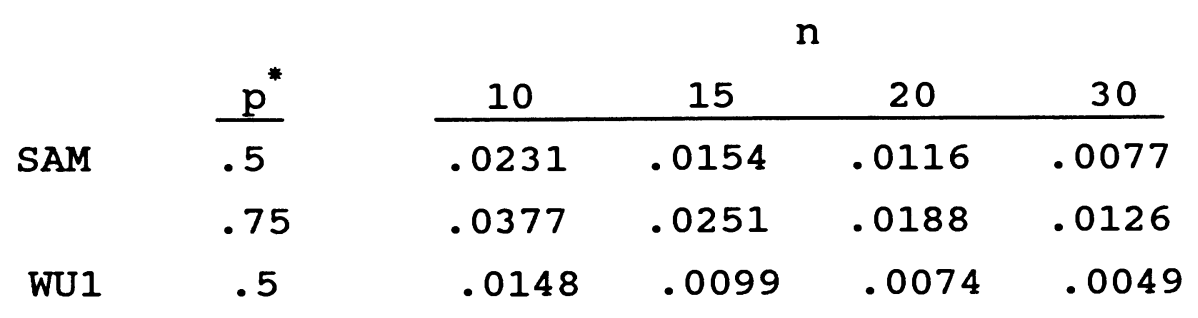

TABLE 26

ASYMPTOTIC (MSE) STANDARD ERRORS $\left(\mathrm{n}^{*}=500\right)$

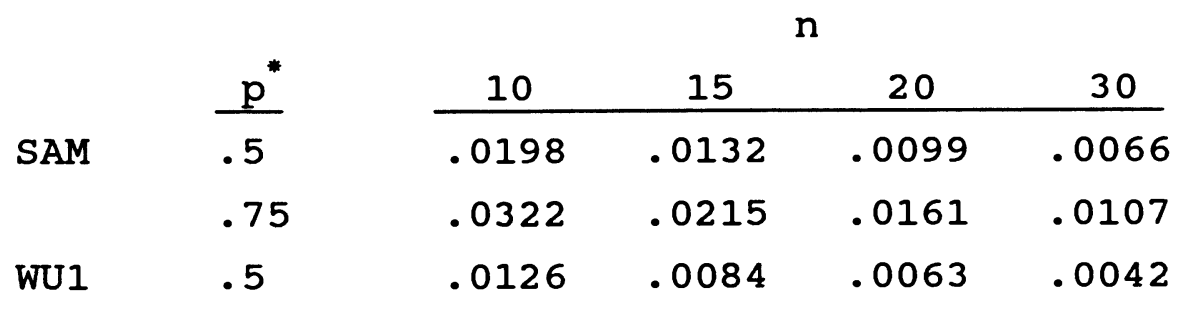

These values have been developed assuming the true expectation is the two parameter logit. Thus, they are appropriate for comparing SAM and WU1's MSEs in Tables 8, 9, 16, 17 and 18. If $M(x)$ differs from the two parameter logit, then $\hat{\mathrm{L}}_{\mathrm{p}^{*}}$ may be biased. Moser and Fei (1989b) provide a detailed discussion of the biases and MSEs for a two dimensional Robbins Monro process.

The above results are based upon asymptotic theory. However, small to medium sample sizes were used in the simulation study. A second approach to estimating the variance of the MSEs is to use the simulation results. 
During the simulation study, the sample standard deviation of $S=\left(\hat{L}_{p^{*}}-L_{p^{*}}\right)^{2}$ was calculated for each procedure. Table 27 contains the standard errors of $\mathrm{S}$ from initial procedure 1 when the logit model was used to generate the binary responses.

TABLE 27

$$
\text { SIMULATION STANDARD ERRORS }\left(\mathrm{n}^{*}=365\right)
$$

\begin{tabular}{lllcccc}
\multirow{2}{*}{ Procedure } & \multicolumn{5}{c}{$\mathrm{p}$} & \multicolumn{5}{c}{$\mathrm{p}$} & & 10 & 15 & 20 & 30 \\
\cline { 4 - 7 } SAM & .5 & & .0247 & .0178 & .0143 & .0084 \\
\multirow{2}{*}{ WU1 } & .75 & .0532 & .0348 & .0253 & .0137 \\
& .5 & .0230 & .0194 & .0112 & .0065 \\
& .75 & .0764 & .0618 & .0462 & .0268
\end{tabular}

In every case, the difference between the asymptotic (Table 25) and simulation standard errors (Table 27) is smaller for SAM than for WUI. Using the simulation standard errros from Table 27 , denoted by $s_{\mathrm{SAM}} / V_{\mathrm{n}}{ }^{*}$ and $\mathrm{s}_{\mathrm{WU} 1} / V_{\mathrm{n}}{ }^{*}$, the least significant difference between MSEs from SAM and WU1 can be constructed. For example, the least significant differences for the MSEs, $z_{\alpha / 2} \cdot\left(\frac{1}{n^{*}} \cdot\left(s_{S A M}^{2}+s_{W{ }_{1}}^{2}\right)\right)^{1 / 2}$, are given in Table 28 
TABLE 28

LEAST SIGNIFICANT DIFFERENCE FOR SAM AND

WU1 MSES $\left(n^{*}=365, \alpha=.05\right)$

n

\begin{tabular}{l|cccc}
$\mathrm{p}$ & 10 & 15 & 20 & 30 \\
\hline .5 & .0662 & .0516 & .0356 & .0208 \\
.75 & .1825 & .1390 & .1032 & .0600
\end{tabular}

The least significant differences of Table 28 are now used to compare the MSEs produced by SAM and WU1 in Tables 8 and 9. Tables 8 and 9 present the MSEs from each procedure for four sample sizes and three upper bounds. Thus, in each table, there are 12 comparisons between SAM and WU1's MSES for $\hat{L}_{.5}$ and 12 for $\hat{L}_{.75^{\circ}}$ (For each sample size $(n=10,15$, $20,30)$, the MSE of SAM-10 is compared with the MSE of WU1-10, SAM-50 is compared with WU1-50, and SAM-100 is compared with WU1-100) In Table 29, the results of these comparisons over both tables are presented. The number of times that each procedure produced a MSE significantly lower $(\alpha=.05)$ than the other procedure is given for each sample size. Note that for each sample size, there are a total of $\operatorname{six} \hat{\mathrm{L}}_{.5}$ comparisons and six $\hat{\mathrm{L}}_{.75}$ comparisons (three from each table). 
TABLE 29

NUMBER OF SIGNIFICANT DIFFERENCES

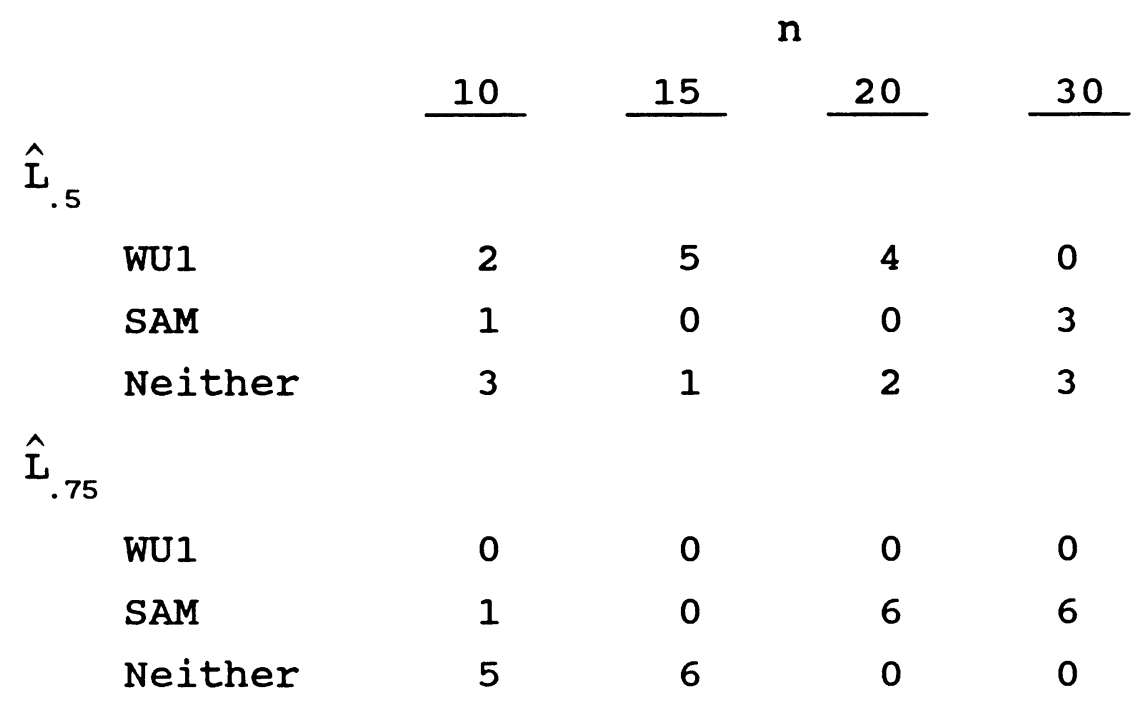

It is clear that SAM produces significantly $(\alpha=.05)$ lower $\hat{L}_{.75}$ MSEs for the larger sample sizes $(n=20,30)$. For estimating $\mathrm{L}_{.5}$, WUl produces significantly lower MSEs when $\mathrm{n}=15,20$. However, wUl's advantage did not hold for $\mathrm{n}=10,30$ 
CHAPTER V

CONCLUSIONS

SAM provides a new approach to estimating multiple roots of an expectation function. A parametric model is used to produce SAM's estimators, although the true expectation is assumed unknown. To produce estimators for binary data, SAM, with the two parameter logit model, is recommended. A first order approximation to the logit version of SAM was shown to be asymptotically equivalent to a two dimensional Robbins-Monro process. Under certain restrictions, SAM's estimators were proven to be consistent. In the binary data simulation study, SAM performed well compared to other sequential approximation methods. SAM performed particularly well when estimating multiple roots. SAM was relatively unaffected by the choice of bounds on the step size and designs used to generate the initial levels. Criteria for selecting the values of $p_{1}, \ldots, p_{k}$ to use in SAM were presented in Chapter II. For the two parameter logit model, using $\mathrm{p}_{1}=.2$ and $\mathrm{p}_{2}=.8$ is recommended. The pair $\left(p_{1}, p_{2}\right)=(.2, .8)$ was found to be either optimal (in the minimum average sense) or near optimal in the situations discussed in Chapter II. Also, using $\left(p_{1}, p_{2}\right)=(.2, .8)$, SAM 
performed well for estimating multiple roots in the simulation study.

In order to use SAM's updating rule, MLEs must exist. Therefore, some procedure other than SAM must be used for the initial updates. Two methods for obtaining the initial design levels have been presented in this paper. The first approach is to select an initial set of design levels and observe a fixed number of samples at these levels (initial procedure 1). If MLEs do not exist after these initial observations, then more design levels would have to be selected. A second approach is to use a RM procedure, then switch to SAM when the MLEs exist. If little information about the location of the roots of $M(x)$ is available prior to the experiment, then the second approach is recommended. 


\section{BIBLIOGRAPHY}

Anbar, D. (1977), "A Stochastic Newton-Raphson Method," Journal of Statistical Planning and Inference, 2, 153 164 .

Anton, H. (1980), Calculus With Analytic Geometry, New York: wiley.

Blum, J. R. (1954), "Approximation Methods Which Converge With Probability one," Annals of Mathematical Statistics, 25, $382-386$.

Chung, K. L. (1954), "On a Stochastic Approximation Method," Annals of Mathematical Statistics, 25, $463-483$.

Cochran, W. G. and Davis, M (1965), "The Robbins-Monro Method for Estimating the Median Lethel Dose," Journal of the Royal Statistical Society, Series $B, 27,28-44$.

Cox, D. R. (1975), "Partial Likelihood," Biometika, 62, $269-276$.

Crowder, M. J. (1975), "Maximum Likelihood Estimation for Dependent Observations," Journal of the Royal Statistical Society, Series $B, 38,45-53$.

Davis, M. (1971), "Comparisons of Sequential Bioassays in Small Samples," Journal of the Royal statistical Society, Series $B, 33,78-87$.

Dixon, W. J. and Mood, A. M. (1948), "A Method for obtaining and Analyzing Sensitivity Data," Journal of the American Statistical Association, 43, $109-126$. 
Dubins, L. E. and Freeman, P. R. (1965), "A Sharper Form of the Borel-Cantelli Lemma and the Strong Law," Annals of Mathematical statistics, 36, $800-807$.

Fei, W. C. (1989), "A New Method for the Robbins-Monro Stochastic Approximation Procedure," unpublished Ph.D. thesis, Oklahoma State University, May, 1989.

Freeman, P. R. (1970), "Optimal Bayesian Sequential Estimation of the Median," Biometrika, 57, $79-89$.

Lord, F. M. (1971), "Tailored Testing, An Application of Stochastic Approximation," Journal of the American Statistical Association, 66, 707 - 711 .

Langlie, H. J. (1962), "A Reliability Test Method for one Shot Items," U-1792, Ford Motor Co., Newport Beach, California.

Lai, T. L. and Wei, C. Z. (1982), "Least Squares Estimates in Stochastic Regression Models with Applications to Identification and Control of Dynamic Systems," Annals of statistics, 10, 154-166.

McCullagh, P. (1981), Discussion of "Randomized Allocation of Treatments in Sequential Experiments," by Bather, Journal of the Royal statistical Society, Series $B, 43$, $286-287$.

Maron, M. J. (1982), Numerical Analysis, A Practical Approach, New York: Macmillan.

Mood, A. M., Graybill, F. A. and Boes D. C. (1974), Introduction to the Theory of statistics, McGraw-Hill: Tokyo.

Moser, B. K. and Fei, W. C. (1989a), "A New Adaptive Robbins-Monro Procedure," submitted to Metrika, Nov., 1989. 
Moser, B. K. and Fei, W. C. (1989b), "Bias and optimal Root Selection for a New Adaptive Robbins-Monro Procedure," submitted to Metrika, Nov., 1989.

Neyer, B. T. (1989), "More Efficient Sensitivity Testing," EGG Mound Applied Technologies, Miamisburg, Ohio.

Robbins, H. and Monro, S. (1951), "A Stochastic Approximation Method," Annals of Mathematical Statistics, 29, 400 407.

Sacks, J. (1958), "Asymptotic Distribution of Stochastic Approximation Procedures," Annals of Mathematical Statistics, 29, $373-405$.

SAS Institute Inc., (1985), SAS User's Guide: Basics, Version 5 Edition, Cary N.C..

Serfling, R. J. (1980), Approximation Theorems of Mathematical Statistics, New York: Wiley.

Silvapulle, M. J. (1981), "On the Existence of Maximum Likelihood Estimators for the Binomial Response Model," Journal of the Royal statistical Society, Series B, 43, $310-313$.

Venter, J. H. (1967), "An Extension of the Robbins-Monro Procedure," Annals of Mathematical Statistics, 38, $181-190$.

Wetherill, G. B. (1963), "Sequential Estimation of Quantal Response Curves," Journal of the Royal statistical Society, Series $B, 25,1-48$.

Wu, C. F. J. (1985), "Efficient Sequential Designs With Binary Data," Journal of the American Statistical Society, $80,974-983$.

Wei, C. Z. (1985), "Asymptotic Properties of Least-Squares Estimates in Stochastic Regression Models," The Annals of statistics,13, 1498 - 1508 . 


\section{APPENDIX A}

PROOF OF THEOREM 1

Theorem 1. Let $x_{1,1}, y_{1,1}, \ldots, x_{n, k}, y_{n, k}$ be a sequence of design levels and binary responses from SAM (9), where $G\left(x \mid \theta_{1}, \theta_{2}\right)$ is the two parameter logit expectation. Assume that the MLE, $\left(\hat{\theta}_{1}^{(n)}, \hat{\theta}_{2}^{(n)}\right)$, converges almost surely to a constant, $\left(\theta_{1}^{*} \theta_{2}^{*}\right), \theta_{2}^{*} \neq 0$. Also, assume that $M(x)$ is an increasing function of $x$. Then $\hat{L}_{p_{1}}^{(n)}$ and $\hat{L}_{p_{2}}^{(n)}$ from SAM converge almost surely to $L_{p_{1}}$ and $L_{p_{2}}$, respectively.

Proof: Since $\left(\hat{\theta}_{1}, \hat{\theta}_{2}\right)$ converges almost surely to $\left(\theta_{1}^{*}, \theta_{2}^{*}\right), x_{n+1,1}$ and $x_{n+1,2}$ converge almost surely to constants $x_{1}^{*}$ and $x_{2}^{*}$, respectively. It will be demonstrated that $\mathrm{x}_{1}^{*}=\mathrm{L}_{\mathrm{p}_{1}}$ and $\mathrm{x}_{2}^{*}=\mathrm{L}_{\mathrm{p}_{2}}$.

From SAM (9), $G\left(x_{n+1,1} \mid \hat{\theta}_{1}^{(n)}, \hat{\theta}_{2}^{(n)}\right)=p_{1}, i=1,2$. As $n$ $-->\infty$, this implies

$$
G\left(x_{1}^{*} \mid \theta_{1}^{*}, \theta_{2}^{*}\right)=p_{1} \text { and } G\left(x_{2}^{*} \mid \theta_{1}^{*}, \theta_{2}^{*}\right)=p_{2}
$$

From (19), the normal equations are 


$$
\begin{aligned}
(1 / n) \cdot \sum_{1}^{n} \sum_{j}^{2} G\left(x_{1 j} \mid \theta_{1}, \theta_{2}\right) & =(1 / n) \cdot \sum_{1}^{n} \sum_{j}^{2} y_{1 j} \\
(1 / n) \cdot \sum_{1}^{n} \sum_{j}^{2} x_{1 j} \cdot G\left(x_{1 j} \mid \theta_{1}, \theta_{2}\right) & =(1 / n) \cdot \sum_{1}^{n} \sum_{j}^{2} x_{1 j} \cdot y_{1 j}
\end{aligned}
$$

From (61), the left hand sides of the normal equations converge almost surely to $\left(p_{1}+p_{2}\right)$ and $\left(x_{1}^{*} p_{1}+x_{2}^{*} p_{2}\right)$, respectively. From the convergence of the MLEs and Theorem 1 of Dubins and Freedman (1965),

$$
\frac{1}{n} \cdot \sum_{1}^{n} \sum_{j}^{2} y_{1 j}-->M\left(x_{1}^{*}\right)+M\left(x_{2}^{*}\right) \text { almost surely. }
$$

Thus, the likelihood equations imply

$$
\begin{gathered}
\mathrm{p}_{1}+\mathrm{p}_{2}=\mathrm{M}\left(\mathrm{x}_{1}^{*}\right)+\mathrm{M}\left(\mathrm{x}_{2}^{*}\right) \text { and } \\
\mathrm{x}_{1}^{*} \cdot \mathrm{p}_{1}+\mathrm{x}_{2}^{*} \cdot \mathrm{p}_{2}=\mathrm{x}_{1}^{*} \cdot \mathrm{M}\left(\mathrm{x}_{1}^{*}\right)+\mathrm{x}_{2}^{*} \cdot \mathrm{M}\left(\mathrm{x}_{2}^{*}\right) \cdot
\end{gathered}
$$

Solving these equations yields $x_{1}^{*}=L_{p_{1}}$ and $x_{2}^{*}=L_{p_{2}}$. 


\section{APPENDIX B}

\section{PROOF OF THEOREM 2}

Theorem 2. Let $\mathrm{Y}$ be a binary random variable with expectation $M(x)$. Assume that $M(x)=G(x \mid \theta)$, where $\theta$ is a single unknown parameter. That is, the model, $G(x \mid \theta)$, used in SAM is the true expectation of $\mathrm{Y}$. The design levels, $\mathrm{x}_{\mathrm{i}}$, are assumed to be such that $0<\mathrm{K}_{1}<\mathrm{p}_{1}=\mathrm{M}\left(\mathrm{x}_{1}\right)<\mathrm{K}_{2}<1$, for some constants $\mathrm{K}_{1}, \mathrm{~K}_{2}$. Assume the standard regularity conditions on the distribution of $\mathrm{Y}$ (given below) hold. If the following conditions are also satisfied, then $\hat{L}_{p}$ from SAM converges to $L_{p}$ in probability.

1) $M(x \mid \theta)$ is continuous in $\theta$.

2) $\exists \delta_{1}, \delta_{2} \in \mathrm{R}$, such that $\delta_{1}<\partial \mathrm{M}(\mathrm{x}, \theta) / \partial \theta<\delta_{2}, \forall \theta$ in some neighborhood of the true value of $\theta, \theta_{0}$, and $\forall \mathbf{x} \in$ $\left(\mathrm{K}_{1}, \mathrm{~K}_{2}\right)$

3) $\partial^{2} M(x, \theta) / \partial \theta^{2}$ is bounded $\forall \theta$ in some neighborhood of the true value of $\theta, \theta_{0}$, and $\forall x \in\left(K_{1}, K_{2}\right)$

Regularity Conditions: from serfling (1981),

Let $\Theta$ be an open interval in $\mathbb{R}$ and $f(y)$ be the p.m.f. of Y • 
a) For each $\theta \in \Theta$, the derivatives

$$
\frac{\partial \log f(y ; \theta)}{\partial \theta}, \frac{\partial^{2} \log f(y ; \theta)}{\partial \theta^{2}}, \frac{\partial^{3} \log f(y ; \theta)}{\partial \theta^{3}}
$$

exist, all y;

b) For each $\theta_{0} \in \Theta$, there exists functions $g(y), h(y)$ and $H(y)$ such that for $\theta$ in a neighborhood $N\left(\theta_{0}\right)$ the relations

$$
\begin{aligned}
\left|\frac{\partial \log f(y ; \theta)}{\partial \theta}\right| \leq g(y),\left|\frac{\partial^{2} \log f(y ; \theta)}{\partial \theta^{2}}\right| \leq h(y), \text { and } \\
\left|\frac{\partial^{3} \log f(y ; \theta)}{\partial \theta^{3}}\right| \leq H(y)
\end{aligned}
$$

hold, all $y$, and

$\sum g(y)<\infty, \sum h(y)<\infty, E\{H(y)\}<\infty$ for $\theta \in N\left(\theta_{0}\right)$;

c) For each $\theta \in \Theta$,

$$
0<E\left[\left(\frac{\partial \log f(y, \theta)}{\partial \theta}\right)^{2}\right]<\infty \text {. }
$$

proof :

Let $x_{1}, \ldots, x_{n}$ and $y_{1}, \ldots, y_{n}$ be the design levels and responses from SAM (9). By section 5 of Wu (1985), $\hat{\mathrm{L}}_{\mathrm{p}}$ converges to $L_{p}$ in probability, if the MLE, $\hat{\theta}$, converges to $\theta$ in probability. To prove $\hat{\theta}$ converges to $\theta_{0}$, the results of Crowder (1975) are used. Following Crowder's notation,

$$
\begin{aligned}
& l_{n}(\theta)=\sum_{1}^{n} \ln \left\{P\left(y_{i}=1 \mid x_{1}, y_{1} \ldots, y_{1-1}\right)\right\} \\
&= \sum_{1}^{n}\left(y_{1} \cdot \ln \left\{p_{1}\right\}+\left(1-y_{1}\right) \cdot \ln \left\{1-p_{i}\right\}\right), \\
& l_{n}^{\prime}(\theta)=\partial l_{n}(\theta) / \partial \theta=\sum_{1}^{n}\left(\partial p_{1} / \partial \theta\right) \cdot \frac{y_{i}-p_{i}}{p_{i}\left(1-p_{1}\right)},
\end{aligned}
$$




$$
\begin{aligned}
I_{n}^{\prime \prime}(\theta)= & \sum_{1}^{n}\left(\frac { y _ { 1 } - p _ { 1 } } { p _ { 1 } ( 1 - p _ { 1 } ) } \cdot \left[\left(\partial^{2} p_{1} / \partial \theta^{2}\right) \cdot p_{1} \cdot\left(1-p_{1}\right)-\right.\right. \\
& \left.\left.\left(\partial p_{1} / \partial \theta\right)^{2} \cdot\left(1-2 \cdot p_{1}\right)\right]-\frac{\left(\partial p_{1} / \partial \theta\right)^{2}}{p_{1}\left(1-p_{1}\right)}\right), \\
B_{n}= & E(-1 \cdot(\theta))=\sum_{1}^{n} E\left(\frac{\left(\partial p_{1} / \partial \theta\right)^{2}}{p_{1}\left(1-p_{1}\right)}\right) .
\end{aligned}
$$

By equation (2.3) of Crowder (1975), $\hat{\theta}_{n}$ converges in probability to $\theta$, if $\exists \Delta>0$ and a sequence $\left\{v_{n}\right\}$ tending to infinity, such that

$$
\mathrm{P}\left\{-\mathrm{v}_{\mathrm{n}}^{-1 / 2} \cdot\left(\theta^{*}-\theta_{0}\right)^{2} \cdot \mathrm{B}_{\mathrm{n}}^{1 / 2} \cdot \mathrm{I}^{\prime}\left(\theta^{*}\right) \geq \delta^{2}\right\}---->1 \text { as } \mathrm{n}--->\infty,
$$

when $\left|\theta^{*}-\theta_{0}\right|=\delta \leq \Delta$.

To show (69) holds, a lower bound for the expression $-\mathrm{B}_{\mathrm{n}}^{-1 / 2} \cdot 1^{\prime \prime}\left(\theta^{*}\right)$ will be derived. Define $\mathrm{p}_{1}^{*}=\mathrm{M}\left(\mathrm{x}_{1}, \theta^{*}\right)$. By the continuity of $M(x, \theta)$, for all $\varepsilon>0, \exists \Delta$ such that $\mid p_{1}-$ $\mathrm{p}_{1}^{*} \mid<\varepsilon$. Define $\delta_{1},\left(\delta_{1},<\delta_{1}\right)$ to be the lower bound of $\left(\partial \mathrm{p}_{1}^{*} / \partial \theta\right)=\left.\left(\partial \mathrm{M}\left(\mathrm{x}_{1} \theta\right) / \partial \theta\right)\right|_{\theta=\theta^{*}}$, for $\theta^{*} \in\left(\theta_{0}-\Delta, \theta_{0}+\Delta\right)$.

$$
\begin{gathered}
\text { Now, }-I^{\prime \prime}\left(\theta^{*}\right) \cdot \mathrm{B}_{\mathrm{n}}^{-1 / 2}=\frac{\mathrm{T}_{1}-\mathrm{T}_{2}}{\mathrm{~T}_{3}} \text {, where } \\
\mathrm{T}_{1}=\sum_{1}^{\mathrm{n}} \frac{\left(\partial \mathrm{p}_{1}^{*} / \partial \theta\right)^{2}}{\mathrm{p}_{1}^{*} \cdot\left(1-\mathrm{p}_{1}^{*}\right)}, \\
\mathrm{T}_{2}=\sum_{1}^{n} \frac{\mathrm{Y}_{1}-\mathrm{p}_{1}^{*}}{\mathrm{p}_{1}^{*} \cdot\left(1-\mathrm{p}_{1}^{*}\right)} \cdot\left[\left(\partial^{2} \mathrm{p}_{1}^{*} / \partial \theta^{2}\right) \cdot \mathrm{p}_{1}^{*}\left(1-\mathrm{p}_{1}^{*}\right)-\left(\partial \mathrm{p}_{1}^{*} / \partial \theta\right)^{2}\left(1-2 \mathrm{p}_{1}^{*}\right)\right], \\
\mathrm{T}_{3}=\left[\sum_{1}^{\mathrm{n}} \mathrm{E}\left(\frac{\left(\partial \mathrm{p}_{1} / \partial \theta\right)^{2}}{\mathrm{p}_{1} \cdot\left(1-\mathrm{p}_{1}\right)}\right)\right]^{1 / 2} .
\end{gathered}
$$


Since $\left(\partial \mathrm{p}_{1}^{*} / \partial \theta\right)>\delta_{1}$,

$$
T_{1} \geq 4 \cdot n \cdot \delta_{1}^{2}
$$

$T_{2}$ is equivalent to $\sum_{1}^{n}\left(y_{1}-p_{1}\right) \cdot q_{1}^{*}+\sum_{1}^{n}\left(p_{1}-p_{1}^{*}\right) \cdot q_{1}^{*}$, where

$$
q_{1}^{*}=\frac{1}{p_{1}^{* 2}\left(1-p_{1}^{*}\right)^{2}} \cdot\left[\left(\partial^{2} p_{1}^{*} / \partial \theta^{2}\right) \cdot p_{1}^{*}\left(1-p_{1}^{*}\right)-\left(\partial p_{1}^{*} / \partial \theta\right)^{2}\left(1-2 \cdot p_{1}^{*}\right)\right]
$$

By Theorem $C$ of Serfling $(1980, p \cdot 27),(1 / n) \cdot \sum_{1}^{n}\left(y_{1}-p_{1}\right) \cdot q_{1}^{*}$

$--->0$, in probability. Also, $\Delta$ can be chosen small enough such that $\left(p_{1}-p_{1}^{*}\right) \cdot q_{1}^{*}<\delta_{1}^{2}, \forall i$. Therefore,

$$
\mathrm{T}_{2} \leq \mathrm{n} \cdot \delta_{1}^{2},
$$

The random variable $\left(\frac{\left(\partial p_{1} / \partial \theta\right)^{2}}{p_{1} \cdot\left(1-p_{1}\right)}\right)$ is bounded, therefore, its expectation is bounded by a positive upper bound, say $\delta_{3}$. Thus,

$$
\begin{gathered}
T_{3} \leq\left(n \cdot \delta_{3}\right)^{1 / 2} \\
\text { Using }(70),(71),(72), \text { and }(74), \text { as } n--->\infty, \\
-I^{\prime \prime}\left(\theta^{*}\right) \cdot B_{n}^{-1 / 2} \geq \frac{n \cdot\left(4 \cdot \delta_{1}^{2},-\delta_{1}^{2}\right)}{\left(n \cdot \delta_{3}\right)^{1 / 2}}=\sqrt{ } n\left(\frac{3 \cdot \delta_{1}^{2}}{\delta_{3}^{1 / 2}}\right)--->\infty
\end{gathered}
$$

A sequence $\left\{v_{n}\right\}$ tending to infinity can now be chosen to satisfy (69). For example, let $\left\{v_{n}\right\}=\sqrt{ } n \cdot\left(\frac{3 \cdot \delta_{1}^{2}}{2 \cdot \delta_{3}^{1 / 2}}\right)$.

Therefore, $\hat{\theta}_{n}-->\theta_{0}$ and $\hat{L}_{p}--->L_{p}$, in probability. 
APPENDIX C

PROOF OF THEOREM 4

Theorem 3. Assuming $\left(x_{n, 1}, x_{n, 2}\right)$ from SAM (9) converge almost surely to $\left(L_{p}, L_{1-p}\right), \hat{\lambda}_{n}$ as defined in (24) converges almost surely to $c_{L}=2 p(1-p) \cdot \ln [(1-p) / p] /\left(L_{1-p}-L_{p}\right)$.

Proof:

Unless otherwise specified, the summations in this proof on $i$ run from $1, \ldots, n$, and for $j$ run from 1 to 2 . Rewrite (24) as

$$
\hat{\lambda}_{n}=\lambda_{n}^{*}-\frac{c^{*} \cdot \sum\left(x_{12}-x_{11}\right)}{\sum \sum\left(x_{1 j}-\bar{x}_{n}\right)^{2}},
$$

where $\lambda_{n}^{*}=\frac{\sum \sum y_{1,}\left(x_{1 j}-\bar{x}_{n}\right)}{\sum \sum\left(x_{1 j}-\bar{x}_{n}\right)^{2}}, \bar{x}_{n}=\sum \sum x_{1 j} / 2 \cdot n$, and $c^{*}=$ $(1 / 2)-p-p(1-p) \cdot \ln \{(1-p) / p\}$. Let $\alpha=(1-2 p) /\left(L_{1-p}-L_{p}\right)$ denote the slope of the line through $\left(L_{p}, p\right)$ and $\left(L_{1-p}, 1-p\right)$. Assuming $x_{n, 1}-\underline{a}-\underline{s} \dot{-}>L_{p}$ and $x_{n, 2}-\underline{a} \cdot \underline{s} \dot{-}>L_{1-p}$, the second term on the right hand side of (75) converges to $2 \cdot c^{*} \cdot \alpha /(1-2 p)$, since

$$
\begin{aligned}
\frac{c^{*} \cdot \sum\left(x_{12}-x_{11}\right)}{\sum \sum\left(x_{1 j}-\bar{x}_{n}\right)^{2}}-\underline{a} \cdot-\underline{s}-> & \frac{c^{*} n \cdot\left(L_{1-p}-L_{p}\right)}{n\left(L_{1-p}-L_{p}\right)^{2} / 2} \\
& =2 \cdot c^{*} \cdot \alpha /(1-2 p) .
\end{aligned}
$$


By Theorem 1 of Lai and Wei (1982) and Theorem 2 of Wei (1985), the first term of the right hand side side of (75), $\lambda_{n}^{*}$, converges almost surely to $\alpha$ if the eigenvalues, $\xi$, of

$$
\left(\begin{array}{cc}
2 \cdot n & 0 \\
0 & \sum \sum\left(x_{1, j}-\bar{x}_{n}\right)^{2}
\end{array}\right)
$$

satisfy

1. $\xi_{\min }(n)--->\infty$ a.s.,

2. $\log \xi_{\max }(n)=\circ\left(\xi_{\min }(n)\right)$ a.s..

However, conditions 1 and 2 are satisfied since

$$
\begin{aligned}
& \sum_{i j}\left(x_{1 j}-\bar{x}_{n}\right)^{2} \\
& =\sum_{i}\left(x_{11}-\bar{x}_{n 1}\right)^{2}+\sum_{i}\left(x_{12}-\bar{x}_{n 2}\right)^{2}+n\left(\bar{x}_{n 1}-\bar{x}_{n}\right)^{2}+n\left(\bar{x}_{n 2}-\bar{x}_{n}\right)^{2} \\
& =O(n), \\
& \text { where } \bar{x}_{n j}=\sum_{i}^{n} x_{1 j} / n, j=1,2 \text { Therefore, } \\
& \lambda_{n}^{*}-\underline{a}-\underline{s}->\alpha
\end{aligned}
$$

Since

$$
\alpha\left\{1-\left[2 c^{*} /(1-2 p)\right\}=\frac{2 p(1-p) \cdot \ln [(1-p) / p]}{L_{1-p}-L_{p}},\right.
$$

(76) and (79) imply $\hat{\lambda}_{n}-\underline{a} \cdot \underline{s}-->c_{L}$. Q.E.D. 
APPENDIX D

SAS CODE FOR THE SIMULATION STUDY

The following is the SAS code (SAS Institute, Inc.)

used in the simulation study for initial procedure 1. The program actually produced the MSEs for each procedure in the $\mathrm{n}=20$ column of Table 9. The other values were generated by changing the sample size $\mathrm{n}$ and the formulas used to generate the binary responses.

DATA ONE;

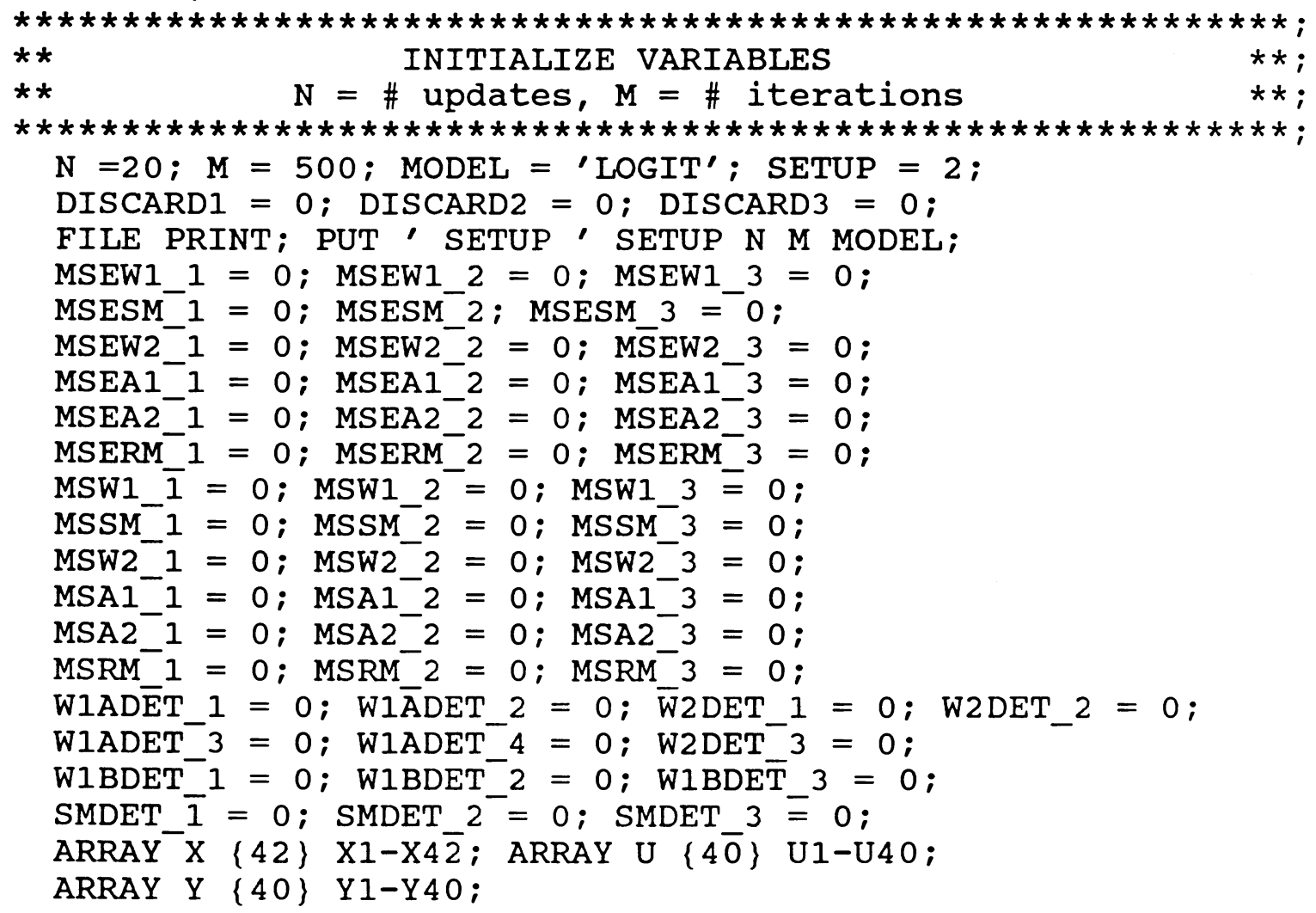




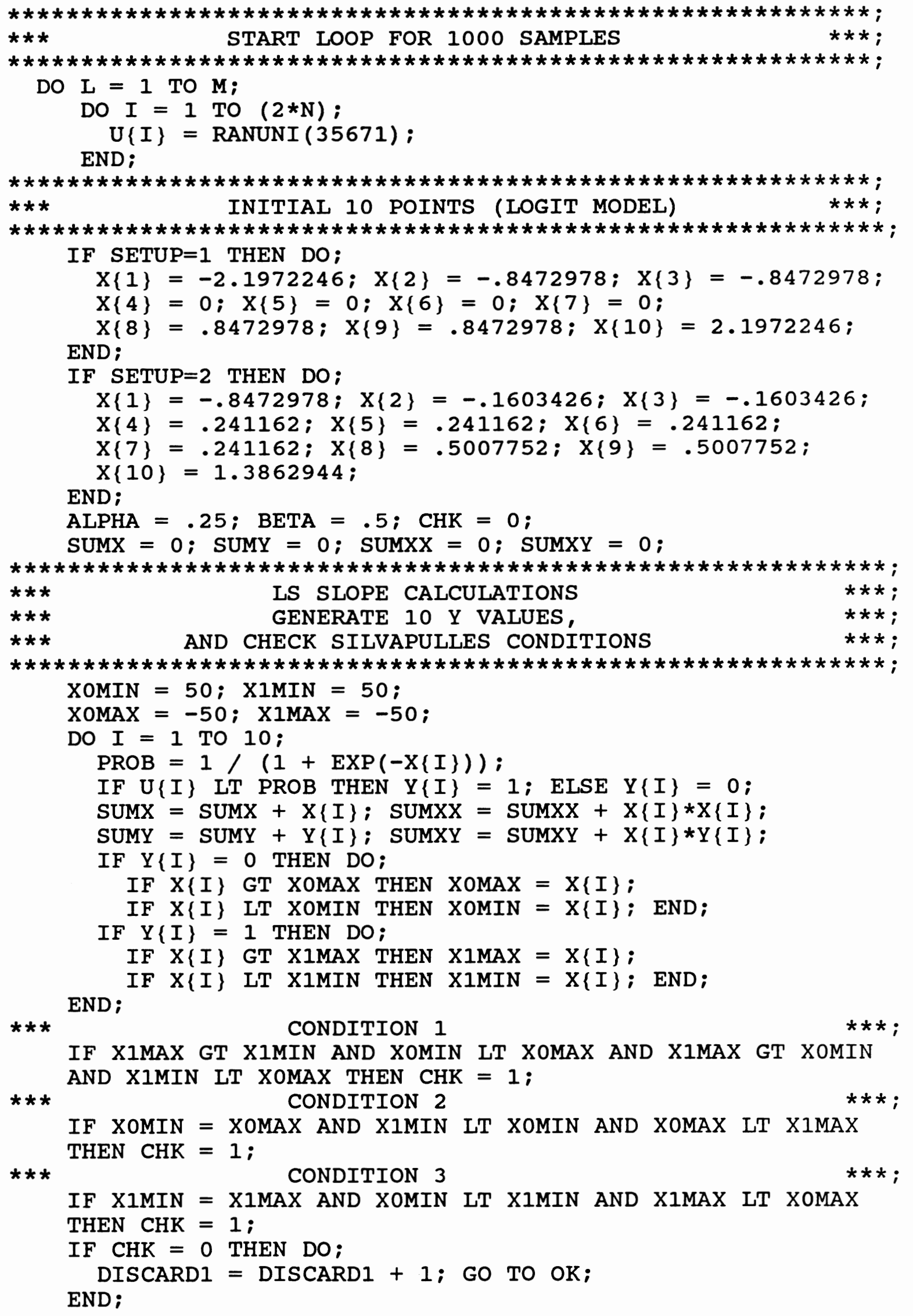




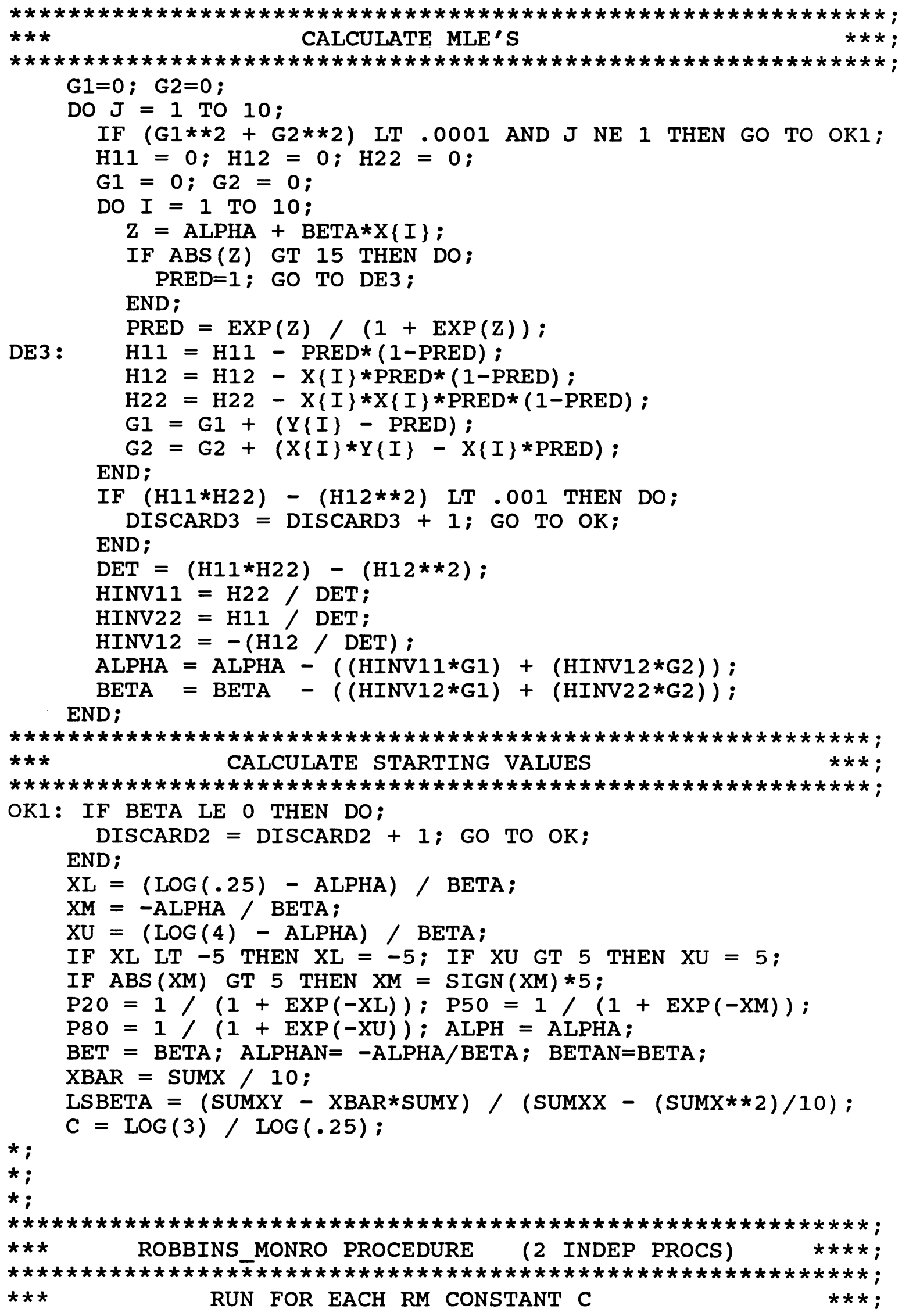




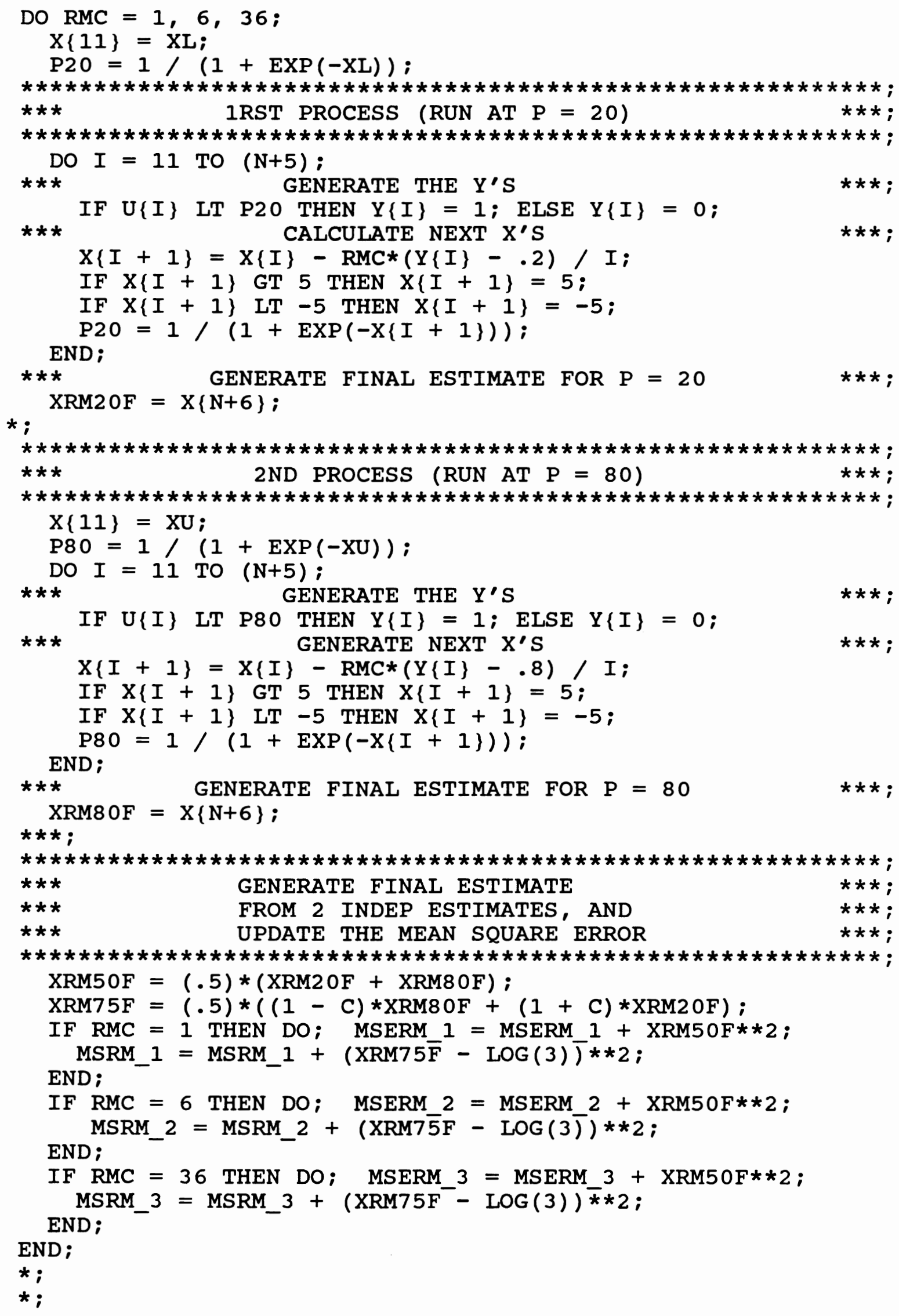




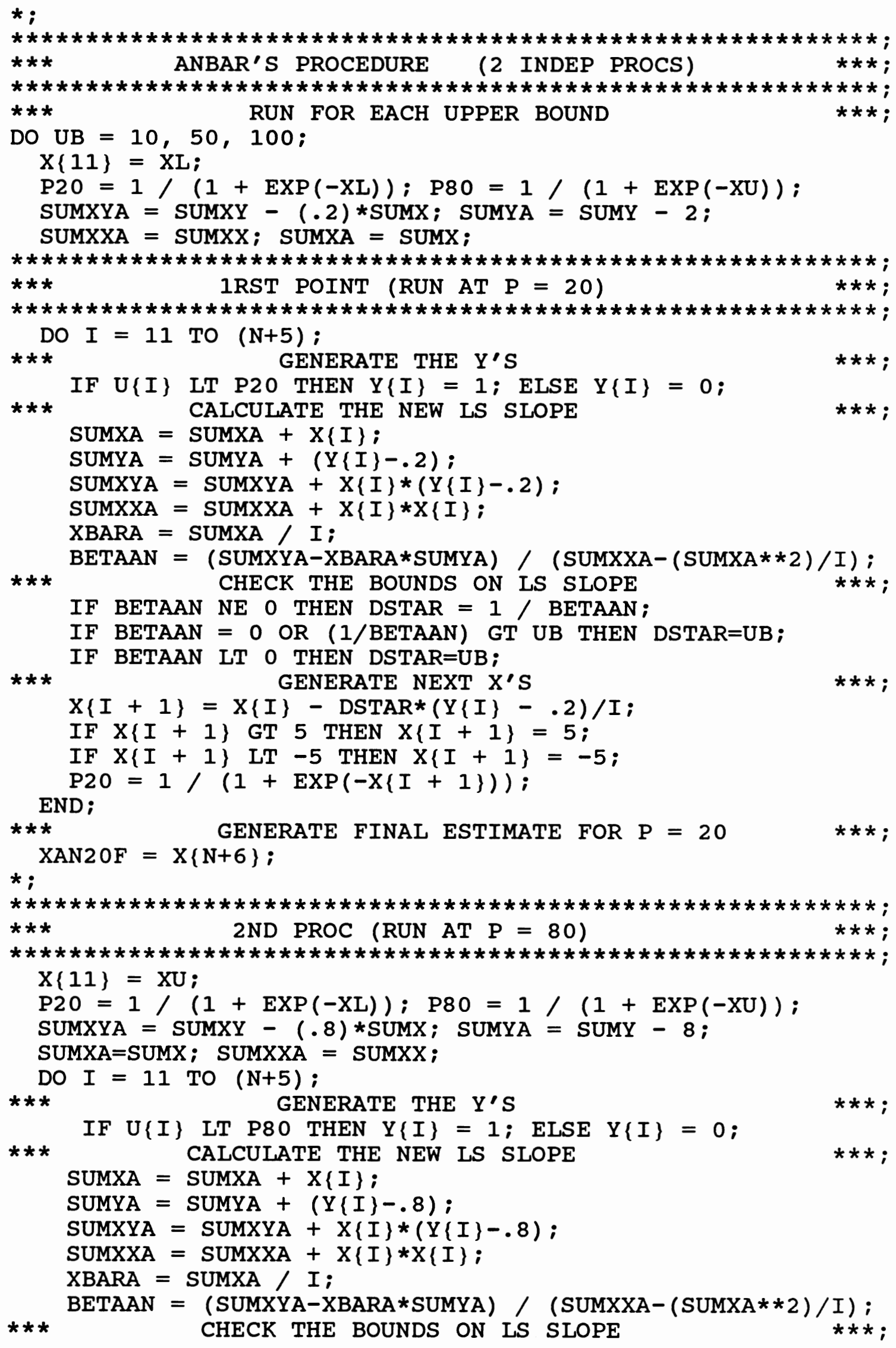


IF BETAAN NE O THEN DSTAR = 1 / BETAAN;

IF BETAAN $=0$ OR (1/BETAAN) GT UB THEN DSTAR=UB;

IF BETAAN LT 0 THEN DSTAR=UB;

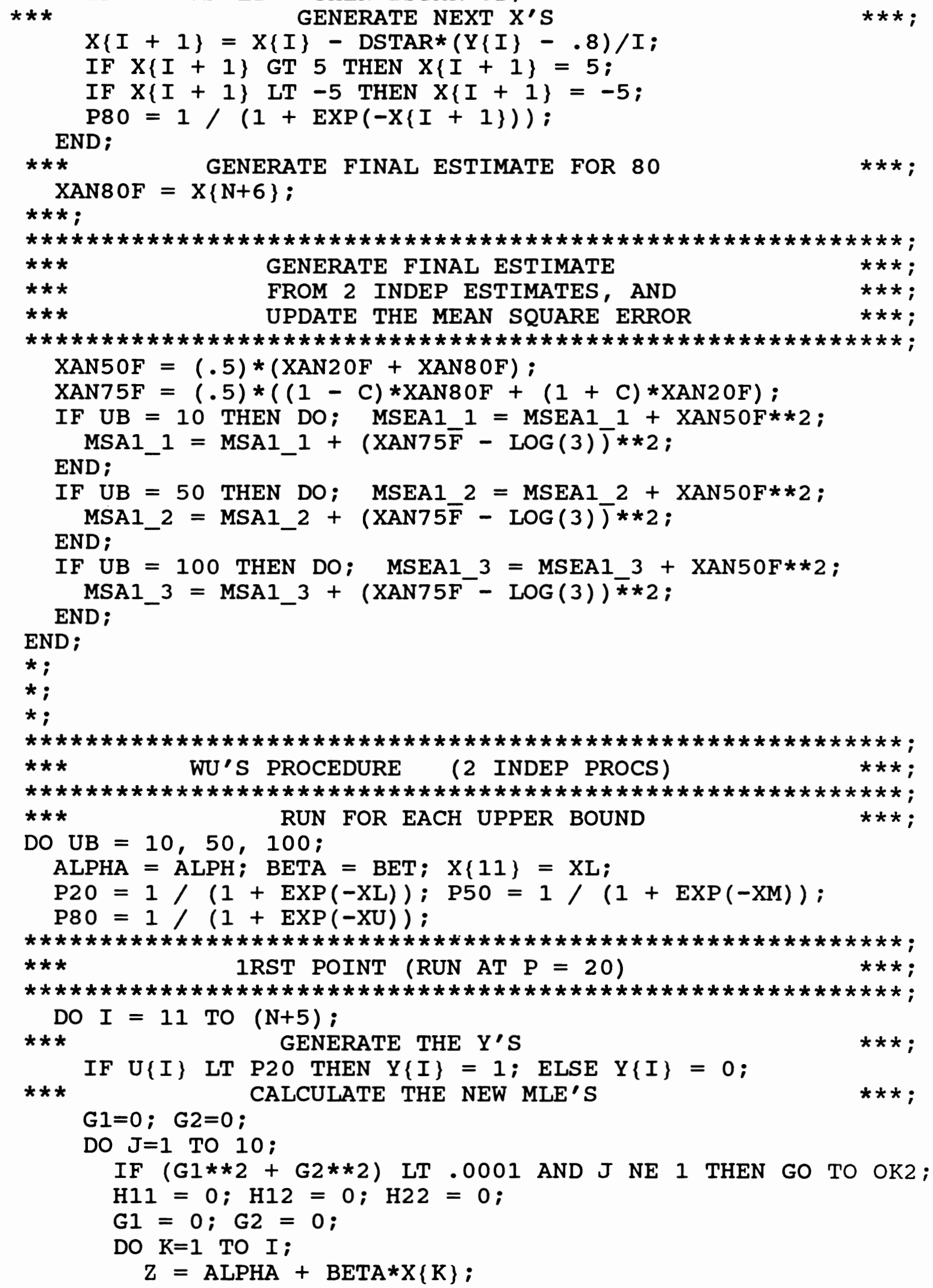




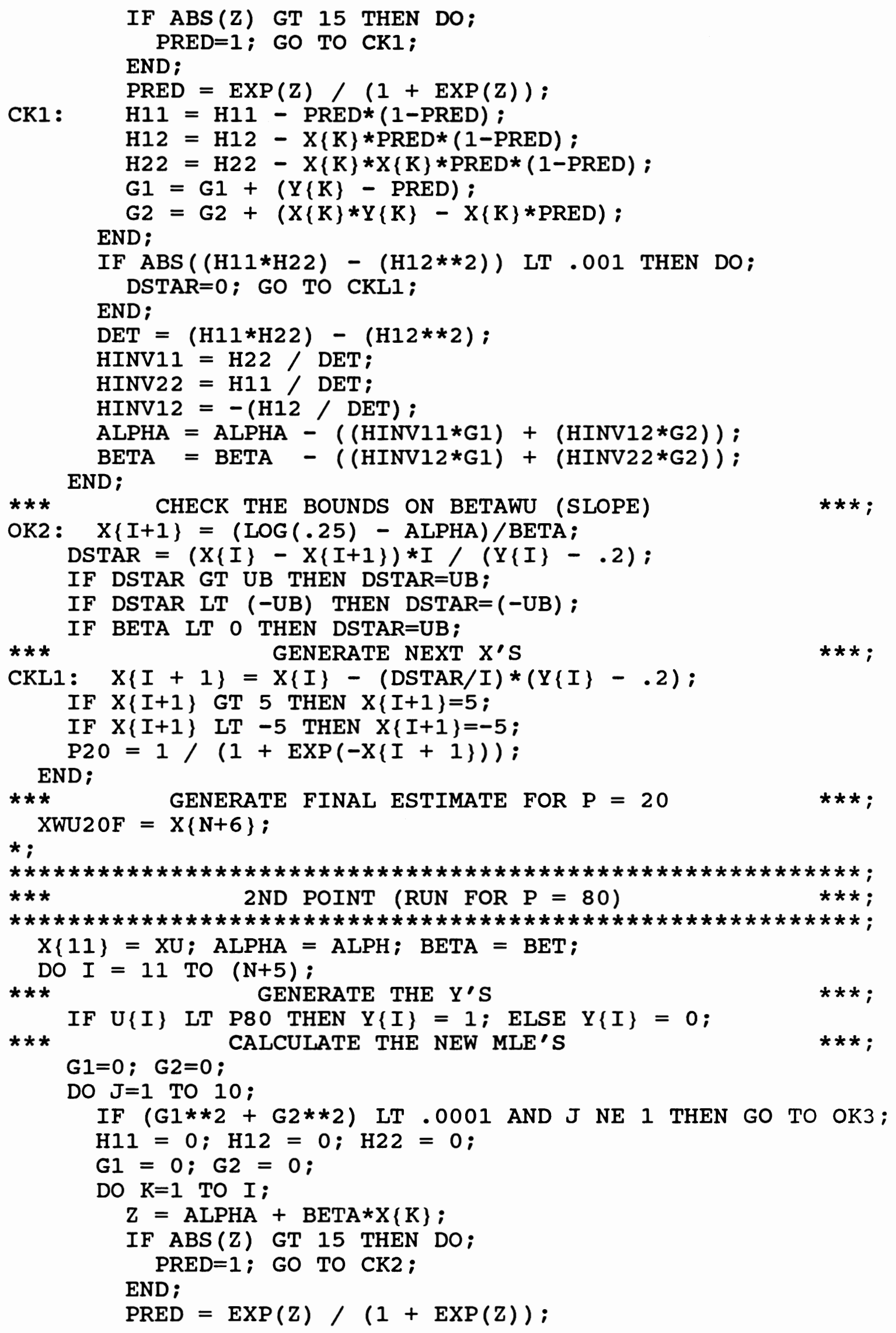




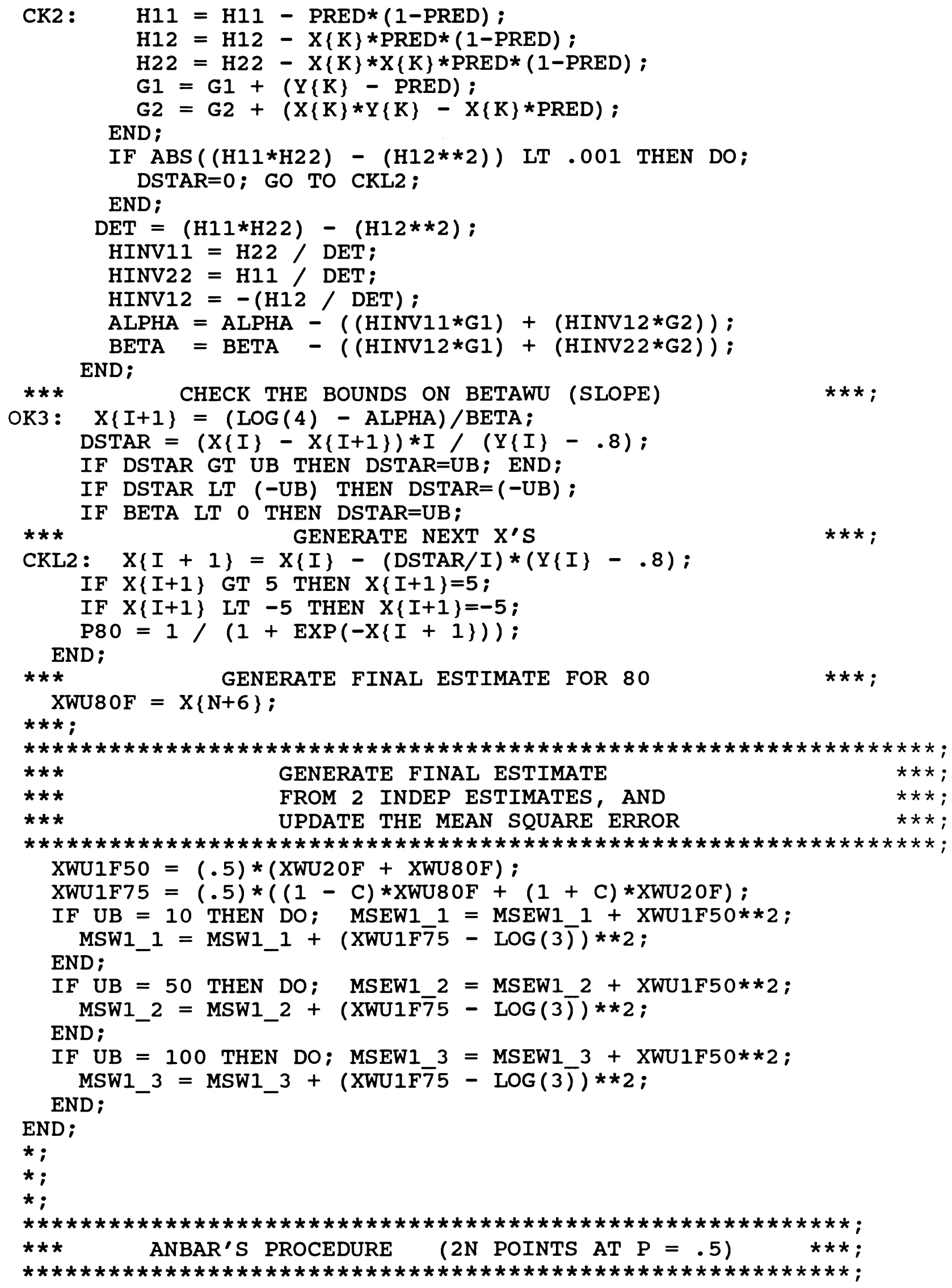




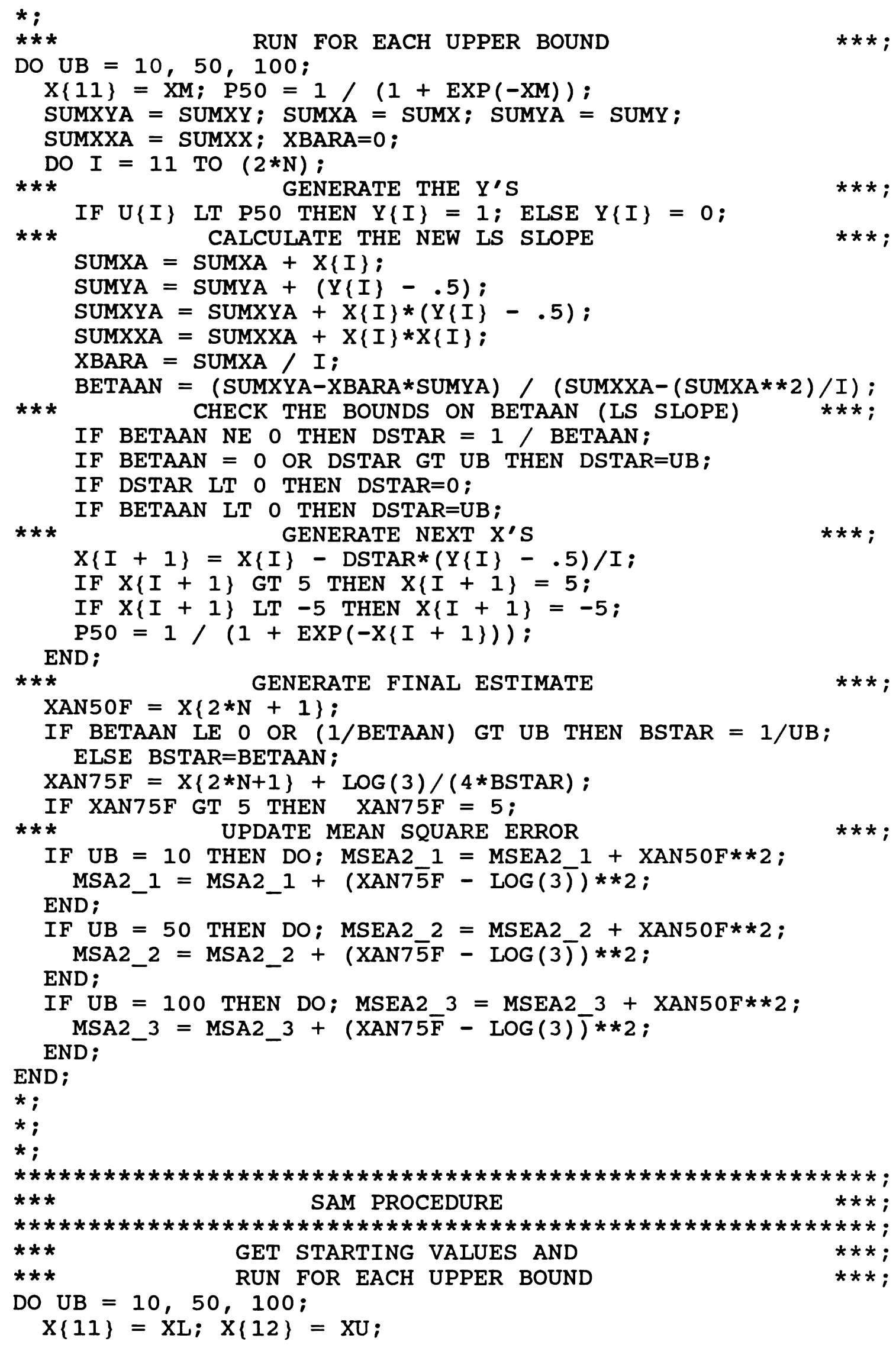




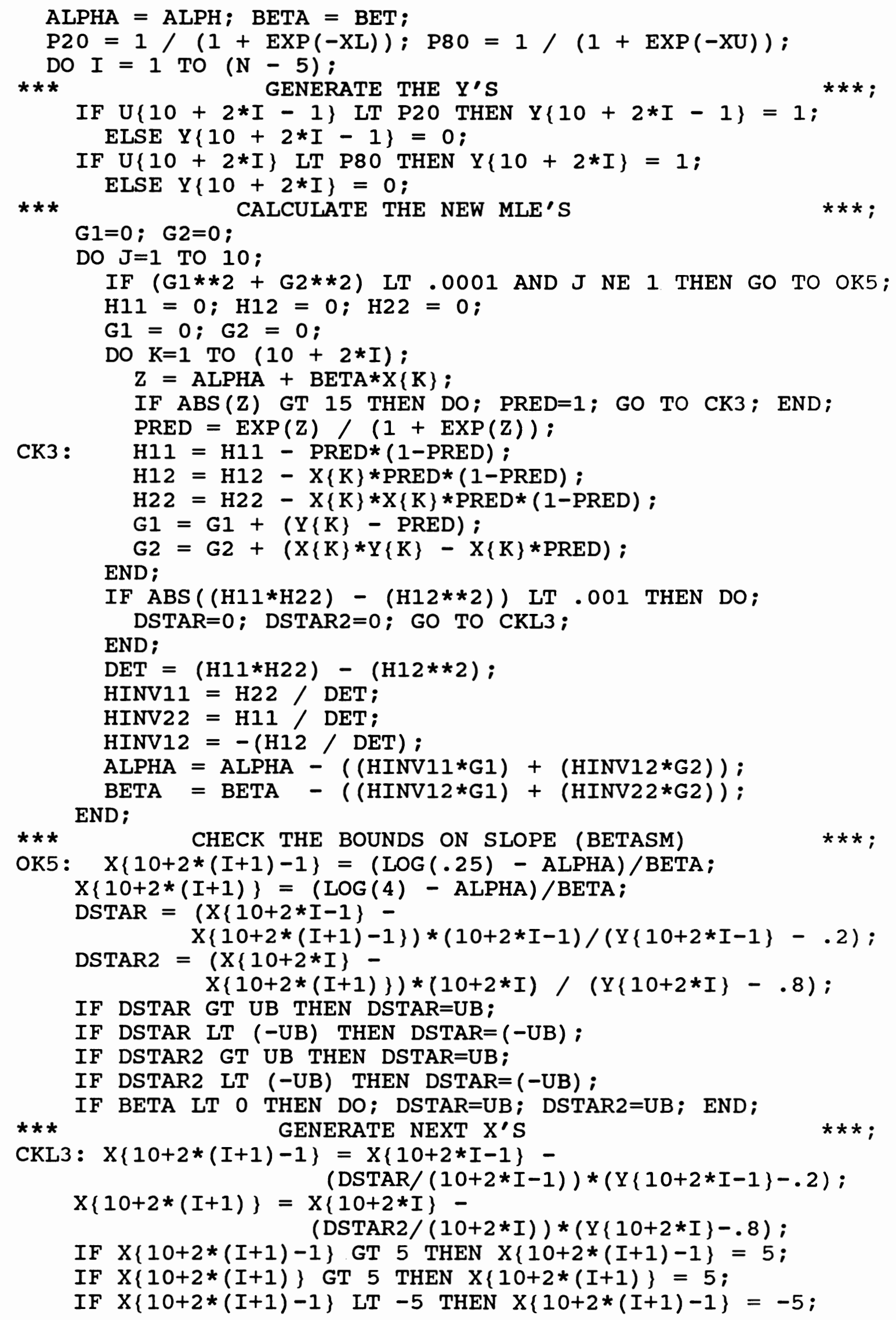




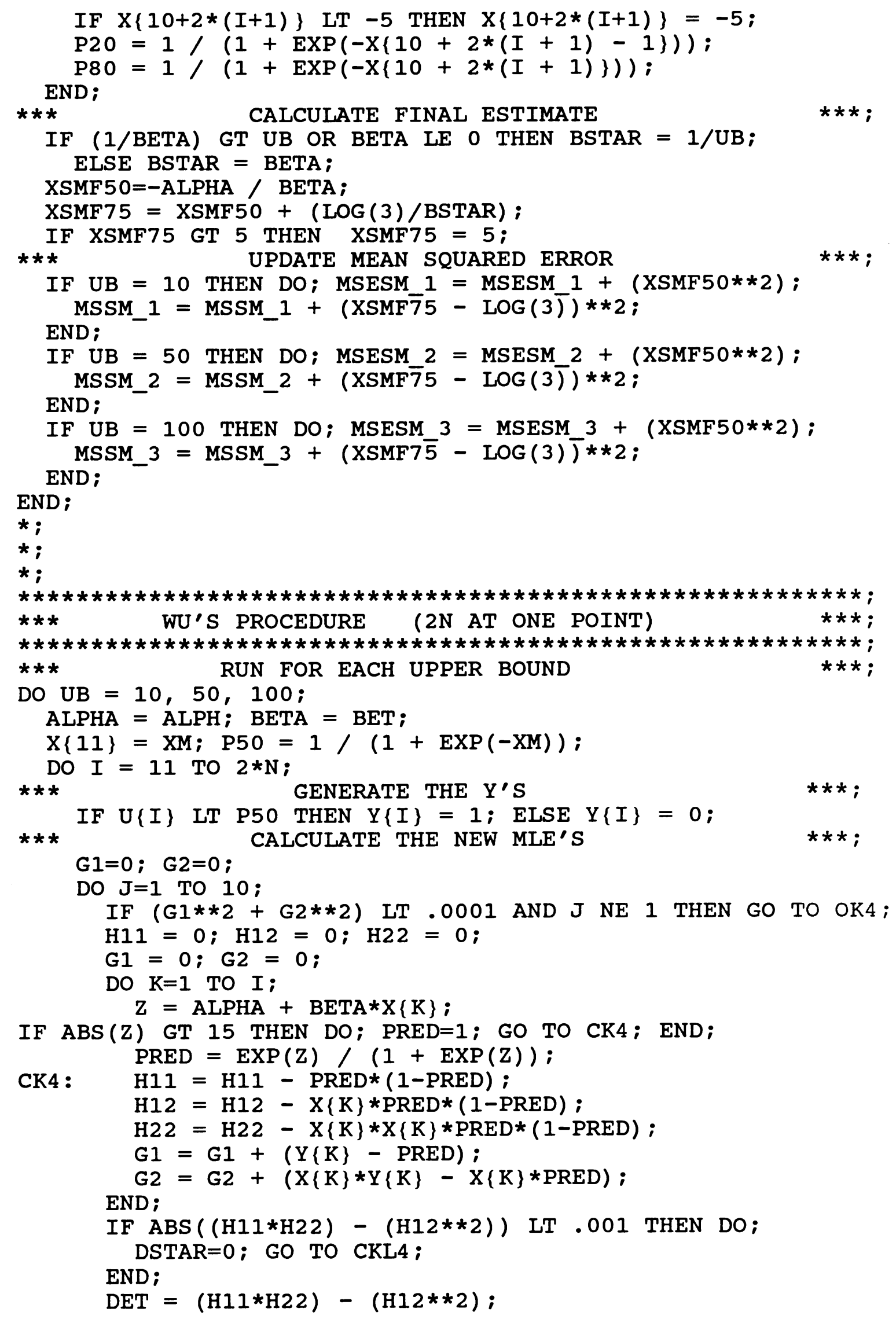




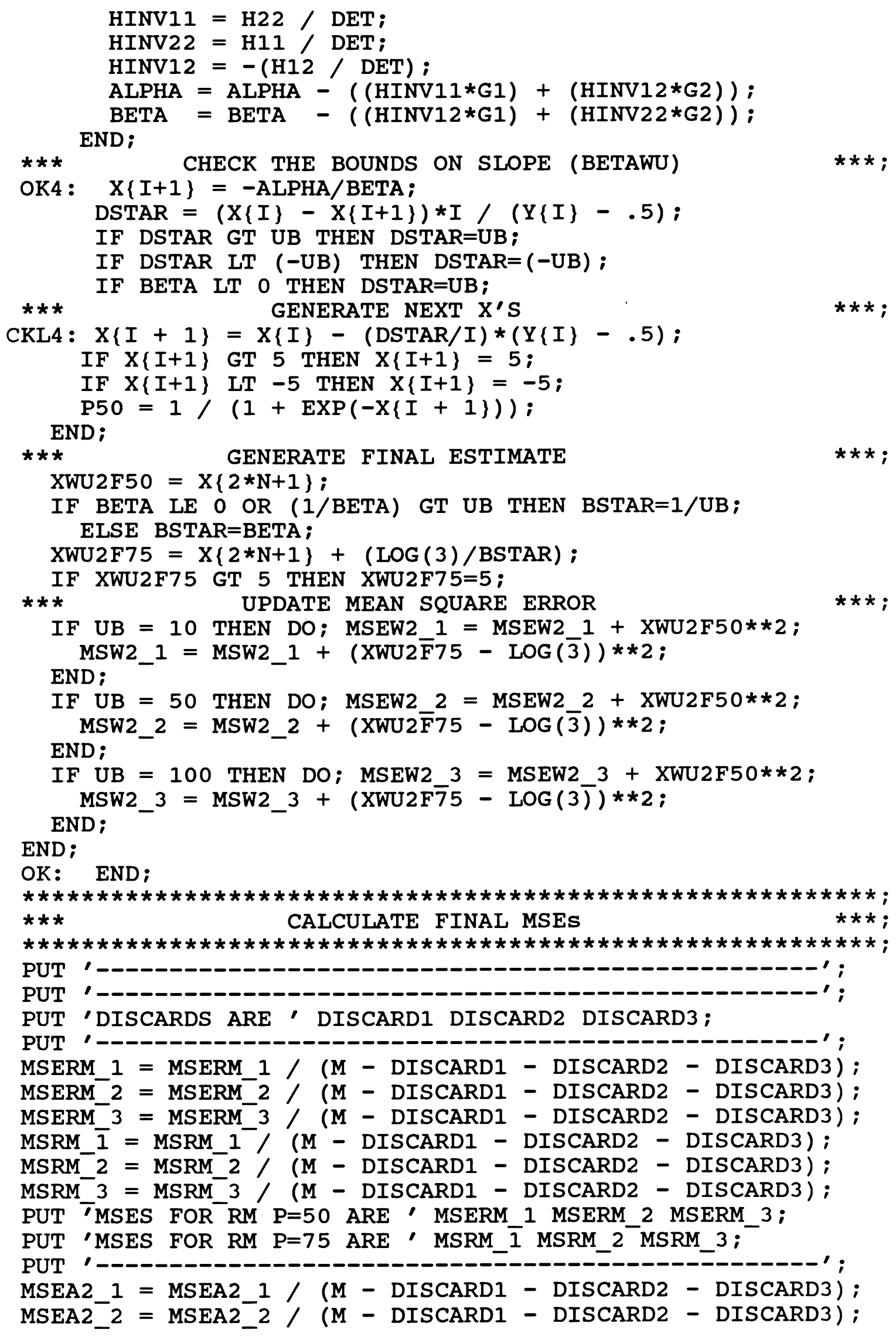




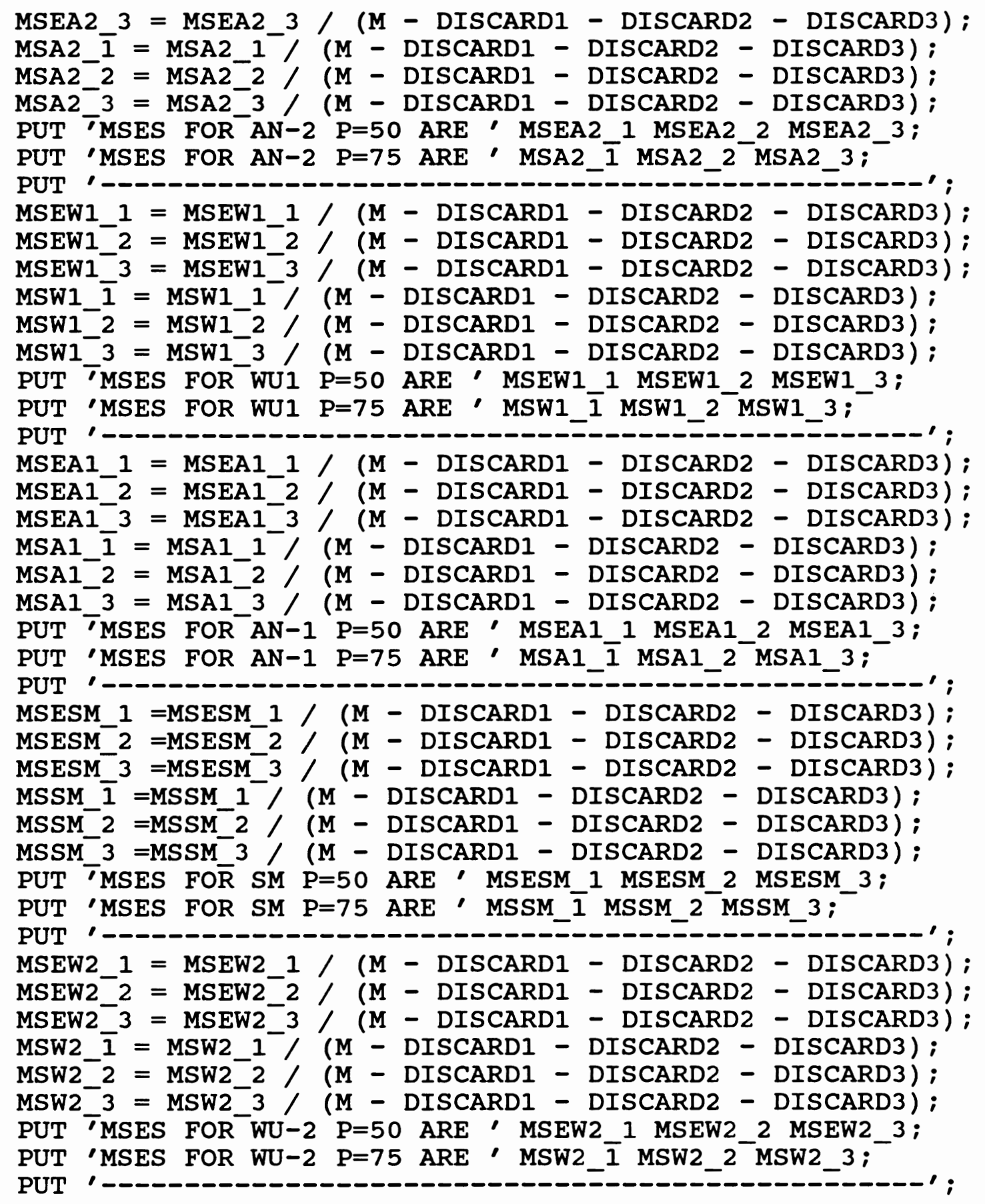




\section{APPENDIX E}

\section{USER PROGRAMS}

Four programs have been written to assist a researcher in using SAM. The two parameter logit model is used for $G(x \mid \theta)$. Also, $(.2, .8)$ is chosen for $\left(p_{1}, p_{2}\right)$. In this appendix, a brief description of each program along with the SAS codes are presented.

\section{INITIAL}

SAM's updating rule requires that MLEs exist. Thus, some procedure is needed to generate the initial design levels. The program INITIAL uses the Two Dimensional RM procedure of Moser and Fei (1989a) to calculate design levels until MLEs exist. The first step in this procedure is to observe the responses at the initial estimates of the $20^{\text {th }}$ and $80^{\text {th }}$ percentiles. New design levels are then calculated using the updating rules of the Two Dimensional RM procedure. Conditions for the existence of MLEs are checked at each update. If the MLEs exist for the data, a message is produced instructing the user to switch to SAM's updating rules (and to the program NEXTSAM). 


\section{MLECHECK}

The program MLECHECK is designed for when a researcher already has an initial set of data, but has not used SAM. The program MLECHECK reads an askii data set and determines whether the MLEs of $\theta_{1}$ and $\theta_{2}$ exist. The user enters the name of the dataset (extension and filename). The dataset should contain three variables, the observation number, design level, and response, in column format. For example, with the data in the example of Chapter III,

$\begin{array}{rll}1 & 2.0 & 0 \\ 2 & 4.0 & 0 \\ 3 & 2.0 & 0 \\ 4 & 4.5 & 1 \\ 5 & 3.0 & 0 \\ 6 & 4.75 & 0 \\ 7 & 3.0 & 1 \\ 8 & 5.0 & 1 \\ 9 & 4.0 & 0 \\ 10 & 5.0 & 1\end{array}$

If the MLEs exists, then a message is produced instructing the user to run the program NEXTSAM, to obtain the next design levels. If the MLEs do not exist, design levels to help obtain existence are suggested. A warning is given if the MLEs exist and the slope estimate, $\hat{\theta}_{2^{\prime}}$ is negative. When the program was run with the above data, a message "MLE exists, run NEXTSAM program" was produced on the screen. 
NEXTSAM

The program, NEXTSAM, calculates the design levels using SAM's updating rules. Prior to using NEXTSAM for the first time, the user should verify that MLEs exist for the set of data (using INITIAL or MLECHECK). The user enters upper and lower bounds on the design levels, as well as initial estimates of the $20^{\text {th }}$ and $80^{\text {th }}$ percentiles. The upper and lower bounds should be chosen such that a response almost always occurs at the upper bound and almost never at the lower bound. A graph of the estimated expectation curve, $\hat{G}_{n}(x)$, is produced along with the design levels for the next update. Figure 3 on page 24 is an example of the graph produced by NEXTSAM.

\section{SAMSUMM}

The final program, SAMSUMM, presents a summary of the study. In an askii file named by the user, the data, final estimates of the parameters, and $\hat{L}_{1}, \hat{L}_{2}, \ldots, \hat{L}_{9}$, with their estimated standard errors and $95 \%$ confidence limits, are presented. A final graph of $\hat{G}_{n}(x)$, along with the parameter estimates, is also produced. Figure 6 on pages 134 and 135 presents the output of SAMSUMM for the data of Table 1 (on page 25 ). 
* DIMENSIONAL ROBBINS-MONRO PROCEDURE TO GENERATE THE IN- *;

* ItIAL DESign LEVEls UNTIl MLEs EXIST. ONCE EXISTENCE IS *;

* ObTAINED, THE PROgRAM NEXTSAM.SAS CAN BE USED to GENER- *;

* ATE THE NEXT DESIGN LEVELS. ONCE MLEs EXIST, THEY EXIST *;

* at Each fUtuRe UPdate (NO NEEd to RERUn this PROGRAM) *;

*

*

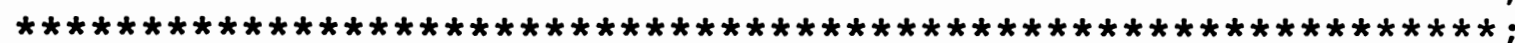

$* * * *$

$\star * * *$

$\star * * *$ FILL IN THE FOLLOWING INFORMATION

$\star \star \star * * ;$

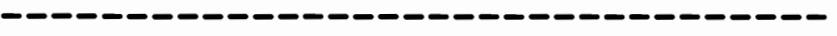

(SEE SAMHELP.DOC FOR MORE DETAILS)

$* * * *$

$\star * * *$

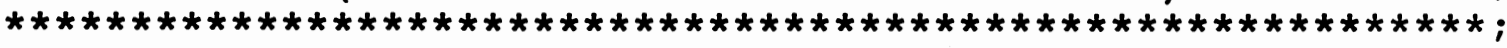

DATA INFO;

*

*

*

*

*

*

*

*

*

*

*

*

*

*

*

*

*

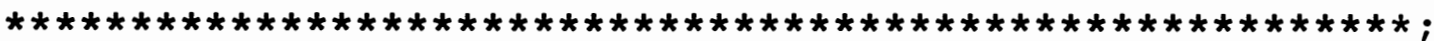

* NO CHANGES NEEDED BEYOND THIS POINT

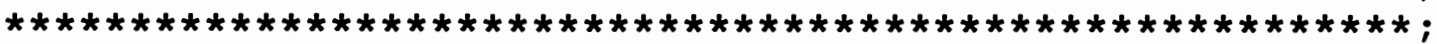

IF LD20EST $=$. THEN LD20EST $=$ LD50 $-(1.3863 /$ SLP $)$;

IF LD80EST $=$. THEN LD80EST $=$ LD50 $+(1.3863 / \mathrm{SLP})$;

$S L P=(2 *$ LOG $(4)) /($ LD80EST - LD20EST $)$;

LD50EST $=($ LD20EST+LD80EST $) / 2$;

IF LG $=$. THEN LG $=(.5) *($ LD2 OEST+LD80EST $)-($ LOG $(50) / S L P)$;

IF UG $=$. THEN UG $=(.5) *($ LD2 OEST+LD80EST $)+($ LOG $(50) / S L P)$;

CALL SYMPUT ('LD20EST',LD20EST) ; CALL SYMPUT ('LG',LG) ;

CALL SYMPUT ('LD8OEST', LD8OEST); CALL SYMPUT ('UG',UG) ;

DATA DAT; INFILE DTI;

KEEP $X Y$;

INPUT OBS $\mathrm{X} Y$;

PROC MEANS NOPRINT DATA=DAT $N$ MAX MIN;

VAR X; OUTPUT OUT=STATS $N=N U M$ MAX $=M X \quad M I N=M N$;

DATA STATS; SET STATS; 
LENGTH NUMC $\$ 10 ;$ NUMC $=$ NUM; NUMC $=$ LEFT (NUMC); NUMX $=' X^{\prime}||$ TRIM (NUMC); NUMY = ' $Y^{\prime}||$ TRIM (NUMC); LNGX $=$ LENGTH (NUMX); LNGC = LENGTH (NUMC); CALL SYMPUT ('NUMX', NUMX); CALL SYMPUT ('NUMY' ,NUMY); CALL SYMPUT ('MX',MX); CALL SYMPUT ('MN',MN); CALL SYMPUT ('NUM', NUM); FILE PRINT;

PROC TRANSPOSE DATA=DAT OUT=TRANS ;

VAR X Y;

DATA DATX; SET TRANS;

ARRAY X \{\&NUM \} X1-\&NUMX; KEEP X1-\&NUMX DUM; IF $N A M E=' X$ '; $D U M=1$;

$\mathrm{X} 1=\overline{\mathrm{COL}} 1 ;{ }^{-} \mathrm{X} 2=\mathrm{COL} 2 ; \mathrm{X} 3=\mathrm{COL} 3 ; \mathrm{X} 4=\mathrm{COL} 4 ; \mathrm{X} 5=\mathrm{COL} 5 ; \mathrm{X} 6=\mathrm{COL} 6$; $\mathrm{X} 7=\mathrm{COL} 7 ; \mathrm{X} 8=\mathrm{COL} 8 ; \mathrm{X} 9=\mathrm{COL} 9 ; \mathrm{X} 10=\mathrm{COL} 10 ; \mathrm{X} 11=\mathrm{COL} 11$;

$\mathrm{X} 12=\mathrm{COL} 12 ; \mathrm{X} 13=\mathrm{COL} 13 ; \mathrm{X} 14=\mathrm{COL} 14 ; \mathrm{X} 15=\mathrm{COL} 15 ; \mathrm{X} 16=\mathrm{COL} 16$; $\mathrm{X} 17=\mathrm{COL} 17 ; \mathrm{X} 18=\mathrm{COL} 18 ; \mathrm{X} 19=\mathrm{COL} 19 ; \mathrm{X} 20=\mathrm{COL} 20$;

IF \&NUM GT 20 THEN DO;

$\mathrm{X} 21=\mathrm{COL} 21 ; \mathrm{X} 22=\mathrm{COL} 22 ; \mathrm{X} 23=\mathrm{COL} 23 ; \mathrm{X} 24=\mathrm{COL} 24 ; \mathrm{X} 25=\mathrm{COL} 25$; END;

$\mathrm{X} 26=\operatorname{COL} 26 ; \mathrm{X} 27=\operatorname{COL} 27 ; \mathrm{X} 28=\operatorname{COL} 28 ; \mathrm{X} 29=\operatorname{COL} 29 ; \mathrm{X} 30=\operatorname{COL} 30 ;$

IF \&NUM GT 30 THEN DO;

$\mathrm{X} 31=\mathrm{COL} 31 ; \mathrm{X} 32=\operatorname{COL} 32 ; \mathrm{X} 33=\mathrm{COL} 33 ; \mathrm{X} 34=\mathrm{COL} 34 ; \mathrm{X} 35=\mathrm{COL} 35 ;$

$\mathrm{X} 36=\mathrm{COL} 36 ; \mathrm{X} 37=\operatorname{COL} 37 ; \mathrm{X} 38=\operatorname{COL} 38 ; \mathrm{X} 39=\operatorname{COL} 39 ; \times 40=\operatorname{COL} 40$; END;

IF \&NUM GT 40 THEN DO;

$\mathrm{X} 41=\mathrm{COL} 41 ; \mathrm{X} 42=\mathrm{COL} 42 ; \mathrm{X} 43=\mathrm{COL} 43 ; \mathrm{X} 44=\mathrm{COL} 44 ; \mathrm{X} 45=\mathrm{COL} 45 ;$

$\mathrm{X} 46=\mathrm{COL} 46 ; \mathrm{X} 47=\mathrm{COL} 47 ; \mathrm{X} 48=\mathrm{COL} 48 ; \mathrm{X} 49=\mathrm{COL} 49 ; \mathrm{X} 50=\mathrm{COL} 50 ;$ END;

IF \&NUM GT 50 THEN DO;

$\mathrm{X} 51=$ COL51; X52=COL52; X53=COL53; X54=COL54; X55=COL55； END;

$\mathrm{X} 56=\mathrm{COL} 56 ; \mathrm{X} 57=\mathrm{COL} 57 ; \mathrm{X} 58=\mathrm{COL} 58 ; \mathrm{X} 59=\mathrm{COL} 59 ; \mathrm{X} 60=\mathrm{COL} 60$;

DATA DATY; SET TRANS;

ARRAY Y \{\&NUM\} Y1-\&NUMY; KEEP Y1-\&NUMY DUM; IF_NAME_ $=$ ' $Y$ '; DUM=1;

$\mathrm{Y} 1=\overline{\mathrm{COL}} 1 ;-\mathrm{Y} 2=\mathrm{COL} 2 ; \mathrm{Y} 3=\mathrm{COL} 3 ; \mathrm{Y} 4=\mathrm{COL} 4 ; \mathrm{Y} 5=\mathrm{COL} 5 ; \mathrm{Y} 6=\mathrm{COL} 6$;

$Y 7=\operatorname{COL} 7 ; \mathrm{Y} 8=\operatorname{COL} 8 ; \mathrm{Y} 9=\mathrm{COL} 9 ; \mathrm{Y} 10=\operatorname{COL} 10 ; \mathrm{Y} 11=\mathrm{COL} 11$;

$Y 12=\operatorname{COL} 12 ; Y 13=\operatorname{COL} 13 ; \mathrm{Y} 14=\operatorname{COL} 14 ; \mathrm{Y} 15=\operatorname{COL} 15 ; \mathrm{Y} 16=\mathrm{COL} 16$;

Y17 $=$ COL17; Y $18=C O L 18 ; Y 19=C O L 19 ; Y 20=C O L 20$;

IF \&NUM GT 20 THEN DO;

$\mathrm{Y} 21=\mathrm{COL} 21 ; \mathrm{Y} 22=\mathrm{COL} 22 ; \mathrm{Y} 23=\mathrm{COL} 23 ; \mathrm{Y} 24=\mathrm{COL} 24 ; \mathrm{Y} 25=\mathrm{COL} 25$; END;

$\mathrm{Y} 26=\operatorname{COL} 26 ; \mathrm{Y} 27=\operatorname{COL} 27 ; \mathrm{Y} 28=\operatorname{COL} 28 ; \mathrm{Y} 29=\operatorname{COL} 29 ; \mathrm{Y} 30=\operatorname{COL} 30$;

IF \&NUM GT 30 THEN DO;

$\mathrm{Y} 31=\mathrm{COL} 31 ; \mathrm{Y} 32=\mathrm{COL} 32 ; \mathrm{Y} 33=\mathrm{COL} 33 ; \mathrm{Y} 34=\mathrm{COL} 34 ; \mathrm{Y} 35=\mathrm{COL} 35$;

$Y 36=\operatorname{COL} 36 ; Y 37=\operatorname{COL} 37 ; Y 38=\operatorname{COL} 38 ; Y 39=\operatorname{COL} 39 ; Y 40=C O L 40 ;$ END;

IF \&NUM GT 40 THEN DO;

$\mathrm{Y} 41=\mathrm{COL} 41 ; \mathrm{Y} 42=\mathrm{COL} 42 ; \mathrm{Y} 43=\mathrm{COL} 43 ; \mathrm{Y} 44=\mathrm{COL} 44 ; \mathrm{Y} 45=\mathrm{COL} 45$;

$\mathrm{Y} 46=\mathrm{COL} 46 ; \mathrm{Y} 47=\mathrm{COL} 47 ; \mathrm{Y} 48=\mathrm{COL} 48 ; \mathrm{Y} 49=\mathrm{COL} 49 ; \mathrm{Y} 50=\mathrm{COL} 50$; END;

IF \&NUM GT 50 THEN DO;

$\mathrm{Y} 51=\mathrm{COL} 51 ; \mathrm{Y} 52=\mathrm{COL} 52 ; \mathrm{Y} 53=\mathrm{COL} 53 ; \mathrm{Y} 54=\mathrm{COL} 54 ; \mathrm{Y} 55=\mathrm{COL} 55$;

$\mathrm{Y} 56=\mathrm{COL} 56 ; \mathrm{Y} 57=\mathrm{COL} 57 ; \mathrm{Y} 58=\mathrm{COL} 58 ; \mathrm{Y} 59=\mathrm{COL} 59 ; \mathrm{Y} 60=\mathrm{COL} 60$; END; 





IF ABS(Z) GT 15 THEN DO; PRED=1; GO TO DE3; END;

DE3 : $\quad \mathrm{H} 11=\mathrm{H} 11-\operatorname{PRED} *(1-\mathrm{PRED})$;

$\mathrm{H} 12=\mathrm{H} 12-\mathrm{X}\{\mathrm{I}\} * \mathrm{PRED} *(1-\mathrm{PRED})$;

$\mathrm{H} 22=\mathrm{H} 22-\mathrm{X}\{I\} * \mathrm{X}\{I\} * \mathrm{PRED} *(1-\mathrm{PRED})$;

$\mathrm{Gl}=\mathrm{GI}+(\mathrm{Y}\{\mathrm{I}\}-\mathrm{PRED}) ;$

END;

$G 2=G 2+(X\{I\} * Y\{I\}-X\{I\} * P R E D) ;$

IF $(\mathrm{H} 11 * \mathrm{H} 22)-(\mathrm{H} 12 * * 2)$ LT .001 THEN DO;

PUT 'DET NEAR ZERO'; DET=1; GO TO OKI; END;

$\mathrm{DET}=(\mathrm{H} 11 * \mathrm{H} 22)-(\mathrm{H} 12 * * 2) ;$

HINV11 $=\mathrm{H} 22 / \mathrm{DET}$;

HINV22 $=\mathrm{H} 11 / \mathrm{DET}$;

HINV12 $=-($ H12 / DET $)$;

ALPHA $=$ ALPHA $-(($ HINV11*G1) $+($ HINV12*G2) $) ;$

END;

BETA $=$ BETA $-(($ HINV12*G1) $+($ HINV22*G2));

OK1: FILE PRINT;

$\mathrm{BETA}=\mathrm{BETA} * 8 /(\& \mathrm{MX}-\& \mathrm{MN}) ; \mathrm{ALPHA}=(-\mathrm{ALPHA} / \mathrm{BETA})+((\& \mathrm{MX}+$ $\& M N) / 2)$;

*;

$A L P H A=-A L P H A * B E T A$;

$* * *$

*;

END OF CALCULATE MLE'S

$* * *$;

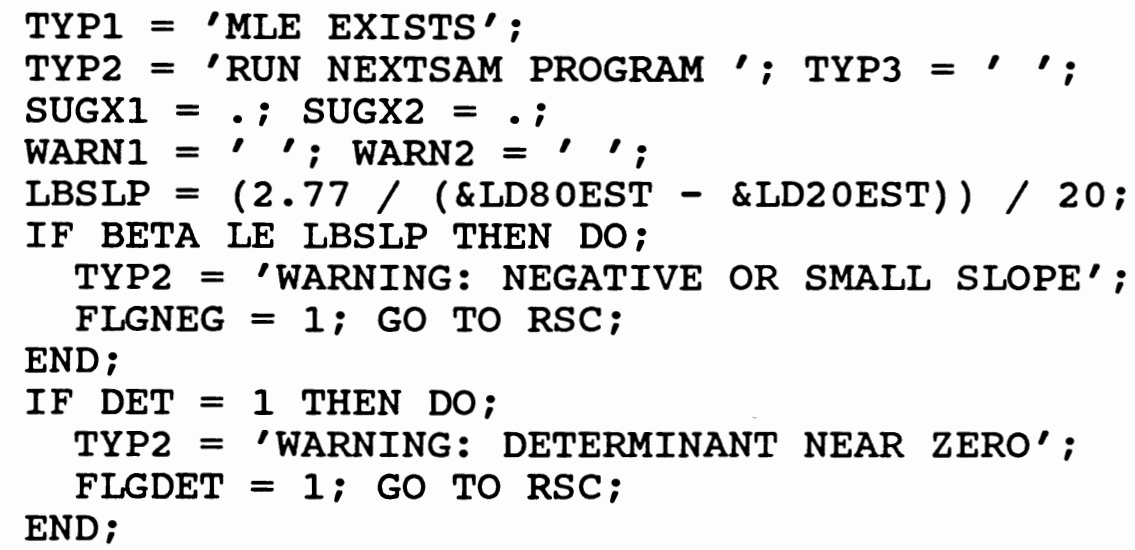




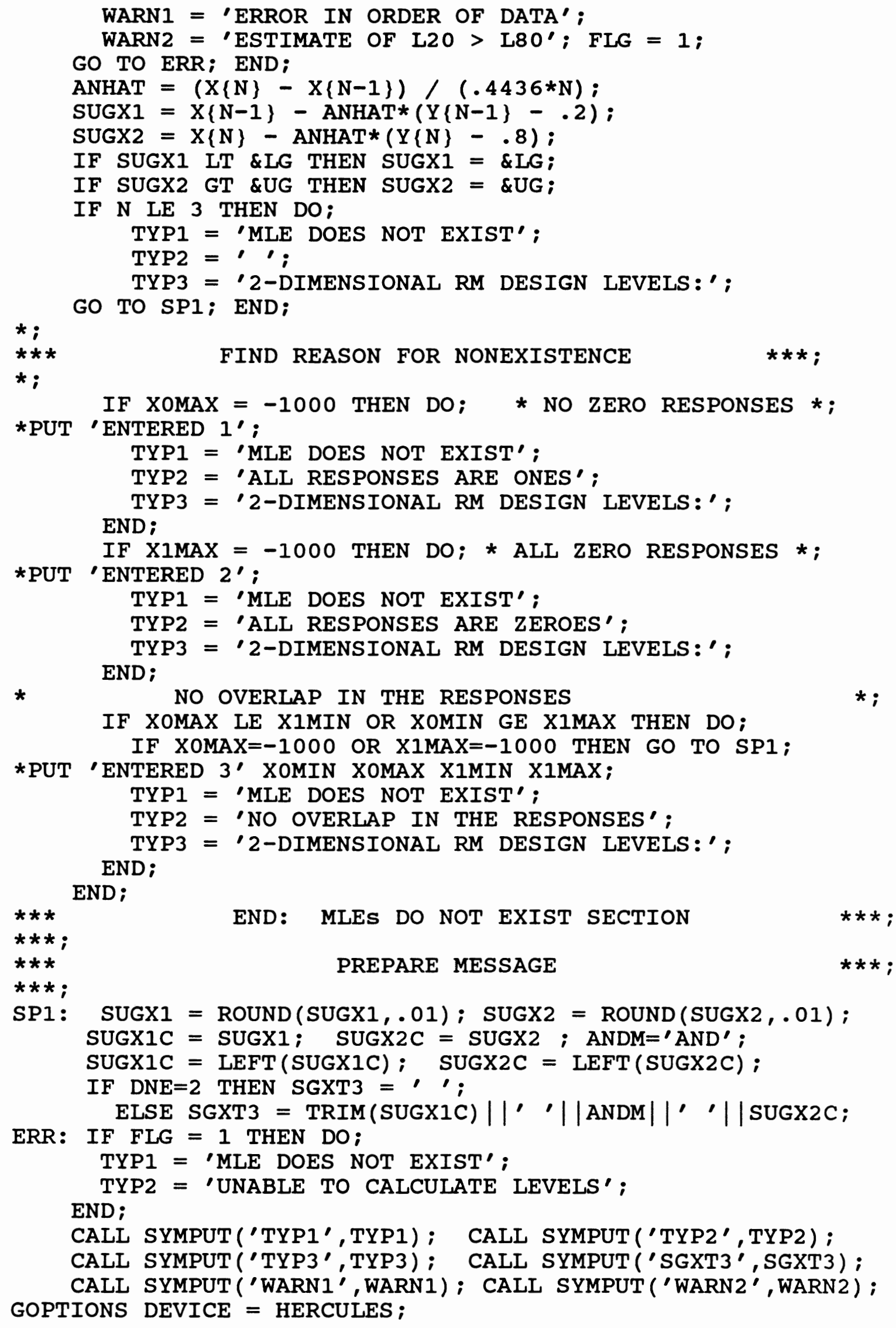




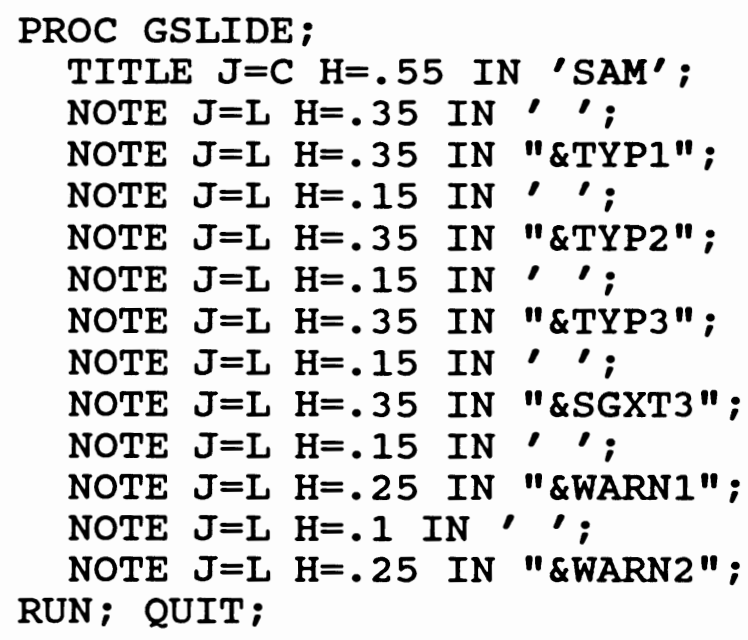

* NOTE : EXISTENCE OF MAXIMUM LIKELIHOOD ESTIMATES IS * ;

* REQUIRED IN ORDER TO USE SAM. THIS PROGRAM CHECKS FOR *;

* EXISTENCE OF MLEs. If MLEs EXIST, THEN THE PROGRAM * ;

* NEXTSAM.SAS CAN BE USED TO GENERATE THE NEXT DESIGN *;

* LEVELS. IF MLES EXIST AT A GIVEN UPDATE THEN THEY EXIST *;

* AT EACH FUTURE UPDATE (NO NEED TO RERUN THIS PROGRAM) . * ;

*

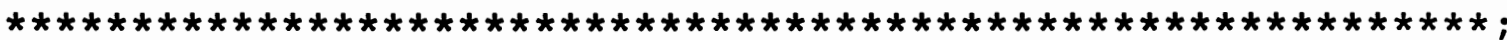

**** FILL IN THE FOLLOWING INFORMATION

****

$* * * *$ (SEE SAMHELP.DOC FOR MORE DETAILS) $* * * *$;

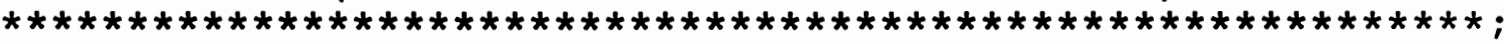

DATA UNO;

* enter the NAME OF the FILE CONTAINING THE DATA *;

* (INCLUDE DIRECTORY OF FILE IE. 'A: \SAMDAT.DAT' *; FILENAME DT1 'A: \TEST.DAT';

* ENTER LOWER AND UPPER BOUND FOR THE DESIGN POINTS * ;

* (IF A . IS ENTERED, THEN A FORMULA BASED ON L20 * ;

* AND L80 WILL BE USED) * *

LG $=0 ;$ Ug $=150 ;$
* enter initial LD20 and Ld80 estimate

* LD20EST $=60 ;$ LD8OEST $=100 ;$

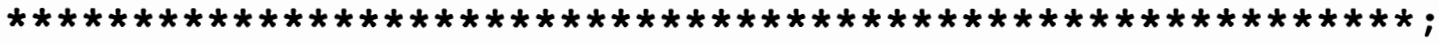

* NO CHANGES NEEDED BEYOND THIS POINT

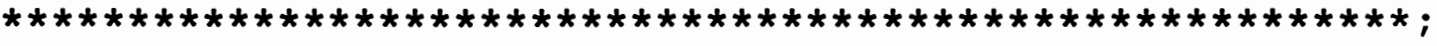

SLPEST $=(2 *$ LOG (4)) / (LD8OEST - LD2OEST) ;

IF LG $=$. THEN LG $=(.5) *($ LD20EST+LD80EST) -

(LOG (50)/SLPEST) ;

IF UG $=$. THEN UG $=(.5) *($ LD20EST+LD80EST $)+$

( LOG (50)/SLPEST) ;

CALL SYMPUT('LG', LG); CALL SYMPUT('UG',UG); 
CALL SYMPUT ('LD2OEST', LD2OEST); CALL

SYMPUT ('LD80EST' , LD80EST) ;

FILE PRINT;

DATA DAT; INFILE DTI;

KEEP X Y ;

INPUT OBS $X Y$;

PROC MEANS NOPRINT DATA=DAT $N$ MAX MIN;

VAR X; OUTPUT OUT=STATS $N=N U M$ MAX=MX $M I N=M N$;

DATA STATS; SET STATS;

LENGTH NUMC \$ 10; NUMC = NUM; NUMC = LEFT (NUMC);

NUMX $=$ ' $X '||$ TRIM (NUMC) $;$ NUMY = ' Y' ||TRIM (NUMC);

INGX = LENGTH (NUMX); LNGC = LENGTH (NUMC);

CALI SYMPUT ('NUMX', NUMX); CALL SYMPUT ('NUMY', NUMY) ;

CALL SYMPUT ('MX',MX); CALL SYMPUT ('MN',MN);

CALI SYMPUT ('NUM', NUM) ;

PROC TRANSPOSE DATA=DAT OUT=TRANS ;

VAR X Y;

DATA DATX; SET TRANS;

ARRAY X \{\&NUM\} X1-\&NUMX; KEEP X1-\&NUMX DUM;

IF ${ }^{N A M E}=' X$; $D U M=1$;

$\mathrm{X} 1=\overline{C O L} 1 ;-\mathrm{X} 2=\mathrm{COL} 2 ; \mathrm{X} 3=\operatorname{COL} 3 ; \mathrm{X} 4=\mathrm{COL} 4 ; \mathrm{X} 5=\mathrm{COL} 5 ; \mathrm{X} 6=\mathrm{COL} 6$;

$\mathrm{X} 7=\mathrm{COL} 7 ; \mathrm{X} 8=\mathrm{COL} 8 ; \mathrm{X} 9=\mathrm{COL} 9 ; \mathrm{X} 10=\operatorname{COL} 10 ; \mathrm{X} 11=\mathrm{COL} 11$;

$\mathrm{X} 12=\operatorname{COL} 12 ; \mathrm{X} 13=\operatorname{COL} 13 ; \mathrm{X} 14=\operatorname{COL} 14 ; \mathrm{X} 15=\operatorname{COL} 15 ; \mathrm{X} 16=\mathrm{COL} 16$;

$\mathrm{X} 17=\operatorname{COL} 17 ; \mathrm{X} 18=\operatorname{COL} 18 ; \mathrm{X} 19=\mathrm{COL} 19 ; \mathrm{X} 20=\mathrm{COL} 20$;

IF \&NUM GT 20 THEN DO;

$\mathrm{X} 21=\mathrm{COL} 21 ; \mathrm{X} 22=\mathrm{COL} 22 ; \mathrm{X} 23=\mathrm{COL} 23 ; \mathrm{X} 24=\mathrm{COL} 24 ; \mathrm{X} 25=\operatorname{COL} 25 ;$

$\mathrm{X} 26=\operatorname{COL} 26 ; \mathrm{X} 27=\operatorname{COL} 27 ; \mathrm{X} 28=\operatorname{COL} 28 ; \mathrm{X} 29=\operatorname{COL} 29 ; \mathrm{X} 30=\operatorname{COL} 30 ;$

END;

IF \&NUM GT 30 THEN DO;

$\mathrm{X} 31=\mathrm{COL} 31 ; \mathrm{X} 32=\mathrm{COL} 32 ; \mathrm{X} 33=\mathrm{COL} 33 ; \mathrm{X} 34=\mathrm{COL} 34 ; \mathrm{X} 35=\mathrm{COL} 35 ;$ $\mathrm{X} 36=\operatorname{COL} 36 ; \mathrm{X} 37=\operatorname{COL} 37 ; \mathrm{X} 38=\operatorname{COL} 38 ; \mathrm{X} 39=\operatorname{COL} 39 ; \mathrm{X} 40=\operatorname{COL} 40 ;$

END;

IF \&NUM GT 40 THEN DO;

$\mathrm{X} 41=\mathrm{COL} 41 ; \mathrm{X} 42=\mathrm{COL} 42 ; \mathrm{X} 43=\mathrm{COL} 43 ; \mathrm{X} 44=\mathrm{COL} 44 ; \mathrm{X} 45=\mathrm{COL} 45 ;$ END;

$\mathrm{X} 46=\operatorname{COL} 46 ; \mathrm{X} 47=\operatorname{COL} 47 ; \mathrm{X} 48=\operatorname{COL} 48 ; \mathrm{X} 49=\operatorname{COL} 49 ; \mathrm{X} 50=\operatorname{COL} 50$;

IF \&NUM GT 50 THEN DO;

$\mathrm{X} 51=\mathrm{COL} 51 ; \mathrm{X} 52=\mathrm{COL} 52 ; \mathrm{X} 53=\mathrm{COL} 53 ; \mathrm{X} 54=\mathrm{COL} 54 ; \mathrm{X} 55=\mathrm{COL} 55 ;$ $\mathrm{X} 56=\mathrm{COL} 56 ; \mathrm{X} 57=\mathrm{COL} 57 ; \mathrm{X} 58=\mathrm{COL} 58 ; \mathrm{X} 59=\mathrm{COL} 59 ; \mathrm{X} 60=\mathrm{COL} 60$; END;

DATA DATY; SET TRANS;

ARRAY Y \{\&NUM\} Y1-\&NUMY; KEEP Y1-\&NUMY DUM;

IF NAME_ = ' $\mathrm{Y}$ '; DUM=1;

$\mathrm{Y} 1=\overline{\mathrm{COL}} 1 ; \mathrm{Y} 2=\mathrm{COL} 2 ; \mathrm{Y} 3=\mathrm{COL} 3 ; \mathrm{Y} 4=\mathrm{COL} 4 ; \mathrm{Y} 5=\mathrm{COL} 5 ; \mathrm{Y} 6=\mathrm{COL} 6$;

$\mathrm{Y} 7=\mathrm{COL} 7 ; \mathrm{Y} 8=\mathrm{COL} 8 ; \mathrm{Y} 9=\mathrm{COL} 9 ; \mathrm{Y} 10=\operatorname{COL} 10 ; \mathrm{Y} 11=\mathrm{COL} 11$;

$\mathrm{Y} 12=\mathrm{COL} 12 ; \mathrm{Y} 13=\mathrm{COL} 13 ; \mathrm{Y} 14=\mathrm{COL} 14 ; \mathrm{Y} 15=\mathrm{COL} 15 ; \mathrm{Y} 16=\mathrm{COL} 16$;

$\mathrm{Y} 17=\mathrm{COL} 17 ; \mathrm{Y} 18=\mathrm{COL} 18 ; \mathrm{Y} 19=\mathrm{COL} 19 ; \mathrm{Y} 20=\mathrm{COL} 20$;

IF \&NUM GT 20 THEN DO;

$\mathrm{Y} 21=\mathrm{COL} 21 ; \mathrm{Y} 22=\mathrm{COL} 22 ; \mathrm{Y} 23=\mathrm{COL} 23 ; \mathrm{Y} 24=\mathrm{COL} 24 ; \mathrm{Y} 25=\mathrm{COL} 25 ;$

$\mathrm{Y} 26=\operatorname{COL} 26 ; \mathrm{Y} 27=\operatorname{COL} 27 ; \mathrm{Y} 28=\operatorname{COL} 28 ; \mathrm{Y} 29=\operatorname{COL} 29 ; \mathrm{Y} 30=\operatorname{COL} 30$;

END;

IF \&NUM GT 30 THEN DO;

$\mathrm{Y} 31=\operatorname{COL} 31 ; \mathrm{Y} 32=\mathrm{COL} 32 ; \mathrm{Y} 33=\operatorname{COL} 33 ; \mathrm{Y} 34=\mathrm{COL} 34 ; \mathrm{Y} 35=\mathrm{COL} 35$; $\mathrm{Y} 36=\operatorname{COL} 36 ; \mathrm{Y} 37=\operatorname{COL} 37 ; \mathrm{Y} 38=\operatorname{COL} 38 ; \mathrm{Y} 39=\operatorname{COL} 39 ; \mathrm{Y} 40=\operatorname{COL} 40$; 
END;

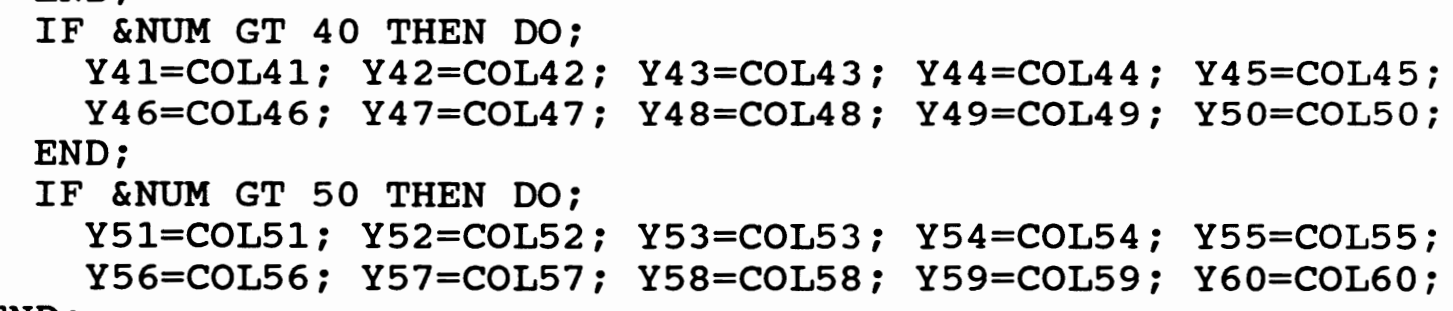




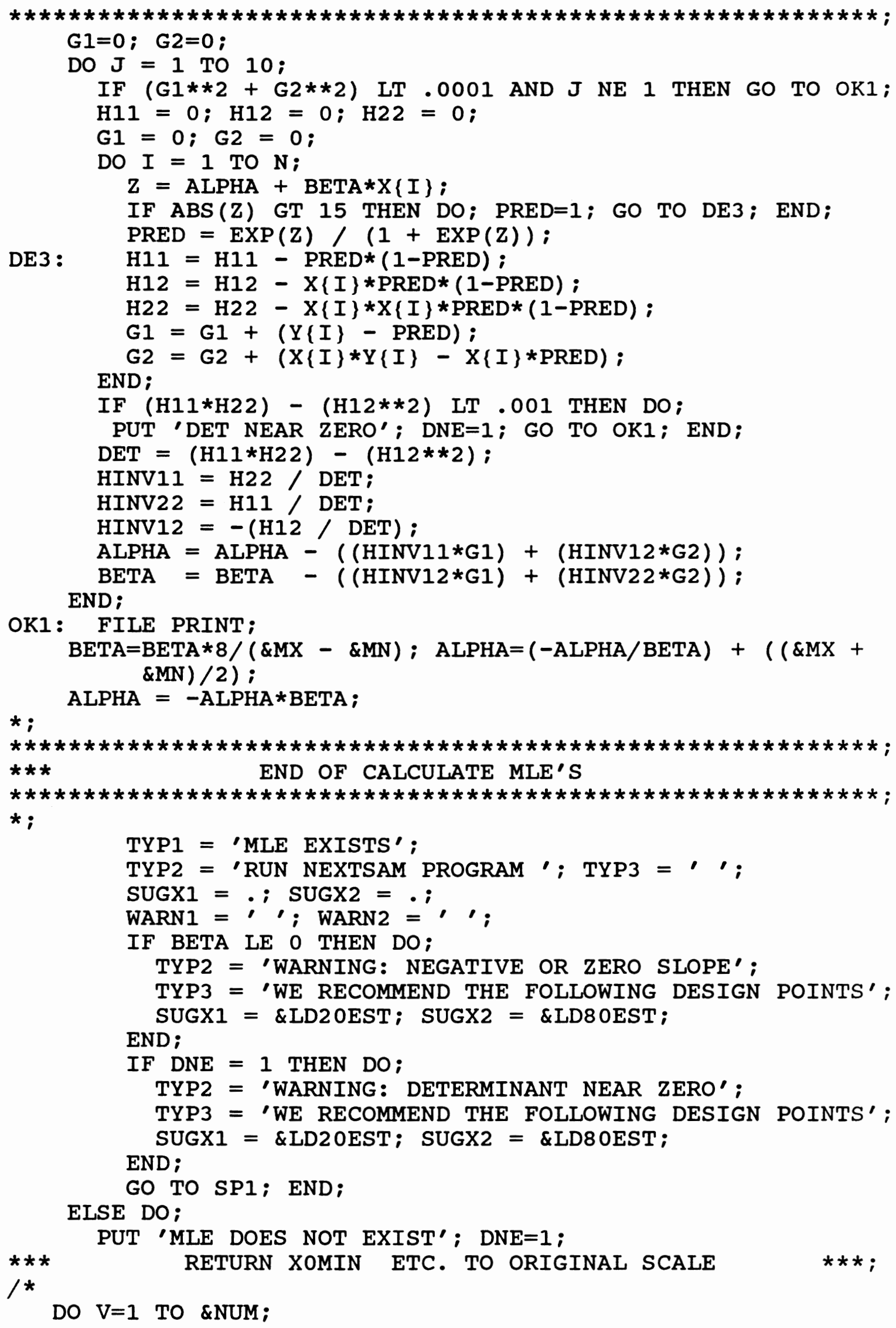




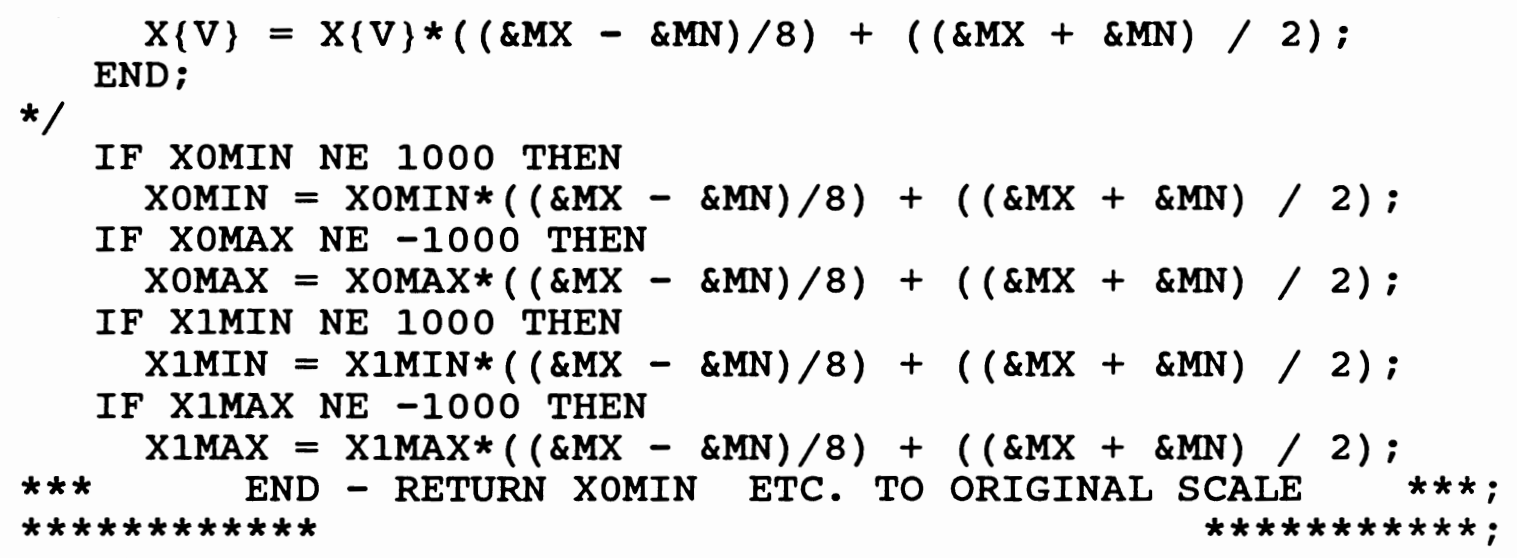

* CALCULATE SUGGESTED DESIGN POINTS FOR WHEN NO MLE EXISTS*;

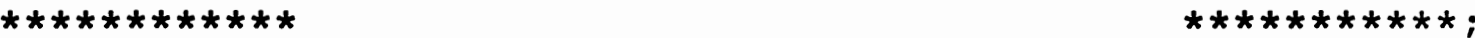

IF XOMAX $=-1000$ THEN DO; * NO ZERO RESPONSES *; TYP1 = 'MLE DOES NOT EXIST'; TYP2 = 'ALL RESPONSES ARE ONES'; TYP3 = 'WE RECOMMEND THE FOLLOWING DESIGN POINTS'; SUGX1 = XIMIN - (.5)*(XIMIN - \&LG); SUGX2 $=$ XIMIN - (.1)* (XIMIN - \&LG); IF XIMIN LE \&LG THEN DO; WARN1 = 'THE LOWER BOUND MAY BE TOO LARGE'; WARN2 = 'ENTER A NEW LOWER BOUND'; SUGX1 $=\& L G-(1 / 3) *(\& L D 80 E S T-\& L D 20 E S T) ;$ SUGX2 = \&LG; END; END;

IF X1MAX $=-1000$ THEN DO; * ALL ZERO RESPONSES *; TYPI = 'MLE DOES NOT EXIST'; TYP2 = 'ALL RESPONSES ARE ZEROES'; TYP3 = 'WE RECOMMEND THE FOLLOWING DESIGN POINTS'; SUGX1 $=$ XOMAX $+(.1) *(\& U G-X O M A X) ;$ SUGX2 $=$ XOMAX $+(1 / 2) *(\& U G-X O M A X) ;$ IF XOMAX GE \&UG THEN DO;

WARN1 = 'THE UPPER BOUND MAY BE TOO SMALL'; WARN2 = 'ENTER A NEW UPPER BOUND'; SUGX1 = \&UG; SUGX2 $=\& U G+(1 / 3) *(\& L D 80 E S T-\& L D 20 E S T) ;$ END; END;

IF XOMAX LE XIMIN THEN DO; * NO OVERLAP IN RESPONSES (1S HIGHER) *;

IF $X O M A X=-1000$ OR $X 1 M A X=-1000$ THEN GO TO SP1; SUGX1 $=$ XOMAX $+(1 / 3) *(X 1 M I N-X O M A X) ;$ SUGX2 $=$ XOMAX $+(2 / 3) *(X 1 M I N-X O M A X) ;$

IF $X O M A X=X I M I N$ THEN DO; SUGX1 $=$ XOMAX - (.1)*(\&LD80EST - \&LD2OEST); END; SUGX2 $=$ XOMAX $+(.1) *(\&$ LD8OEST $-\&$ LD20EST $) ;$

TYPI = 'MLE DOES NOT EXIST';

TYP2 = 'NO OVERLAP IN THE RESPONSES';

TYP3 = 'WE RECOMMEND THE FOLLOWING DESIGN POINTS'; END;

IF XOMIN GE XIMAX THEN DO;* NO OVERLAP IN RESPONSES (OS HIGHER) *; 


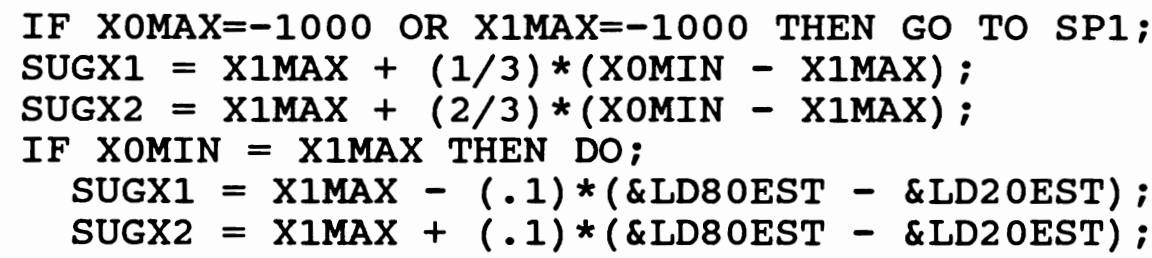

END;

TYP1 = 'MLE DOES NOT EXIST';

TYP2 = 'NO OVERLAP IN THE RESPONSES'; END;

TYP3 = 'WE RECOMMEND THE FOLLOWING DESIGN POINTS';

END;

SP1: $\quad$ SUGX1 $=$ ROUND (SUGX1,.01); $\operatorname{SUGX2}=\operatorname{ROUND}($ SUGX2,.01);

SUGX1C $=$ SUGX1; SUGX2C $=$ SUGX2 ; $A N D M=' A N D ' ;$

SUGX1C = LEFT (SUGX1C); SUGX2C = LEFT (SUGX2C);

SGXT3 = TRIM (SUGX1C) ||$, '||$ ANDM ||$^{\prime},||$ SUGX2C;

IF DNE NE 1 AND BETA GT 0 THEN SGXT3 $=\prime \prime \prime$

CALL SYMPUT ('TYP1', TYP1); CALL SYMPUT('TYP2',TYP2);

CALL SYMPUT ('TYP3',TYP3); CALI SYMPUT('SGXT3',SGXT3);

CALI SYMPUT ('WARN1',WARN1); CALL SYMPUT ('WARN2',WARN2); GOPTIONS DEVICE = HERCULES;

PROC GSLIDE;

TITLE J=C H=.55 IN 'SAM';

NOTE $\mathrm{J}=\mathrm{L} \mathrm{H}=.35 \mathrm{IN}, '$;

NOTE $\mathrm{J}=\mathrm{L} \mathrm{H}=.35$ IN "\&TYPI";

NOTE $\mathrm{J}=\mathrm{L} \mathrm{H}=.15 \mathrm{IN}, '$;

NOTE $\mathrm{J}=\mathrm{L} \mathrm{H}=.35$ IN "\&TYP2";

NOTE $\mathrm{J}=\mathrm{L} \mathrm{H}=.15 \mathrm{IN}, '$;

NOTE $\mathrm{J}=\mathrm{L} \mathrm{H}=.35$ IN "\&TYP3";

NOTE $\mathrm{J}=\mathrm{L} \mathrm{H}=.15 \mathrm{IN}$ ' ';

NOTE $\mathrm{J}=\mathrm{L} \mathrm{H}=.35$ IN "\&SGXT3";

NOTE $\mathrm{J}=\mathrm{L} \mathrm{H}=.15 \mathrm{IN}$ ' ';

NOTE $J=L \mathrm{H}=.25$ IN "\&WARN1";

NOTE $\mathrm{J}=\mathrm{L} \mathrm{H}=.1 \mathrm{IN}, '$;

NOTE J=L H=.25 IN "\&WARN2";

RUN; QUIT;

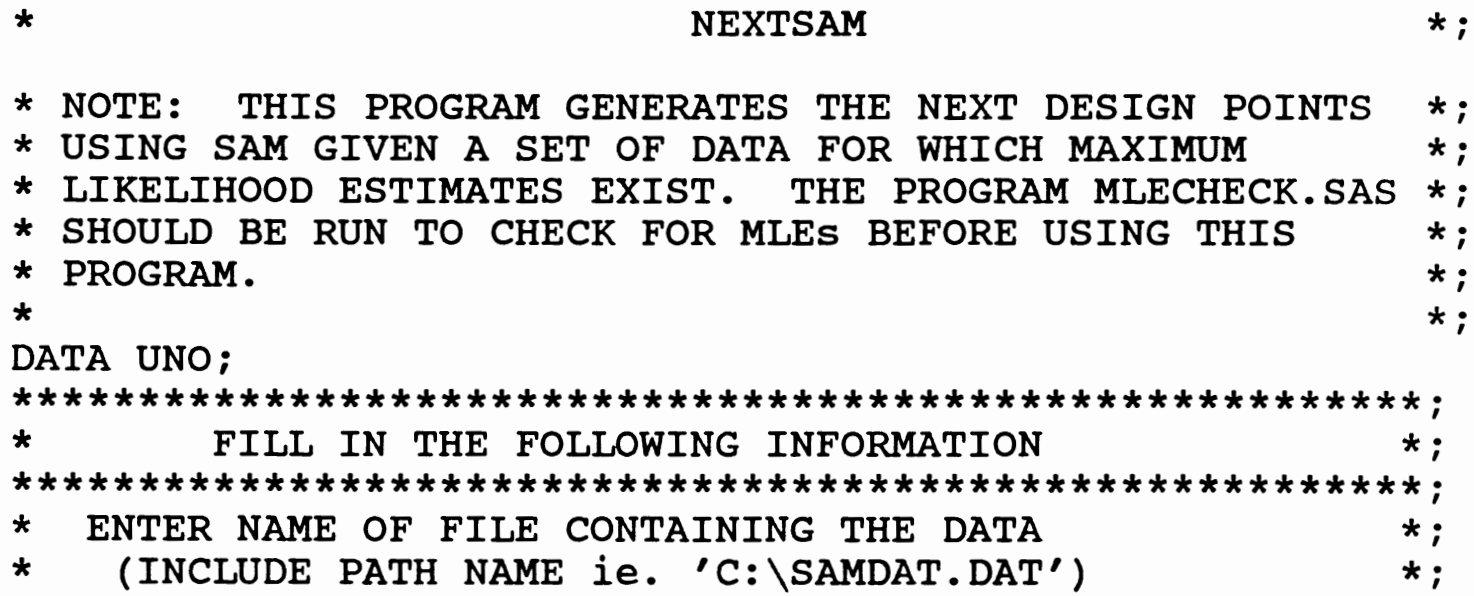


filename datl 'A: \TEST3.DAT';

* ENTER LOWER AND UPPER BOUND FOR THE DESIGN POINTS
* (WE SUGGEST A FORMULA BASED ON L20 L8O)
* (THESE WILL BE USED IF YOU LEAVE THE SPACES BLANK) *; $\mathrm{LG}=0 ; \mathrm{UG}=300$;

* enter ld20 and LD80 ESTIMATE *; LD20EST $=150 ;$ LD80EST $=200 ;$

* aRE the LAST TWO POINTS ESTIMATES GENERATED by SAM *;

* (ENTER 1 SAM has BEEN PREVIOUSLY RUN, O OTHERWISE *; FRST $=0$;

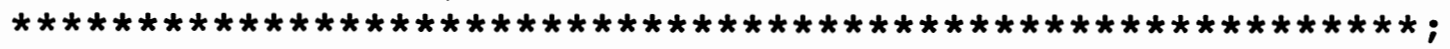

* NO CHANGES NEEDED BEYOND THIS POINT *;

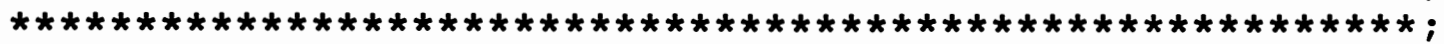

CALL SYMPUT ('FRST',FRST); CALL SYMPUT ('LG', LG) ;

CALL SYMPUT ('UG',UG); CALL SYMPUT('LD2OEST', LD2OEST);

CALL SYMPUT ('LD8OEST', LD8OEST) ;

DATA DAT; INFILE DATI; KEEP X Y;

INPUT OBS X Y;

PROC MEANS NOPRINT DATA=DAT N MAX MIN;

VAR $X$; OUTPUT OUT=STATS $N=N U M \quad M A X=M X \quad M I N=M N$;

DATA STATS; SET STATS;

LENGTH NUMC \$8; NUMC = NUM; NUMC = LEFT (NUMC);

NUMX $=$ ' $X '||$ TRIM (NUMC); NUMY = 'Y' $\mid$ TRIM (NUMC);

CALL SYMPUT ('NUMX', NUMX); CALL SYMPUT ('NUMY', NUMY);

CALL SYMPUT ('MX',MX); CALL SYMPUT ('MN',MN);

CALL SYMPUT ('NUM',NUM) ;

PROC TRANSPOSE DATA=DAT OUT=TRANS ;

VAR X Y;

DATA DATX; SET TRANS;

ARRAY X \{\&NUM\} X1-\&NUMX; KEEP X1-\&NUMX DUM;

IF $\mathrm{NAME}=$ ' $\mathrm{X}$ '; $\mathrm{DUM}=1$;

$\mathrm{X} 1=\overline{\mathrm{COLL}} 1 ; \mathrm{X} 2=\mathrm{COL} 2 ; \mathrm{X} 3=\mathrm{COL} 3 ; \mathrm{X} 4=\mathrm{COL} 4 ; \mathrm{X} 5=\mathrm{COL} 5 ; \mathrm{X} 6=\mathrm{COL} 6$;

$\mathrm{X} 7=\mathrm{COL} 7 ; \mathrm{X8}=\mathrm{COL} 8 ; \mathrm{X9}=\mathrm{COL} 9 ; \mathrm{X} 10=\mathrm{COL} 10 ; \mathrm{X} 11=\mathrm{COL} 11$;

$\mathrm{X} 12=\operatorname{col} 12 ; \mathrm{X} 13=\operatorname{col} 13 ; \mathrm{X} 14=\operatorname{COL} 14 ; \mathrm{X} 15=\operatorname{COL} 15 ; \mathrm{X} 16=\operatorname{col} 16$;

$\mathrm{X} 17=\operatorname{COL} 17 ; \mathrm{X} 18=\operatorname{COL} 18$;

IF \&NUM GT 18 THEN DO;

$\mathrm{X} 19=\operatorname{COL} 19 ; \mathrm{X} 20=\operatorname{COL} 20 ; \mathrm{X} 21=\mathrm{COL} 21 ; \mathrm{X} 22=\operatorname{COL} 22 ; \mathrm{X} 23=\operatorname{COL} 23$;

$\mathrm{X} 24=\operatorname{COL} 24 ; \mathrm{X} 25=\operatorname{COL} 25 ; \mathrm{X} 26=\operatorname{COL} 26 ; \mathrm{X} 27=\operatorname{COL} 27 ; \mathrm{X} 28=\operatorname{COL} 28$;

$\mathrm{X} 29=\operatorname{COL} 29 ; \mathrm{X} 30=\operatorname{COL} 30$;

END;

IF \&NUM GT 30 THEN DO;

$\mathrm{X} 31=\mathrm{COL} 31 ; \mathrm{X} 32=\mathrm{COL} 32 ; \mathrm{X} 33=\mathrm{COL} 33 ; \mathrm{X} 34=\mathrm{COL} 34 ; \mathrm{X} 35=\mathrm{COL} 35$;

$\mathrm{X} 36=\operatorname{COL} 36 ; \mathrm{X} 37=\operatorname{COL} 37 ; \mathrm{X} 38=\operatorname{COL} 38 ; \mathrm{X} 39=\operatorname{COL} 39 ; \mathrm{X} 40=\operatorname{COL} 40 ;$

END;

IF \&NUM GT 40 THEN DO;

$\mathrm{X} 41=\mathrm{COL} 41 ; \mathrm{X} 42=\mathrm{COL} 42 ; \mathrm{X} 43=\mathrm{COL} 43 ; \mathrm{X} 44=\mathrm{COL} 44 ; \mathrm{X} 45=\mathrm{COL} 45$; $\mathrm{X} 46=\operatorname{COL} 46 ; \mathrm{X} 47=\operatorname{COL} 47 ; \mathrm{X} 48=\operatorname{COL} 48 ; \mathrm{X} 49=\operatorname{COL} 49 ; \mathrm{X} 50=\operatorname{COL} 50$;

END;

IF \&NUM GT 50 THEN DO;

$\mathrm{X} 51=$ COL51; $\mathrm{X52}=\mathrm{COL} 52 ; \mathrm{X53}=\mathrm{COL} 53 ; \mathrm{X} 54=\mathrm{COL} 54 ; \mathrm{X} 55=\mathrm{COL} 55$;

$\mathrm{X} 56=\mathrm{COL} 56 ; \mathrm{X} 57=\mathrm{COL} 57 ; \mathrm{X} 58=\mathrm{COL} 58 ; \mathrm{X} 59=\mathrm{COL} 59 ; \mathrm{X} 60=\mathrm{COL} 60$; END;

DATA DATY; SET TRANS;

ARRAY Y \{\&NUM\} Y1-\&NUMY; KEEP Y1-\&NUMY DUM; 
IF ${ }_{\text {NAME_ }}=$ ' $\mathrm{Y}$ '; DUM=1;

$\mathrm{Y} 1=\overline{\mathrm{COLL}} 1 ; \mathrm{Y} 2=\mathrm{COL} 2 ; \mathrm{Y} 3=\mathrm{COL} 3 ; \mathrm{Y} 4=\mathrm{COL} 4 ; \mathrm{Y} 5=\mathrm{COL} 5 ; \mathrm{Y} 6=\mathrm{COL} 6 ;$

$\mathrm{Y} 7=\mathrm{COL} 7 ; \mathrm{Y} 8=\mathrm{COL} 8 ; \mathrm{Y} 9=\mathrm{COL} 9 ; \mathrm{Y} 10=\mathrm{COL} 10 ; \mathrm{Y} 11=\mathrm{COL} 11$;

Y12=COL12; Y13=COL13; Y14=COL14; Y15=COL15; Y16=COL16;

$Y 17=\operatorname{COL} 17$; $Y 18=\operatorname{COL} 18$;

IF \&NUM GT 18 THEN DO;

Y19=COL19; Y20=COL20; Y21=COL $21 ; Y 22=C O L 22 ; Y 23=C O L 23$;

Y24=COL24; Y25=COL $25 ; Y 26=C O L 26 ; Y 27=C O L 27 ; Y 28=C O L 28$;

$\mathrm{Y} 29=\operatorname{COL} 29 ; \mathrm{Y} 30=\operatorname{COL} 30$;

END;

IF \&NUM GT 30 THEN DO;

Y $31=C O L 31 ; Y 32=C O L 32 ; Y 33=C O L 33 ; Y 34=C O L 34 ; Y 35=C O L 35$;

$\mathrm{Y} 36=\operatorname{COL} 36 ; \mathrm{Y} 37=\operatorname{COL} 37 ; \mathrm{Y} 38=\operatorname{COL} 38 ; \mathrm{Y} 39=\operatorname{COL} 39 ; \mathrm{Y} 40=\operatorname{COL} 40 ;$ END;

IF \&NUM GT 40 THEN DO;

$Y 41=C O L 41 ; Y 42=\operatorname{COL} 42 ; Y 43=\operatorname{COL} 43 ; Y 44=\operatorname{COL} 44 ; Y 45=C O L 45 ;$

$\mathrm{Y} 46=\mathrm{COL} 46 ; \mathrm{Y} 47=\mathrm{COL} 47 ; \mathrm{Y} 48=\mathrm{COL} 48 ; \mathrm{Y} 49=\mathrm{COL} 49 ; \mathrm{Y} 50=\mathrm{COL} 50$;

END:

IF \&NUM GT 50 THEN DO;

$Y 51=C O L 51 ; Y 52=C O L 52 ; \quad Y 53=C O L 53 ; Y 54=C O L 54 ; Y 55=C O L 55$;

Y56=COL56; Y $57=C O L 57 ; Y 58=C O L 58 ; Y 59=C O L 59 ; Y 60=C O L 60 ;$ END;

DATA DAT MERGE DATX DATY;

BY DUM; DROP DUM;

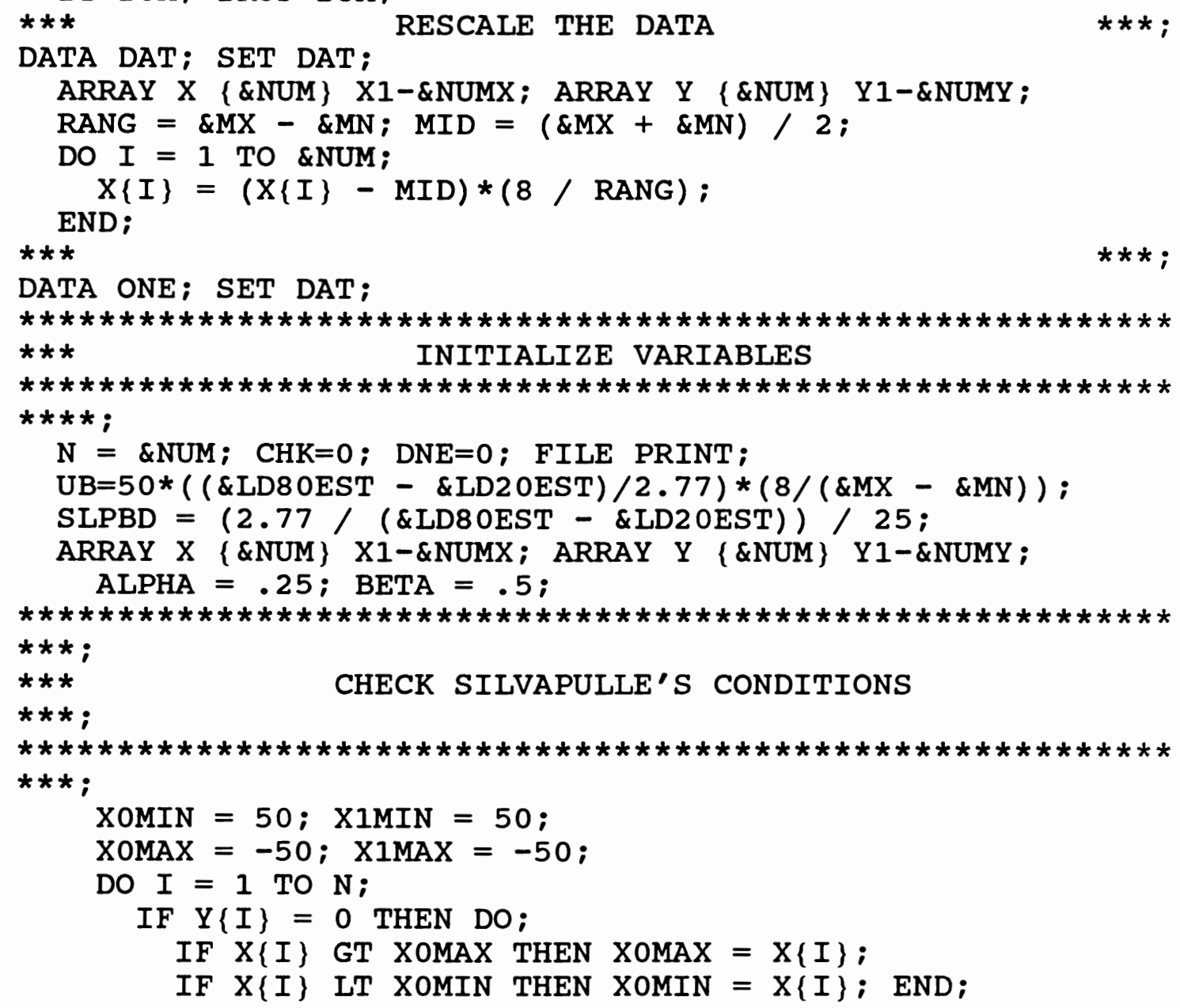




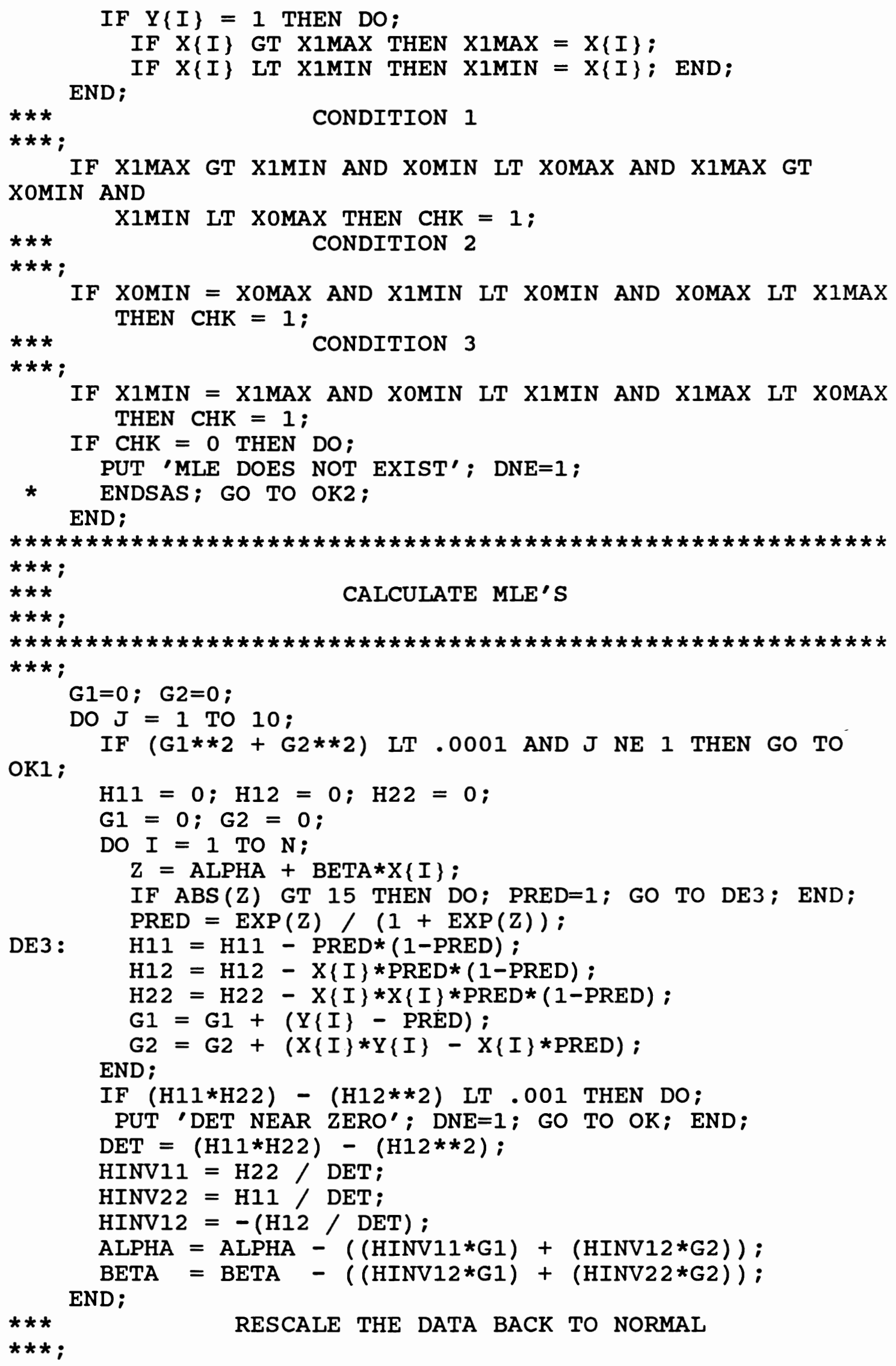


OKI: $B E T A=B E T A * 8 /(\& M X-\& M N) ; A L P H A=(-A L P H A / B E T A)+((\& M X$ $+\& M N) / 2) ;$

$A L P H A=-A L P H A * B E T A$;

DO $\mathrm{V}=1$ TO \&NUM;

$\mathrm{X}\{\mathrm{V}\}=\mathrm{X}\{\mathrm{V}\} *((\& M X-\& M N) / 8)+((\& M X+\& M N) / 2) ;$

END;

* USE FRST TO DECIDE hOW TO CALCULATE NEXT DESIGN POINTS

*;

* IE. USE DSTAR OR JUST THE MLES WITH NO STEP SIZE BOUND $\star$;

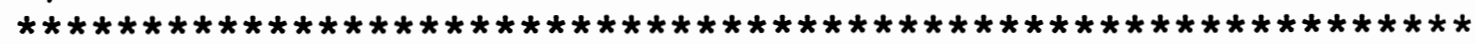

$\star * * ;$

*** CALCULATE STARTING VALUES

$\star \star *$ NOT USING STEP SIZE BOUNDS

$\star \star * * ;$

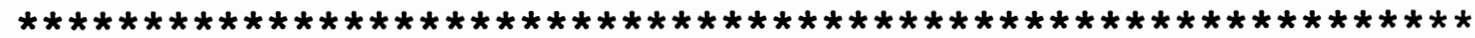

$* * * ;$

IF \&FRST $=0$ THEN DO;

IF BETA LE SLPBD THEN BETA = SLPBD;

* IF BETA GT \&UBBETA THEN BETA = \&UBBETA;

XSMF50=-ALPHA / BETA;

XSMF80 $=$ XSMF50 $+($ LOG $(4) / B E T A) ;$

XSMF20 0 XSMF50 - (LOG (4)/BETA $) ;$

IF XSMF80 GT \&UG THEN XSMF80 = \&UG;

IF XSMF20 LT \&LG THEN XSMF20 = \&LG;

IF XSMF50 GT \&UG THEN XSMF50=\&UG; IF XSMF50 LT \&LG THEN

XSMF50 $=\& L G$;

GO TO OK;

END;

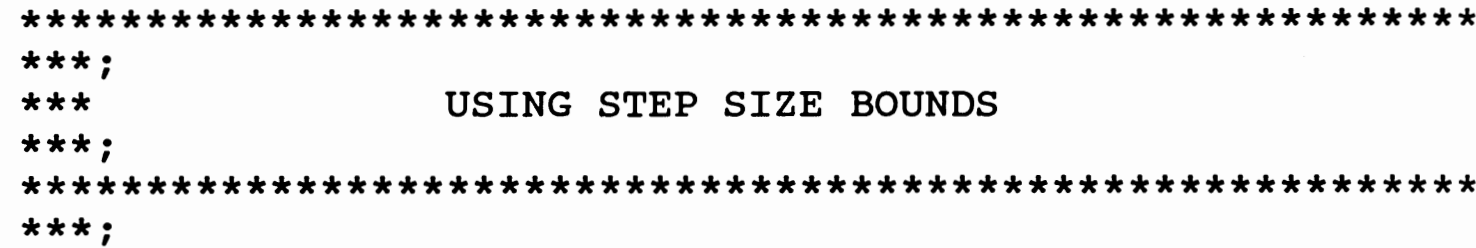

IF \&FRST=1 THEN DO;

IF BETA LE SLPBD THEN BETA = SLPBD;

* IF BETA GT \&UBBETA THEN BETA = \&UBBETA;

XSMF20 $=(\operatorname{LOG}(.25)-A L P H A) / B E T A$;

XSMF80 $=($ LOG $(4)-A L P H A) / B E T A ;$

DSTAR $=(X\{N-1\}-X S M F 20) * N /(Y\{N-1\}-.2) ;$

DSTAR2 $=(X\{N\}-X S M F 80) * N /(Y\{N\}-.8) ;$

IF DSTAR GT UB THEN DSTAR=UB;

IF DSTAR LT (-UB) THEN DSTAR=-UB;

IF DSTAR2 GT UB THEN DSTAR=UB;

IF DSTAR2 LT (-UB) THEN DSTAR=-UB;

IF BETA LT 0 THEN DO; DSTAR=UB ; DSTAR2=UB; END;

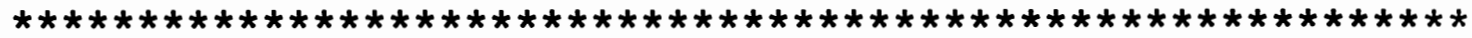

$\star * *$;

$\star * *$

$* * *$;

GENERATE NEXT $X^{\prime} S$

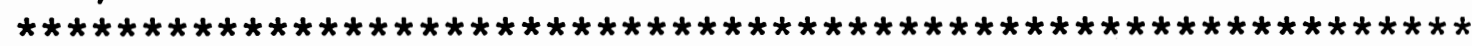
$\star \star *$;

$\mathrm{XSMF} 20=\mathrm{X}\{\mathrm{N}-1\}-(\mathrm{DSTAR} / \mathrm{N}) *(\mathrm{Y}\{\mathrm{N}-1\}-.2)$ 

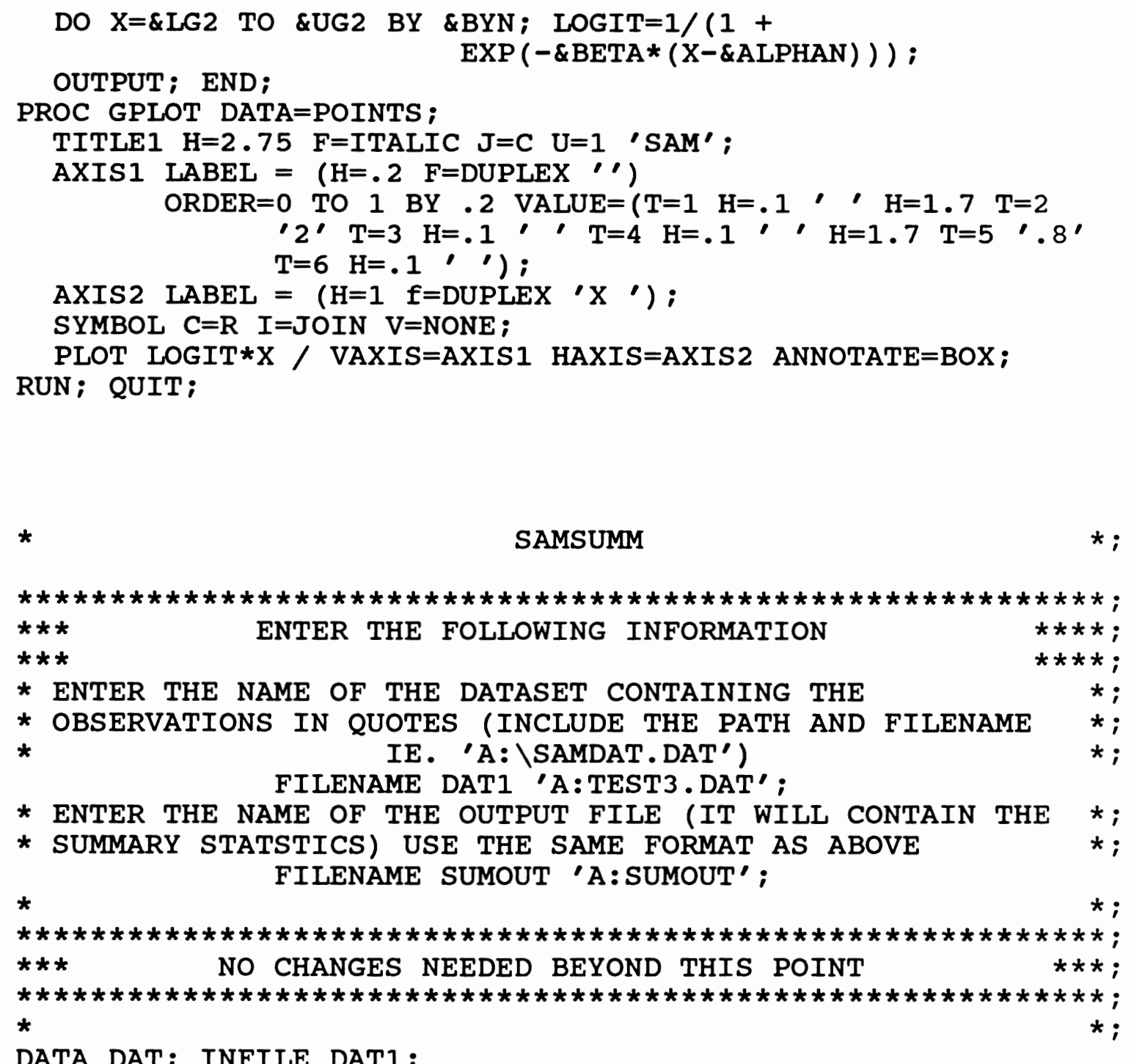

DATA DAT; INFILE DATI;

KEEP X Y;

INPUT OBS $\mathrm{X} Y$;

PROC MEANS NOPRINT DATA=DAT N MAX MIN;

VAR X; OUTPUT OUT=STATS $N=N U M$ MAX $=M X$ MIN=MN;

DATA STATS; SET STATS;

LENGTH NUMC \$ 8; NUMC = NUM; NUMC = LEFT (NUMC);

NUMX $=$ ' $X '||$ TRIM (NUMC); NUMY ='Y'||TRIM(NUMC);

CALL SYMPUT ('NUMX', NUMX); CALL SYMPUT ('NUMY', NUMY);

CALL SYMPUT ('MX',MX); CALL SYMPUT ('MN',MN) ;

CALL SYMPUT' ('NUM', NUM) ;

PROC TRANSPOSE DATA=DAT OUT=TRANS ;

VAR X Y;

DATA DATX; SET TRANS;

ARRAY X \{\&NUM $\}$ X1-\&NUMX; KEEP X1-\&NUMX DUM;

IF $N A M E=' X$ ' $D U M=1$;

$\mathrm{X} 1=\overline{\mathrm{COLL}} 1 ; \overline{\mathrm{X}}_{2}=\mathrm{COL} 2 ; \mathrm{X} 3=\mathrm{COL} 3 ; \mathrm{X} 4=\mathrm{COL} 4 ; \mathrm{X5}=\mathrm{COL} 5 ; \mathrm{X} 6=\mathrm{COL} 6$;

$\mathrm{X} 7=\mathrm{COL} 7 ; \mathrm{X} 8=\mathrm{COL} 8 ; \mathrm{X} 9=\mathrm{COL} 9 ; \mathrm{X} 10=\operatorname{COL} 10 ; \mathrm{X} 11=\mathrm{COL} 11$;

$\mathrm{X} 12=\operatorname{COL} 12 ; \mathrm{X} 13=\mathrm{COL} 13 ; \mathrm{X} 14=\operatorname{COL} 14 ; \mathrm{X} 15=\mathrm{COL} 15 ; \mathrm{X} 16=\mathrm{COL} 16$;

$\mathrm{X} 17=\operatorname{COL} 17 ; \mathrm{X} 18=\operatorname{COL} 18 ; \mathrm{X} 19=\operatorname{COL} 19 ; \mathrm{X} 20=\operatorname{COL} 20 ; \mathrm{X} 21=\operatorname{COL} 21$; 
$X 22=\operatorname{COL} 22 ; \times 23=\operatorname{COL} 23 ; \times 24=\operatorname{COL} 24 ;$

IF \&NUM GT 20 THEN DO;

$\mathrm{X} 21=\operatorname{COL} 21 ; \mathrm{X} 22=\operatorname{COL} 22 ; \mathrm{X} 23=\operatorname{COL} 23 ; \mathrm{X} 24=\operatorname{COL} 24 ; \times 25=\operatorname{COL} 25 ;$

$\mathrm{X} 26=\operatorname{COL} 26 ; \mathrm{X} 27=\operatorname{COL} 27 ; \mathrm{X} 28=\operatorname{COL} 28 ; \mathrm{X} 29=\operatorname{COL} 29 ; \mathrm{X} 30=\operatorname{COL} 30 ;$ END;

IF \&NUM GT 30 THEN DO;

$\mathrm{X} 31=\mathrm{COL} 31 ; \mathrm{X} 32=\operatorname{COL} 32 ; \mathrm{X} 33=\operatorname{COL} 33 ; \mathrm{X} 34=\mathrm{COL} 34 ; \mathrm{X} 35=\mathrm{COL} 35$;

$\mathrm{X} 36=\operatorname{COL} 36 ; \mathrm{X} 37=\operatorname{COL} 37 ; \mathrm{X} 38=\operatorname{COL} 38 ; \mathrm{X} 39=\operatorname{COL} 39 ; \mathrm{X} 40=\operatorname{COL} 40 ;$

END;

IF \&NUM GT 40 THEN DO;

$\mathrm{X} 41=\mathrm{COL} 41 ; \mathrm{X} 42=\mathrm{COL} 42 ; \mathrm{X} 43=\mathrm{COL} 43 ; \mathrm{X} 44=\mathrm{COL} 44 ; \mathrm{X} 45=\mathrm{COL} 45 ;$

$\mathrm{X} 46=\operatorname{COL} 46 ; \mathrm{X} 47=\operatorname{COL} 47 ; \mathrm{X} 48=\operatorname{COL} 48 ; \mathrm{X} 49=\operatorname{COL} 49 ; \mathrm{X} 50=\operatorname{COL} 50 ;$ END;

IF \&NUM GT 50 THEN DO;

$X 51=$ COL51; $X 52=C O L 52 ; X 53=C O L 53 ; X 54=C O L 54 ; X 55=C O L 55$;

$\mathrm{X} 56=\operatorname{COL} 56 ; \mathrm{X} 57=\operatorname{COL} 57 ; \mathrm{X} 58=\operatorname{COL} 58 ; \mathrm{X} 59=\operatorname{COL} 59 ; \mathrm{X} 60=\operatorname{COL} 60$; END;

DATA DATY; SET TRANS;

ARRAY Y \{\&NUM\} Y1-\&NUMY; KEEP Y1-\&NUMY DUM;

IF $\mathrm{NAME}_{-}=$'Y'; $\mathrm{DUM}=1$;

$\mathrm{Y} 1=\overline{\mathrm{COL}} 1 ; \mathrm{Y} 2=\mathrm{COL} 2 ; \mathrm{Y} 3=\mathrm{COL} 3 ; \mathrm{Y} 4=\mathrm{COL} 4 ; \mathrm{Y} 5=\mathrm{COL} 5 ; \mathrm{Y} 6=\mathrm{COL} 6 ;$

$\mathrm{Y} 7=\mathrm{COL} 7 ; \mathrm{Y} 8=\mathrm{COL} 8 ; \mathrm{Y9}=\mathrm{COL} 9 ; \mathrm{Y} 10=\mathrm{COL} 10 ; \mathrm{Y} 11=\mathrm{COL} 11$;

$\mathrm{Y} 12=\operatorname{COL} 12 ; \mathrm{Y} 13=\operatorname{COL} 13 ; \mathrm{Y} 14=\operatorname{COL} 14 ; \mathrm{Y} 15=\mathrm{COL} 15 ; \mathrm{Y} 16=\mathrm{COL} 16 ;$

$\mathrm{Y} 17=\operatorname{COL} 17 ; \mathrm{Y} 18=\operatorname{COL} 18 ; \mathrm{Y} 19=\operatorname{COL} 19 ; \mathrm{Y} 20=\mathrm{COL} 20$;

IF \&NUM GT 20 THEN DO;

$\mathrm{Y} 21=\mathrm{COL} 21 ; \mathrm{Y} 22=\operatorname{COL} 22 ; \mathrm{Y} 23=\operatorname{COL} 23 ; \mathrm{Y} 24=\mathrm{COL} 24 ; \mathrm{Y} 25=\mathrm{COL} 25 ;$

$\mathrm{Y} 26=\mathrm{COL} 26 ; \mathrm{Y} 27=\operatorname{COL} 27 ; \mathrm{Y} 28=\operatorname{COL} 28 ; \mathrm{Y} 29=\operatorname{COL} 29 ; \mathrm{Y} 30=\operatorname{COL} 30 ;$ END;

IF \&NUM GT 30 THEN DO;

$\mathrm{Y} 31=\mathrm{COL} 31 ; \mathrm{Y} 32=\mathrm{COL} 32 ; \mathrm{Y} 33=\mathrm{COL} 33 ; \mathrm{Y} 34=\mathrm{COL} 34 ; \mathrm{Y} 35=\mathrm{COL} 35$;

$\mathrm{Y} 36=\operatorname{COL} 36 ; \mathrm{Y} 37=\operatorname{COL} 37 ; \mathrm{Y} 38=\operatorname{COL} 38 ; \mathrm{Y} 39=\operatorname{COL} 39 ; \mathrm{Y} 40=\operatorname{COL} 40 ;$ END;

IF \&NUM GT 40 THEN DO;

$Y 41=C O L 41 ; Y 42=C O L 42 ; Y 43=\operatorname{COL} 43 ; Y 44=\operatorname{COL} 44 ; \quad Y 45=\operatorname{COL} 45 ;$

$\mathrm{Y} 46=\operatorname{COL} 46 ; \mathrm{Y} 47=\operatorname{COL} 47 ; \mathrm{Y} 48=\operatorname{COL} 48 ; \mathrm{Y} 49=\operatorname{COL} 49 ; \mathrm{Y} 50=\operatorname{COL} 50 ;$ END;

IF \&NUM GT 50 THEN DO;

$\mathrm{Y} 51=\mathrm{COL} 51 ; \mathrm{Y} 52=\mathrm{COL} 52 ; \mathrm{Y} 53=\mathrm{COL} 53 ; \mathrm{Y} 54=\mathrm{COL} 54 ; \mathrm{Y} 55=\mathrm{COL} 55$;

$\mathrm{Y} 56=\mathrm{COL} 56 ; \mathrm{Y} 57=\mathrm{COL} 57 ; \mathrm{Y} 58=\mathrm{COL} 58 ; \mathrm{Y} 59=\mathrm{COL} 59 ; \mathrm{Y} 60=\mathrm{COL} 60$; END;

DATA DAT; MERGE DATX DATY;

BY DUM; DROP DUM;

PROC PRINT DATA=DAT; TITLE 'TRANSPOSED DATASET';

$* * *$ RESCALE THE DATA

$\star * * ;$

DATA DAT; SET DAT;

ARRAY X \{\&NUM\} X1-\&NUMX; ARRAY Y \{\&NUM\} Y1-\&NUMY;

RANG $=\& M X-\& M N ; M I D=(\& M X+\& M N) / 2 ;$

DO $I=1$ TO \&NUM;

END;

$X\{I\}=(X\{I\}-M I D) *(8 /$ RANG $) ;$

PROC PRINT DATA=DAT; TITLE 'RESCALED DATASET';

DATA ONE; SET DAT; 


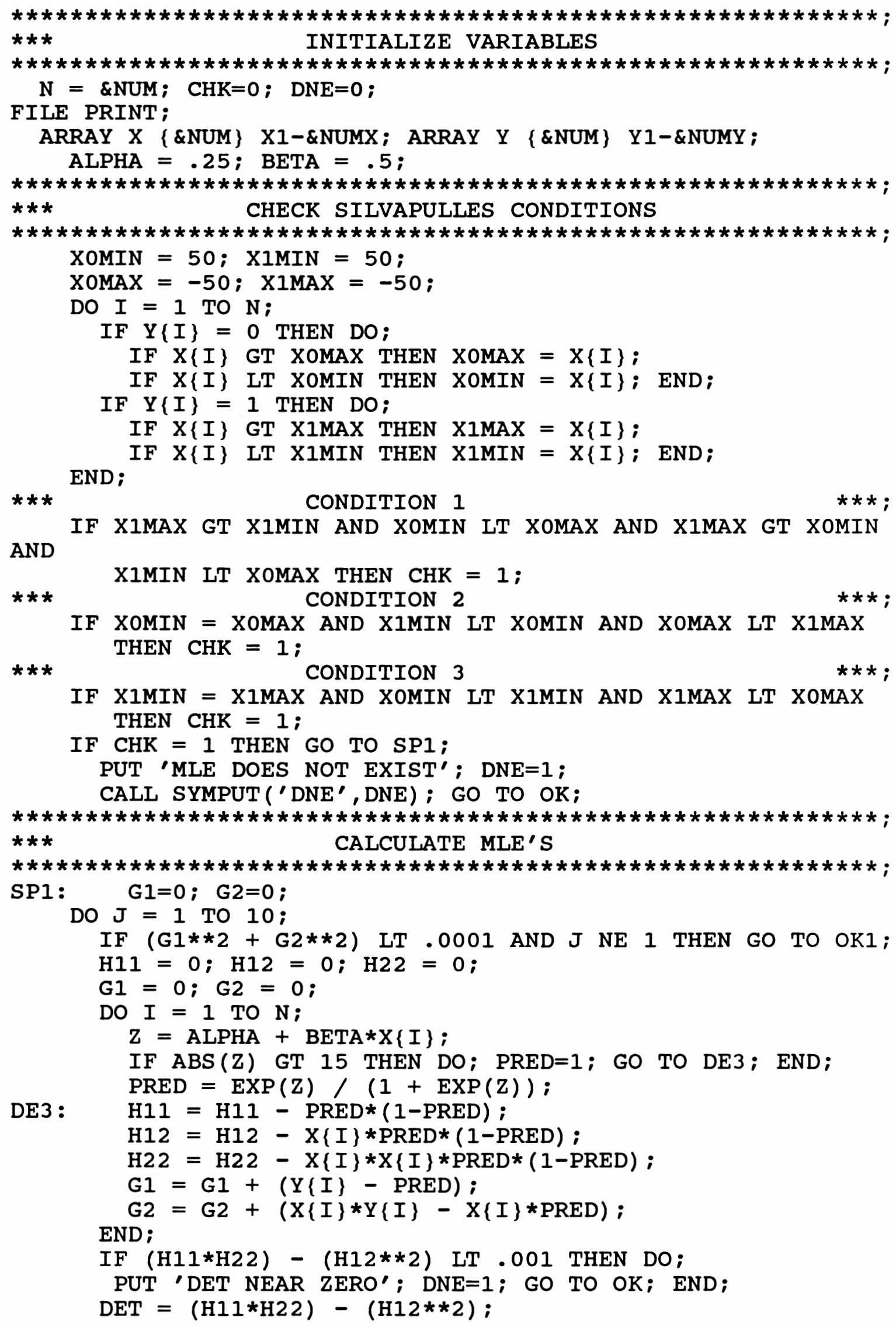




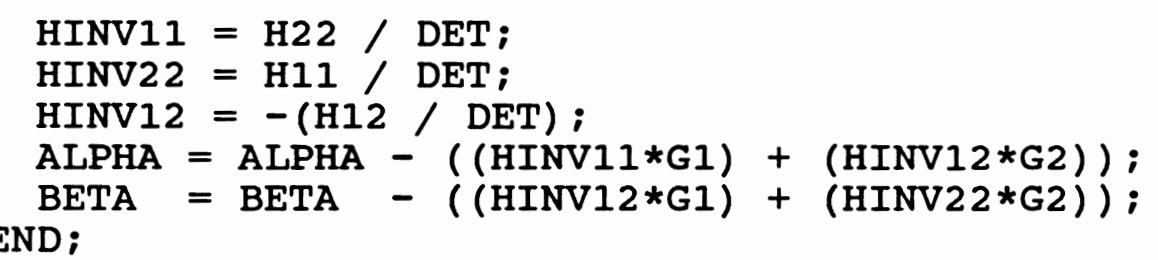

OK1: FILE PRINT;
*** RESCALE DATA AND ESTIMATES TO NORMAL ***; $\mathrm{BETA}=\mathrm{BETA} * 8 /(\& \mathrm{MX}-\& \mathrm{MN}) ; \mathrm{ALPHA}=(-\mathrm{ALPHA} / \mathrm{BETA})+$ $((\& M X+\& M N) / 2) ;$
$A L P H A=-A L P H A * B E T A ;$
DO $V=1$ TO \&NUM;
ALPHAN = -ALPHA/BETA; CALL SYMPUT ('ALPHAN', ALPHAN);
LG2 = ALPHAN - (LOG (75)/BETA $) ;$ UG2 = ALPHAN + (LOG (75) /BETA) ;
BYN $=($ UG2-LG2) $/ 300 ;$ OFS $=($ UG2-LG2) $/ 75 ;$
CALL SYMPUT ('BYN', BYN); CALL SYMPUT ('OFS',OFS) ;
CALL SYMPUT ('ALPHA', ALPHA); CALL SYMPUT ('BETA', BETA) ;
CALL SYMPUT ('LG2', LG2); CALL SYMPUT ('UG2',UG2) ;
SYMPUT ('BETAR' , BETAR);

OK: CALL SYMPUT ('DNE', DNE);

*;

*;

DATA TWO; SET ONE;

ARRAY X \{\&NUM\} X1-\&NUMX; ARRAY Y \{\&NUM\} Y1-\&NUMY;

LENGTH ALPHAC \$ 10 BETAC \$ 10;

ALPHA $=$ ROUND (\&ALPHA , . 001); BETA = ROUND (\&BETA, . 001);

FILE PRINT; PUT' 'ALPHA AND BETA ARE ' ALPHA BETA;

FILE SUMOUT; NUM = \&NUM;

ALPHAC = ALPHA; BETAC = BETA;

ALPHAC $=$ LEFT $($ ALPHAC $) ;$ BETAC = LEFT $(B E T A C) ;$

$* * * *$ PRINT DATASET $* * * * *$;

PUT 930 'DESIGN POINTS' 948 'RESPONSE' OVERPRINT

PUT ;

Q30 '

DO $J=1$ TO NUM;

PUT @32 X $\{\mathrm{J}\} \quad 6.2 @ 50 \mathrm{Y}\{\mathrm{J}\} \quad 2$.; END;

**** CALCULATE ESTIMATES AND STANDARD ERRORS $* * * * *$;

SUM1 $=0 ;$ SUM2 $=0$;

DO $I=1$ TO NUM;

$\mathrm{PI}=(1+\operatorname{EXP}(-\& B E T A *(X\{I\}-\& A L P H A N))) * *(-1) ;$

SUMI $=$ SUMI $+\mathrm{PI} *(1-\mathrm{PI}) ;$

END;

SUM2 $=$ SUM2 $+(X\{I\} * \star 2) * P I *(1-P I) ;$

SEALPHA $=\operatorname{SQRT}(1 /(n * \operatorname{SUM} 1)) ; \operatorname{SEBETA}=\operatorname{SQRT}(1 /(n * \operatorname{SUM} 2)) ;$ PUT ' ';

PUT 930 'ALPHA = ' ALPHA 6.3' BETA =' BETA 6.3;

PUT 930 'WITH STANDARD ERRORS OF' SEALPHA 8.3 SEBETA 8.3 ;

PUT ' ' ;

PUT @16 'PERCENTILE' @30 'ESTIMATE' @40 'S.E.' @50 'LOWER 95\%' @60 'UPPER 95\%' OVERPRINT @16'_ ' 


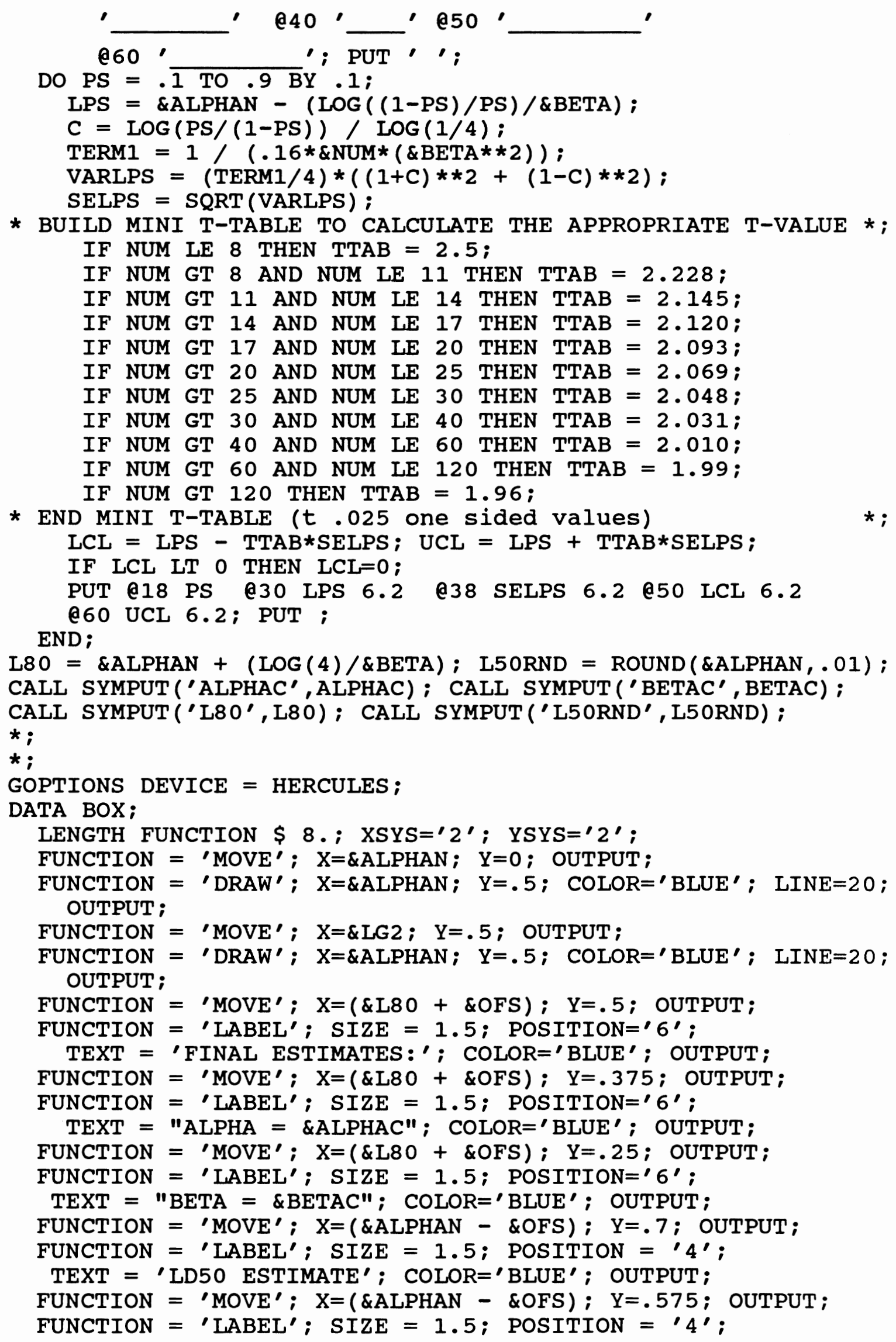




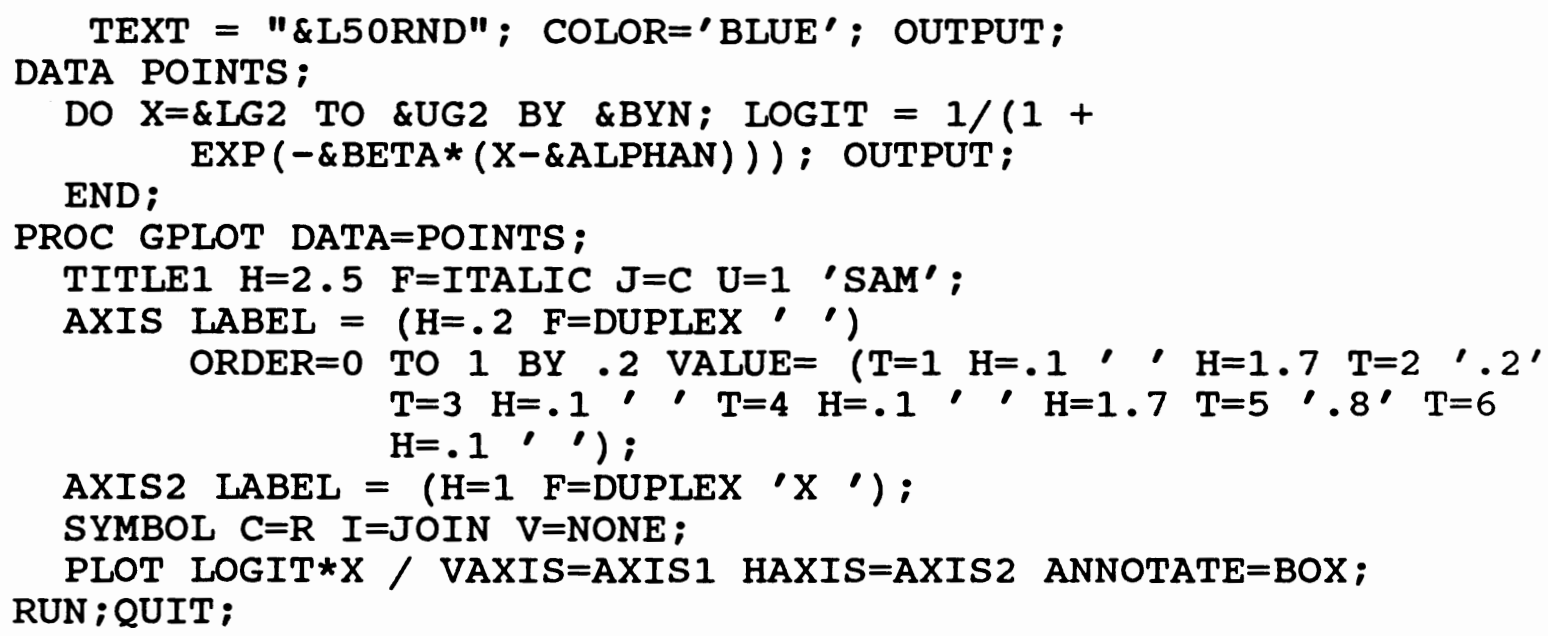




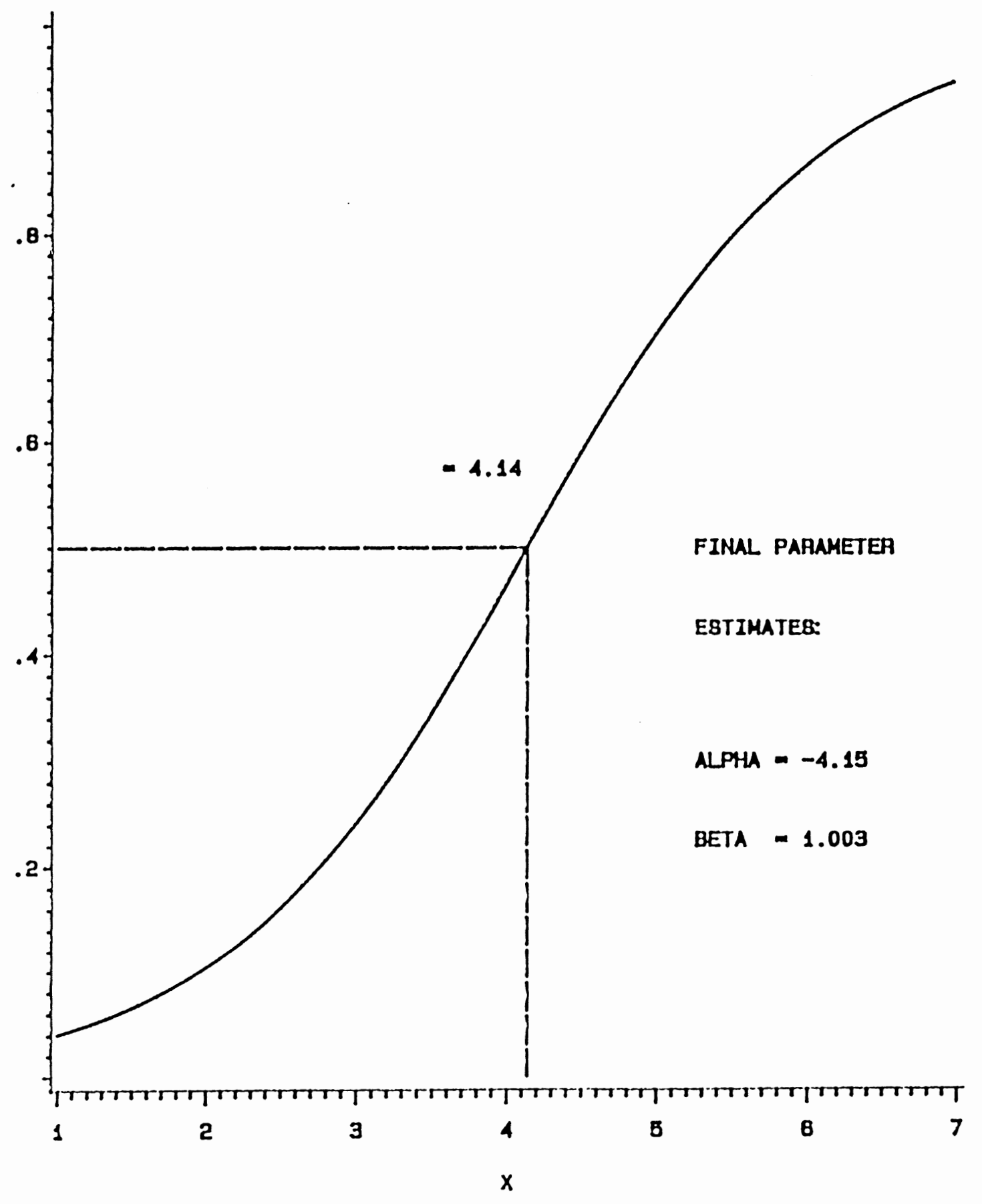

Figure 6. SAMSUMM Output 
DESIGN POINTS

2.00

4.00

2.00

4.50

3.00

4.75

3.00

5.00

4.00

5.00

3.04

5.46

2.35

5.32

2.62

5.06

2.79

4.91

2.92

5.33

3.04

5.20

2.60

5.70

$A L P H A=-4.150$

\begin{tabular}{|c|c|c|c|c|}
\hline PERCENT ILE & ESTIMATE & S.E. & LOWER 958 & UPPER $95 \%$ \\
\hline 10 & 1.95 & 0.67 & 0.55 & 3.34 \\
\hline 20 & 2.76 & 0.51 & 1.70 & 3.81 \\
\hline 30 & 3.29 & 0.42 & 2.42 & 4.16 \\
\hline 40 & 3.73 & 0.37 & 2.96 & 4.51 \\
\hline 50 & 4.14 & 0.36 & 3.39 & 4.88 \\
\hline 60 & 4.54 & 0.37 & 3.77 & 5.32 \\
\hline 70 & 4.98 & 0.42 & 4.11 & 5.85 \\
\hline 80 & 5.52 & 0.51 & 4.47 & 6.57 \\
\hline 90 & 6.33 & 0.67 & 4.93 & 7.72 \\
\hline
\end{tabular}

\section{RESPONSE}

0
0
0
1
0
0
1
1
0
1
1
1
0
1
0
1
0
0
0
1
1
0
0
1

$\mathrm{BETA}=1.003$

Figure 6 (continued) 
VITA

Douglas E. Faries

Candidate for the degree of

Doctor of Philosophy

Thesis: A NEW SEQUENTIAL APPROXIMATION METHOD

Major Field: Statistics

Biographical :

Personal Data: Born in Murray, Kentucky, september, 11, 1963, to Clyde and Elizabeth Faries. Married Karen stanton, of Russellville, Arkansas, on December 17, 1988.

Education: Graduated from Macomb High School, Macomb, Illinois, in June, 1981; Received a Bachelor of Science degree (December, 1984) and a Master of Science degree (August, 1986) in Mathematics from Western Illinois University; Completed the requirements for a Doctor of Philosophy degree in Statistics at oklahoma State University in May, 1990 .

Professional Experience: Teaching Assistant (Elementary and Intermediate Algebra), Department of Mathematics, Western Illinois University, January, 1985, to May, 1986; Research Assistant, Department of Mathematics, Western Illinois University, June, 1986, to August, 1986; Research Assistant to Dr. Ron McNew (statistical consultant to the Agricultural Experiment Station), Oklahoma State University, August, 1986, to May, 1988; Summer Intern Statistician, Eli Lilly \& Co. (Pre-Clinical), Greenfield, Indiana, May, 1988, to July, 1988; Teaching Assistant (Statistical Methods I, Engineering statistics), Oklahoma State University, Department of statistics, August, 1988, to May, 1990; Summer Intern Statistician, E.I. DuPont deNemours \& Co. (Biometrics Department), Wilmington, Delaware, May, 1989, to August, 1989. 
Scholarly Organizations: American Statistical Association member, OSU Statistics Club (President, 1988), WIU Math Club (Vice President, 1985), Phi Kappa Phi

Scholarships and Honors: Robert Glenn Rapp Distinguished Graduate Fellowship (OSU), Oklahoma state Foundation Scholarship, Olive and Grove Billingsley Tyson Scholarship (WIU), Western Illinois University Foundation Scholarship, Jacob Burlak Award (WIU Mathematics Department) 